\title{
A surge of $p$-values between 0.041 and 0.049 in recent decades (but negative results are increasing rapidly too)
}

Joost de Winter, Dimitra Dodou

It is known that statistically significant (positive) results are more likely to be published than non-significant (negative) results. However, it has been unclear whether any increasing prevalence of positive results is stronger in the "softer" disciplines (social sciences) than in the "harder" disciplines (physical sciences), and whether the prevalence of negative results is decreasing over time. Using Scopus, we searched the abstracts of papers published between 1990 and 2013, and measured longitudinal trends of multiple expressions of positive versus negative results, including $p$-values between 0.041 and 0.049 versus $p$-values between 0.051 and 0.059 , textual reporting of "significant difference" versus "no significant difference", and the reporting of $p<0.05$ versus $p>$ 0.05 . We found no support for a "hierarchy of sciences" with physical sciences at the top and social sciences at the bottom. However, we found large differences in reporting practices between disciplines, with $p$-values between 0.041 and 0.049 over 1990-2013 being 65.7 times more prevalent in the biological sciences than in the physical sciences. $p$-values near the significance threshold of 0.05 on either side have both increased but with those $p$-values between 0.041 and 0.049 having increased to a greater extent (2013to-1990 ratio of the percentage of papers $=10.3$ ) than those between 0.051 and 0.059 (ratio $=3.6$ ). Contradictorily, $p<0.05$ has increased more slowly than $p>0.05$ (ratios $=$ 1.4 and 4.8 , respectively), while the use of "significant difference" has shown only a modest increase compared to "no significant difference" (ratios = 1.5 and 1.1, respectively). We also compared reporting of significance in the United States, Asia, and Europe and found that the results are too inconsistent to draw conclusions on crosscultural differences in significance reporting. We argue that the observed longitudinal trends are caused by negative factors, such as an increase of questionable research practices, but also by positive factors, such as an increase of quantitative research and structured reporting. 


\section{A surge of $p$-values between 0.041 and 0.049 in recent decades (but negative 2 results are increasing rapidly too)}

3 J. C. F. de Winter, D. Dodou

4 Department of BioMechanical Engineering, Delft University of Technology, Delft, The Netherlands

5

\section{Abstract}

It is known that statistically significant (positive) results are more likely to be published than non-significant (negative) results. However, it has been unclear whether any increasing prevalence of positive results is stronger in the "softer" disciplines (social sciences) than in the "harder" disciplines (physical sciences), and whether the prevalence of negative results is decreasing over time. Using Scopus, we searched the abstracts of papers published between 1990 and 2013, and measured longitudinal trends of multiple expressions of positive versus negative results, including $p$-values between 0.041 and 0.049 versus $p$-values between 0.051 and 0.059 , textual reporting of "significant difference" versus "no significant difference", and the reporting of $p<0.05$ versus $p>0.05$. We found no support for a "hierarchy of sciences" with physical sciences at the top and social sciences at the bottom. However, we found large differences in reporting practices between disciplines, with $p$-values between 0.041 and 0.049 over 1990-2013 being 65.7 times more prevalent in the biological sciences than in the physical sciences. $p$-values near the significance threshold of 0.05 on either side have both increased but with those $p$-values between 0.041 and 0.049 having increased to a greater extent (2013-to-1990 ratio of the percentage of papers $=10.3)$ than those between 0.051 and $0.059($ ratio $=$

3.6). Contradictorily, $p<0.05$ has increased more slowly than $p>0.05$ (ratios $=1.4$ and 4.8 , respectively), while the use of

"significant difference" has shown only a modest increase compared to "no significant difference" (ratios $=1.5$ and 1.1, respectively). We also compared reporting of significance in the United States, Asia, and Europe and found that the results are too inconsistent to draw conclusions on cross-cultural differences in significance reporting. We argue that the observed longitudinal trends are caused by negative factors, such as an increase of questionable research practices, but also by positive factors, such as an increase of quantitative research and structured reporting.

\section{Introduction}

\subsection{The abundance of positive results in the scientific literature}

It is well known that the distribution of $p$-values in the scientific literature exhibits a discontinuity around alpha $=$ 0.05 , with $p$-values just below 0.05 being more prevalent than $p$-values just above 0.05 (Brodeur et al., 2013; Gerber \& Malhotra, 2008a, 2008b; Kühberger et al., 2014; Pocock et al., 2004; Ridley et al., 2007). The abundance of positive results has often been attributed to selective publication, also called the file drawer effect (Dwan et al., 2008; Hopewell et al., 2009; Rothstein et al., 2006). Another explanation for the discontinuity in the $p$-value distribution is that many statistically significant findings in the literature are false positives. Ioannidis' (2005) highly-cited article claimed that over $50 \%$ of the published results that are declared statistically significant are false, meaning that they actually are negative (i.e., null) effects. Concerns regarding publication bias and false positives have been expressed in a variety of research fields, including but not limited to biology and ecology (Jennions \& Møller, 2002), economics (Basu \& Park, 2014), medicine and pharmaceutics (Dwan et al., 2008; Hopewell et al., 2009; Kyzas et al., 2007), neurosciences (Jennings \& Van Horn, 2012), epidemiology (Pocock et al., 2004), cognitive sciences (Ioannidis et al., 2014), genetics (Chabris et al., 2012; Ioannidis, 2003), and psychology (Ferguson \& Heene, 2012; Francis, 2013, 2014; Franco et al., 2014; Laws, 2013; Simmons et al., 2011).

False positives can be caused by questionable statistical practices (called ' $p$-hacking', 'fiddling', 'spin', or 'data massage') that turn a negative result into a positive result (Boutron et al., 2010; Chan et al., 2014; Dwan et al., 2008; Kirkham et al., 2010; Simmons et al., 2011). Selectively removing particular outliers, undisclosed data dredging, selective stopping, incorrect rounding down of $p$-values, or trying out various statistical tests and subsequently reporting only the most significant outcomes, are some of the mechanisms that can cause false positives to appear in a publication (e.g., Bakker \& Wicherts, 2014; Camfield et al., 2014; Goodman, 2014; Leggett et al., 2013; Simmons et al., 2011; Strube, 2006). Yet another mechanism that could cause spurious positive results is data fabrication. A meta-analysis by Fanelli (2009) found that $2 \%$ of researchers admitted fabricating, falsifying (i.e., distorting), or modifying (i.e., altering) data, and 14\% knew a colleague who fabricated, falsified, or modified data. The underlying causes of these phenomena are purportedly an emphasis on productivity (De Rond \& Miller, 2005), high rejection rates of journals (Young et al., 2008), and competitive schemes for funding and promotion (Joober et al., 2012). Not just researchers, but also journal editors (Sterling et al., 1995; Thornton \& Lee, 2000) and sponsoring/funding parties (Djulbegovic et al., 2000; Lexchin et al., 2003; Sismondo, 2008) have been criticised for favouring positive results over negative ones. It has been argued that there are so many false positives published in certain fields within the social and medical sciences that these fields are currently in crisis (Pashler \& Harris, 2012; Rouder et al., 2014). 
As a reaction to the abundance of statistically significant results in the scientific literature, methodologists have emphasized that null results should not remain in the file drawer, and that the decision to publish should be based on methodological soundness rather than novelty or statistical significance (Asendorpf et al., 2013; Dirnagl \& Lauritzen, 2010). Methodologists have also warned of the perils of publishing exploratory research, and have encouraged preregistration of formulated hypotheses, research protocols, and expected data analyses in public trial registries in an attempt to prevent spurious positive findings (Asendorpf et al., 2013; De Angelis et al., 2004). Furthermore, statistical corrections have been introduced that decrease observed effects, including corrections for publication bias (Duval \& Tweedie, 2000; Rücker et al., 2008; Terrin et al., 2003) and "credibility calibration" (Ioannidis, 2008).

It is worth noting that earlier, in the 1980s and 1990s, the social sciences were also said to be in a crisis. Funding agents threatened to cut budgets, because they were frustrated with the ongoing production of small and inconsistent effect sizes (Hunter \& Schmidt, 1996). As an answer, methodologists introduced several artefact corrections, namely corrections for range restriction, measurement error, and dichotomization. These corrections almost always increase the observed effect sizes (Fern \& Monroe, 1996; Schmidt \& Hunter, 1996).

\subsection{Longitudinal trends of positive versus negative results}

Akin to signal detection theory, measures that decrease false positives will lead to more false negatives (Fiedler et al., 2012; Finkel et al., in press). Hence, we ought to ask ourselves whether the alleged crisis reflects the true state of affairs. Have positive results really become more prevalent over the years? Furthermore, it is important to determine whether the prevalence of positive results has dropped recently, which would indicate that the methodological recommendations have been endorsed by the scientific community.

So far, research on longitudinal trends of positive versus negative results has been scarce. An exception is Fanelli (2012), who manually coded 4,656 journal papers. In his article "Negative results are disappearing from most disciplines and countries", Fanelli found that the number of papers providing support for the main hypothesis had increased from $70 \%$ in 1990 to $86 \%$ in 2007 . Fanelli further concluded that the increase was significantly stronger in the social sciences and in some biomedical fields than in the physical sciences. He also reported that Asian countries have been producing more positive results than the United States, which in turn produce more positive results than European countries. It is worth noting that, according to Fanelli (2012), negative results are disappearing relative to the number of papers that tested a hypothesis. As clarified by Fanelli (2014): "the absolute number of negative results in Fanelli (2012) did not show a decline" (Italics added).

Fanelli's (2012) paper has some limitations. First, although his sample size is impressive (considering that the coding was done manually), the statistical power does not seem high enough for assessing differences in growth between disciplines or countries. We extracted and re-analyzed data shown in Fanelli's figures and found that the 95\% of the confidence intervals $(\mathrm{CI})$ of the regression slopes are overlapping between disciplines $(1.44 \% /$ year increase in positive results for the social sciences $[95 \% \mathrm{CI}=0.99,1.90], 0.92 \% /$ year increase for the biological sciences $[95 \%$ $\mathrm{CI}=0.53,1.32]$, and $0.65 \% /$ year increase for the physical sciences $[95 \% \mathrm{CI}=0.19,1.11]$, see also Fig. 1 , in which the longitudinal trends in the three scientific disciplines are presented together to assist comparison). Fanelli (2012, see also 2010) claimed support for a hierarchy of sciences with physical sciences at the top and social sciences at the bottom, and positive results increasing toward the hierarchy's lower end: "The average frequency of positive results was significantly higher when moving from the physical, to the biological to the social sciences, and in applied versus pure disciplines..., all of which confirms previous findings (Fanelli 2010b)" (Fanelli, 2012, p. 893). Although the results shown in Fig. 1 are consistent with this ordinal relationship, the average percentages of positive results over the period 1991-2007 are highly similar for the three disciplines $(78.3 \%$ in physical sciences $[N=1,044]$, $80.1 \%$ in biological sciences $[N=2,811]$, and $81.5 \%$ in social sciences $[N=801])$. Fanelli's alleged differences between Europe, Asia, and the United States are not statistically strong either. For example, Fanelli (2012) reported $p$-values of 0.017 and 0.048 for paired comparisons between the three world regions, based on the results of a stepwise regression procedure that included all main effects and interactions. A second limitation is that Fanelli's (2012) assessment of positive/negative results was based on the reading of abstracts or full-texts by the author himself. This approach could have introduced bias, because Fanelli's coding was not blind to the scientific discipline that the papers belong to. Randomization issues are at play as well, because the coding was first done for papers published between 2000 and 2007, and subsequently for papers published between 1990 and 1999 . 


\section{PeerJ Reviewing Manuscript}

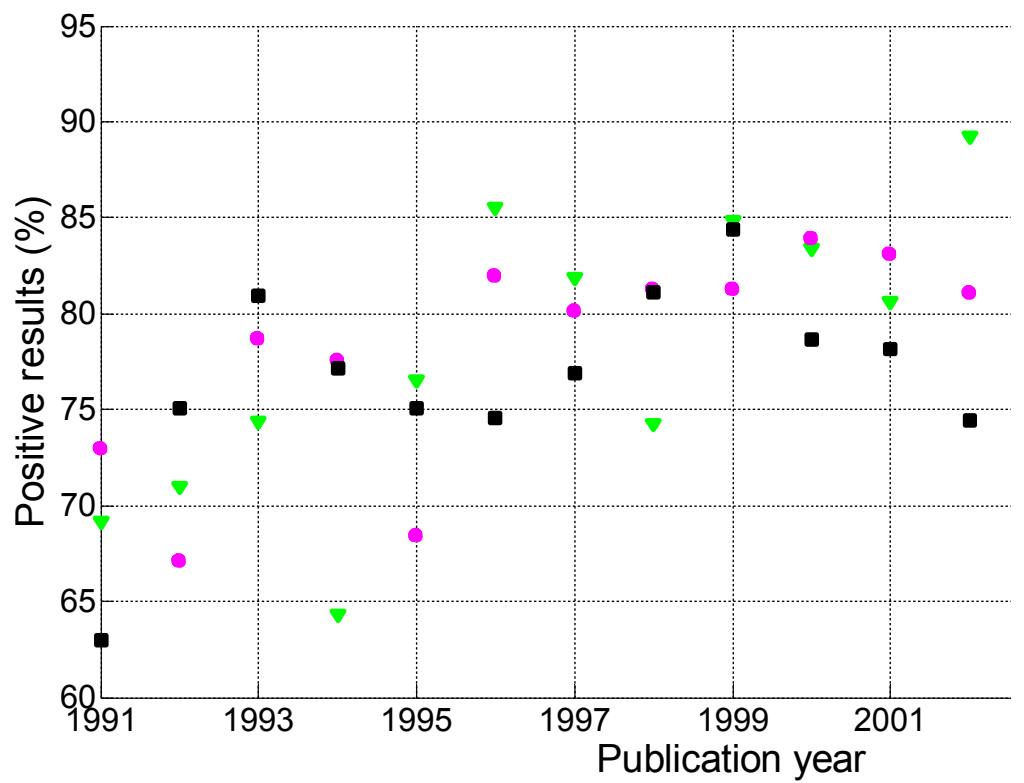

102

103

104

105

106

107

108

109

110

111

112

113

114

115

116

117

118

119

120

121

122

123

124

125

126

127

128

129

130

131

132

133

134

135

Figure 1. Number of papers reporting a positive result divided by the total number of papers examined (i.e., papers reporting a positive result + papers reporting a negative result) per publication year, for three scientific disciplines. The figure was created by graphically extracting the data shown in Fanelli's (2012) figures. The dashed lines represent the results of a simple linear regression analysis.

Pautasso (2010) also studied longitudinal trends of positive versus negative research findings. Opposite to Fanelli's (2012) manual coding, Pautasso searched automatically for the phrases "significant difference" versus "no significant difference" (and variants thereof) in the titles and abstracts of papers in the (Social) Science Citation Index for 1991-2008, and in CAB Abstracts and Medline for 1970-2008. Pautasso (2010) found that the percentage of both positive and negative results with respect to all papers had increased over time (cf. Fanelli, 2012, who focused on the percentage of papers reporting a positive result with respect to the selected papers that tested a hypothesis, i.e., the sum of papers reporting either positive or negative results). Pautasso (2010) further showed that the positive results had increased more rapidly than the negative results, hence yielding a "worsening file drawer problem", consistent with Fanelli's (2012) observation that negative results are disappearing. However, some of Pautasso's (2010) conclusions seem not in line with Fanelli's (2010) hierarchy of sciences. For example, Pautasso found that the worsening file-drawer problem was not apparent for papers retrieved with the keyword "psychol*", whereas psychology lies within the bottom of the hierarchy proposed by Fanelli (2010).

Leggett et al. (2013) manually collected 3,701 p-values between 0.01 and 0.10 that were reported in all articles published in 1965 and in 2005 in two psychological journals, Journal of Experimental Psychology: General (JEP) and Journal of Personality and Social Psychology (JPSP). The authors found a distinctive peak of $p$-values just below 0.05 . Moreover, the overrepresentation of $p$-values just below the threshold of significance was more manifest in 2005 than in 1965. For example, for $J P S P$, in 2005, there were 3.27 (i.e., 108/33) times as many $p$-values in the range $0.04875<p \leq 0.05000$ as compared to $p$-values in the range $0.04750<p \leq 0.04875$, while for 1965 the corresponding ratio was 1.40 (i.e., 28/20; data extracted from Leggett et al.'s figures). Moreover, Leggett et al. found that in $2005,42 \%$ of the 0.05 values were erroneously rounded down $p$-values, as compared to $19 \%$ in 1965 . According to the authors, these longitudinal trends could be caused by software-driven statisticizing: "Modern statistical software now allows for simple and instantaneous calculations, permitting researchers to monitor their data continuously while collecting it. The ease with which data can be analysed may have rendered practices such as 'optional stopping' (Wagenmakers, 2007), selective exclusion of outliers, or the use of post hoc covariates (Sacket, 1979) easier to engage in” (p. 2304).

Jager and Leek (2014) used a parsing algorithm to automatically collect $p$-values from the abstracts of five medical journals (The Lancet, The Journal of the American Medical Association, The New England Journal of Medicine, The British Medical Journal, and The American Journal of Epidemiology) between 2000 and 2010 and reported that between $75 \%$ and $80 \%$ of the $5,322 p$-values they collected were lower than the significance threshold of 0.05 . These authors found that the distribution of reported $p$-values has not changed over those years. 
136 All four aforementioned longitudinal analyses require updating, as they cover periods up to 2007 (Fanelli, 2012), 1372008 (Pautasso, 2010), 2005 (Leggett et al., 2013), and 2010 (Jager \& Leek, 2014). Considering the alleged crisis 138 (Wagenmakers, 2007) and the exponential growth of scientific literature (Larsen \& Von Ins, 2010), a modern 139 replication of these works seems warranted. Replication is also needed because Fanelli's (2012) work has received 140 ample citations and attention from the popular press (cf. Yong, 2012, stating in Nature that psychology and 141 psychiatry are the "worst offenders", based on Fanelli, 2012).

\section{1.3. Aim of this research}

143 In summary, it is well known that positive results (i.e., results that are statistically significant) are more likely to be

144

145

146 published than negative (i.e., null) results (e.g., Hopewell et al., 2009; Smart, 1964; Sterling et al., 1995). However, it is unclear whether the prevalence of negative results is decreasing over time, whether the increase of positive results is stronger in the "softer" disciplines than in the "harder" disciplines, and whether different regions in the world exhibit different tendencies in reporting positive versus negative results.

148 The aim of this study was to estimate longitudinal trends of positive versus negative results in the scientific literature, 149 and to compare these trends between disciplines and countries. We chose for an automated search, akin to Pautasso 150 (2010) and Jager and Leek (2014). The quantitative analysis of digitized texts, also known as culturomics, has 151 become an established method for investigating secular trends in cultural phenomena (e.g., Michel et al., 2011).

We investigated longitudinal trends between 1990 and 2013 for $p$-values between 0.041 and 0.049 versus $p$-values between 0.051 and 0.059 , that is, for $p$-values on either side of the typical alpha value of 0.05 . The assumption is that $p$-values just below the threshold of significance are occasionally the result of questionable statistical practices (cf. Gadbury \& Allison, 2012; Gerber \& Malhotra, 2008a; Masicampo \& Lalande, 2012; Ridley et al., 2007). We also investigated longitudinal trends of textual reporting of statistical significance (i.e., "significant difference" vs. "no significant difference") to replicate Pautasso's (2010) method, as well as of $p<0.05$ versus $p>0.05$. A comparison of the reporting of a variety of $p$-values, $p$-value ranges, textual expressions of significance, and idiosyncratic expressions in 1990 versus 2013 (a total of 83 queries) was conducted as well.

160

161

162

163

164

165

166

167

168

169

170

171

172

173

174

175

176

177

178

179

180

181

182

183

1 2

\subsection{Choice of search engine}

\section{Methods}

Our searches were conducted with Elsevier's Scopus. After trying out other search engines (i.e., Web of Science and Google Scholar), we concluded that Scopus offers the most accurate and powerful search and export features.

Google Scholar indexes more papers than Web of Science and Scopus but has various disadvantages: (1) Google Scholar does not allow for nested Boolean searches; (2) Google Scholar does not provide a possibility for exclusively searching in the abstracts of papers; (3) When the total number of records is greater than 1,000, the estimate of this number is inaccurate ${ }^{1}$; (4) Google Scholar suffers from meta-data errors (Jacsó, 2008); (5) Google Scholar suffers from an underrepresentation of work created before the digital age (De Winter et al., 2014); (6) Bulk exportation of records is against the policy of Google Scholar and therefore severely inhibited (De Winter et al., 2014; Google Scholar, 2014); and (7) Google Scholar does not provide a possibility for searches per discipline or country. Web of Science has various disadvantages as well: (1) Web of Science covers fewer journals and conferences than Scopus; and (2) Web of Science severely underrepresents the social sciences (De Winter et al., 2014).

Scopus has some unique strengths. By using braces $(\{\})$, it allows for searches in which punctuation marks and mathematical operators are taken into consideration, whereas quotation marks are used for more liberal searches. Both Web of Science and Google Scholar neglect punctuation marks and mathematical operators. That is, Scopus is the only one of the three search engines that can distinguish between the search queries $\{p=0.001\}$ and $\{p<0.001\}$. Another difference between Scopus and Web of Science (and the associated Essential Science Indicators [The Thomson Cooperation, 2008] used by Fanelli, 2012) is that although both indexing services classify journals rather than individual papers, Scopus allows journals to be classified into more than one discipline, whereas Web of Science "assigns each paper to a discipline - and only one discipline" (Thomson Reuters, 2014). Results for 'pure' disciplines can be obtained with Scopus by excluding cross-disciplinary papers, whereas cross-classification of records is not possible with Web of Science.

\subsection{Longitudinal trends and their comparisons between scientific disciplines and between world regions}

1 For example, the query “ $p=0.05$ ” yielded 137,000 results for articles dated 2011, 113,000 results for articles dated 2012, and 96,500 results for articles dated between 2011 and 2012 (search date: 26 November 2014). These findings are logically contradictory.

PeerJ reviewing PDF | (v2014:07:2428:1:2:ACCEPTED 6 Dec 2014) 
184

Scopus classifies papers into 27 subject areas; we grouped these into three scientific disciplines, each discipline including subject areas as close as possible to Fanelli's (2012) classification.

1) Social sciences, consisting of the following Scopus subject areas: Social Sciences; Psychology; Arts and Humanities; Economics, Econometrics and Finance; Decision Sciences; Business, Management and Accounting.

2) Biological sciences, consisting of the following Scopus subject areas: Agricultural and Biological Sciences; Biochemistry, Genetics and Molecular Biology; Medicine; Neuroscience; Immunology and Microbiology; Pharmacology, Toxicology and Pharmaceutics; Veterinary; Environmental Science; Dentistry.

3) Physical sciences, consisting of the following Scopus subject areas: Physics and Astronomy; Engineering; Earth and Planetary Sciences; Chemistry; Chemical Engineering; Materials Science; Energy; Computer Science.

The Mathematics and Multidisciplinary subject areas were not grouped in any of the aforementioned disciplines, to replicate Fanelli's (2012) clusters. Health Professions and Nursing were not grouped in any of the disciplines either, because we were not sure which discipline they should be classified into; these two subject areas are relatively small, accounting together for $2.3 \%(711,406 / 30,677,779)$ of all records with an abstract in Scopus with publication date between 1990 and 2013, and it is unlikely that they would have affected our results. Note that we did not explicitly exclude these four subject areas from the searches: an abstract classified into, for example, both Medicine and Nursing would still be classified in the biological sciences.

To investigate whether longitudinal trends in significance reporting differ between regions of the world, we distinguished the following world regions as in Fanelli (2012), namely:

1) United States (US).

2) Fifteen European countries (EU15): Austria, Belgium, Denmark, Finland, France, Germany, Greece, Ireland, Italy, Luxembourg, The Netherlands, Portugal, Spain, Sweden, and United Kingdom.

3) Seven Asian countries (AS7): China, Hong Kong, India, Japan, Singapore, South Korea, and Taiwan.

Note that a paper can belong to multiple world regions due to multiple authors with affiliations in countries from different world regions, or due to an author having multiple affiliations in countries from different world regions.

The following queries were conducted using the advanced search function of Scopus for the abstracts of all papers in the database as well as for each discipline and world region defined above:

1) $\mathrm{ABS}(\{\}$.$) , to extract the total number of papers with an abstract.$

2) $p$-values between 0.041 and 0.049 versus $p$-values between 0.051 and 0.059 , namely:

a. A query containing $p$-values between 0.041 and 0.049 , that is: $\operatorname{ABS}(\{\mathrm{p}=0.041\}$ OR $\{\mathrm{p}=.041\}$ OR $\{\mathrm{p}=$ $0.042\}$ OR $\{\mathrm{p}=.042\} \ldots$ OR $\{\mathrm{p}=0.049\}$ OR $\{\mathrm{p}=.049\})$, to extract the number of papers with $p$-values between 0.041 and 0.049 , that is, just below the typical alpha value of 0.05 .

b. A query containing $p$-values between 0.051 and 0.059 , that is: $\mathrm{ABS}(\{\mathrm{p}=0.051\}$ OR $\{\mathrm{p}=.051\}$ OR $\{\mathrm{p}=$ $0.052\}$ OR $\{p=.052\} \ldots$ OR $\{p=0.059\}$ OR $\{p=.059\})$, to extract the number of papers with $p$-values between 0.051 and 0.059 , that is, just above the alpha value of 0.05 .

3) "Significant difference" versus "no significant difference" and variants thereof, namely:

a. A query containing typical expressions for reporting significant differences, that is: $\mathrm{ABS}((\{$ significant difference\} OR \{significant differences\}) AND NOT (\{no significant difference $\}$ OR \{no significant differences\} OR \{no statistically significant difference\} OR \{no statistically significant differences\})), to extract the number of papers with a textual manifestation of significant results.

b. A query containing typical expressions for reporting no significant differences, that is: $\mathrm{ABS}$ (\{no significant difference\} OR \{no significant differences\} OR \{no statistically significant difference\} OR \{no statistically significant differences $\}$ ), to extract the number of papers with a textual manifestation of non-significant results.

4) $p<0.05$ (so-called less-than threshold reporting) versus $p>0.05$, namely:

a. A query containing variants of the expression $p<0.05$, that is: $\operatorname{ABS}(\{\mathrm{p}<0.05\}$ OR $\{\mathrm{p}<.05\}$ OR $\{\mathrm{p}<=$ $0.05\}$ OR $\{\mathrm{p}<=.05\}$ OR $\{\mathrm{p}=<0.05\}$ OR $\{\mathrm{p}=<.05\}$ OR $\{\mathrm{p} \leq 0.05\}$ OR $\{\mathrm{p} \leq .05\})$, to extract the number of papers reporting significance in reference to the 0.05 threshold of the alpha value.

b. A query containing variants of the expression $p>0.05$, that is: $\operatorname{ABS}(\{\mathrm{p}>0.05\}$ OR $\{\mathrm{p}>.05\}$ OR $\{\mathrm{p}>=$ $0.05\}$ OR $\{\mathrm{p}>=.05\}$ OR $\{\mathrm{p}=>0.05\}$ OR $\{\mathrm{p}=>.05\}$ OR $\{\mathrm{p} \geq 0.05\}$ OR $\{\mathrm{p} \geq .05\})$, to extract the number of papers reporting non-significance in reference to the 0.05 threshold of the alpha value.

The following measures were calculated for items $2-4$ of the previous list, per publication year, for all papers in the Scopus database as well as per scientific discipline and per world region: 
236

237

238

239

240

241

242

243

244

245

246

247

248

249

250

251

252

253

254

255

256

257

258

259

260

261

262

263

264

265

266

267

268

269

270

271

272

273

274

275

276

277

278

279

280

281

282

283

284

285

286

287

1) Percentage of papers reporting significant results $(100 \% *[S / T])$ : the number of papers reporting significant results $(S)$ divided by the total number of papers with an abstract $(T)$ and multiplied by 100 .

2) Percentage of papers reporting non-significant results $(100 \% *[N S / T])$ : the number of papers reporting nonsignificant results $(N S)$ divided by the total number of papers with an abstract $(T)$ and multiplied by 100 .

3) Ratio of significant to non-significant results $(S / N S)$ : the number of papers reporting significant results $(S)$ divided by the number of papers reporting non-significant results (NS).

4) Percentage of significance-testing papers reporting significant results $(100 \% *[S /(S+N S)])$ : the number of papers reporting significant results $(S)$ divided by the sum of papers reporting significant and non-significant results $(S+N S)$ and multiplied by $100 \%$.

Longitudinal trends were assessed by means of the slope coefficient estimates and corresponding $95 \%$ confidence intervals of a simple linear regression analysis, with the publication year as predictor variable and the ratio of significant to non-significant results $(S / N S)$ or the percentage of significance-testing papers reporting significant results $(100 \% *[S /(S+N S)])$ as dependent variable. Note that just-not-overlapping $95 \%$ confidence intervals correspond to a $p$-value smaller than 0.006 (Cumming \& Finch, 2005).

\subsection{Pure scientific disciplines and pure world regions}

As mentioned above, Scopus classifies papers into multiple subject areas. To gain insight into the number of papers belonging 'purely' to one discipline and to assess how cross-classification may have affected our analyses, we repeated the search queries described in section 2.2 for: (1) pure disciplines: papers classified by Scopus into subject areas that belong to the same discipline; and (2) discipline intersections: papers classified by Scopus into subject areas that belong to two or all three disciplines.

Similarly, to gain insight into the number of papers with authors affiliated with countries from the same world region versus the number of papers with author affiliations spanning across world regions, we repeated the search queries described in section 2.2 for: (1) pure world regions: papers all authors of which were affiliated solely with countries belonging to one and the same world region; and (2) world region intersections: papers by authors affiliated with countries belonging to two or all three world regions.

Venn diagrams were constructed for $p$-values between 0.041 and $0.049, p$-values between 0.051 and 0.059 , and all abstracts, to illustrate the number of papers belonging to pure disciplines/world regions and to discipline/world region intersections. Longitudinal trends in the three pure disciplines/world regions were estimated as in section 2.2.

\subsection{Significance versus using idiosyncratic expressions in 1990 and 2013}

To investigate whether the longitudinal trends of $p$-values between 0.041 and 0.049 and between 0.051 and 0.059 differ from the corresponding trends of other manifestations of significance, we conducted 25 additional Scopus search queries of multiple $p$-values and $p$-value ranges (some of which were proposed in Tweets commenting on a preprint of the present paper; e.g., Hankins, 2014; Sherman, 2014). We also conducted 23 additional queries of textual expressions of statistical (non-)significance; some of these were proposed by the journal editor and 18 were taken from Hankins (2013). Specifically, we checked the number of records in 1990 and 2013 for the 509 textual expressions of significance reported by Hankins (2013). From these 509, we included the 18 that yielded 10 records or more for both 1990 and 2013. Finally, 29 queries of idiosyncratic expressions were conducted. Some of these were related to structured reporting (e.g., "results showed that"), whereas others were not (e.g., "room temperature") and used as controls. Table 1 provides an overview of all search queries and corresponding syntaxes in Scopus.

For these 77 queries as well as for the 6 queries described in section 2.2 (i.e., queries 2a,b, 3a,b, and 4a,b), the ratio $\left(N_{2013} / T_{2013}\right) /\left(N_{1990} / T_{1990}\right)$ was calculated, where $N_{2013}$ and $N_{1990}$ are the total numbers of abstracts with terms of one of the 83 search queries in 2013 and 1990, respectively, and $T_{2013}$ and $T_{1990}$ are the total numbers of papers with an abstract for these two years (as derived by query 1 in section 2.2).

\subsection{Supplementary search queries}

The following data were also extracted:

1) Yearly number of papers containing $p<0.05$ but not $p>0.05, p>0.05$ but not $p<0.05$, and both $p<0.05$ and $p$ $>0.05$ (i.e., three search queries in total).

2) Yearly number of papers with abstracts containing $p$-values between 0.001 and 0.099 with a 0.001 interval, that is, $p=0.001, p=0.002, \ldots p=0.099$ (i.e., 99 search queries in total).

3) Yearly number of papers containing $p$-values between 0.041 and $0.049, p$-values between 0.051 and 0.059 , and the total number of papers with an abstract, in three research fields of biological sciences, proposed by one of the reviewers: psychiatry, surgery, and cardiovascular medicine. This was done by restricting our searches to the 
terms psychiatr*, surg*, and cardio* OR heart, respectively, in the journal name (i.e., 3 search terms $\mathrm{x} 3$ research fields $=9$ search queries).

290

291

292

293

294

295

296

297

298

299

300

301

302

303

304

305

306

307

308

309

310

311

312

313

314

315

316

317

318

\subsection{General methodological considerations}

Each abstract was counted only once per search query, independent of whether it included one or more manifestations of significance. All data were extracted between 15 and 30 November 2014. All searches of numerical $p$-values were conducted both for strings with and without zero before the decimal separator (e.g., 0.05 and .05). For all search queries containing " $<$ " or " $>$ " we also included variants with " $<=$ ", "=<", " $\leq$ " or " $>=$, " "=>", " $\geq$ ". Searches in Scopus are not case sensitive, that is, a search query in lower cases (e.g., $\{p=0.001\}$ ) also retrieves records with the same query in upper cases (e.g., $\mathrm{P}=0.001)$. Spaces around mathematical operators are neglected by Scopus; that is, queries with and without spaces yield the same results. All analyses were conducted for papers published in the period 1990-2013. The employed MATLAB (version R2011b) script, the CSV files with the raw data as exported from Scopus, and an Excel file with all search syntaxes and the names of the corresponding CSV files are provided as supplementary material.

\subsection{Total number of papers}

\section{Results}

According to our searches, Scopus contained a total of 30,677,779 papers with an abstract published between 1990 and 2013. Of these, 3,061,170 papers belonged to the social sciences, 14,412,460 papers belonged to the biological sciences, and 15,364,142 papers belonged to the physical sciences. The sum of the number of papers in the three disciplines was greater than the total number of papers, because some papers were classified into multiple disciplines. The US were found in the affiliations of 8,073,346 papers, EU15 in 8,790,965 papers, and AS7 in $7,413,236$ papers.

The number of papers has increased over the years in all three scientific disciplines (Fig. 2). Over the period 19902013, papers in the social sciences represented $12.4 \%$ (i.e., $100 \% * 1,003,555 / 8,073,346$ ) of all papers from the US, $10.0 \%$ of all papers from the EU15, and only $4.8 \%$ of all papers from the AS7. Papers in the biological sciences represented $52.2 \%$ of all papers from the US, $51.8 \%$ of all papers from the EU15, and $35.7 \%$ of all papers from the AS7. Papers in the physical sciences represented $42.8 \%$ of all papers from the US, $46.1 \%$ of all papers from the EU15, and $66.6 \%$ of all papers from the AS7. In other words, AS7 has been publishing considerably less than the US and EU15 in the social sciences and considerably more in the physical sciences. AS7's production of physical sciences papers was half the production of physical sciences papers in the US in 1990 (physical sciences papers AS7/physical sciences papers US $=30,558 / 65,045=0.47$ ) and more than double the production of physical sciences papers in the US in 2013 (physical sciences papers AS7/physical sciences papers US = 512,513/208,698 = 2.46).

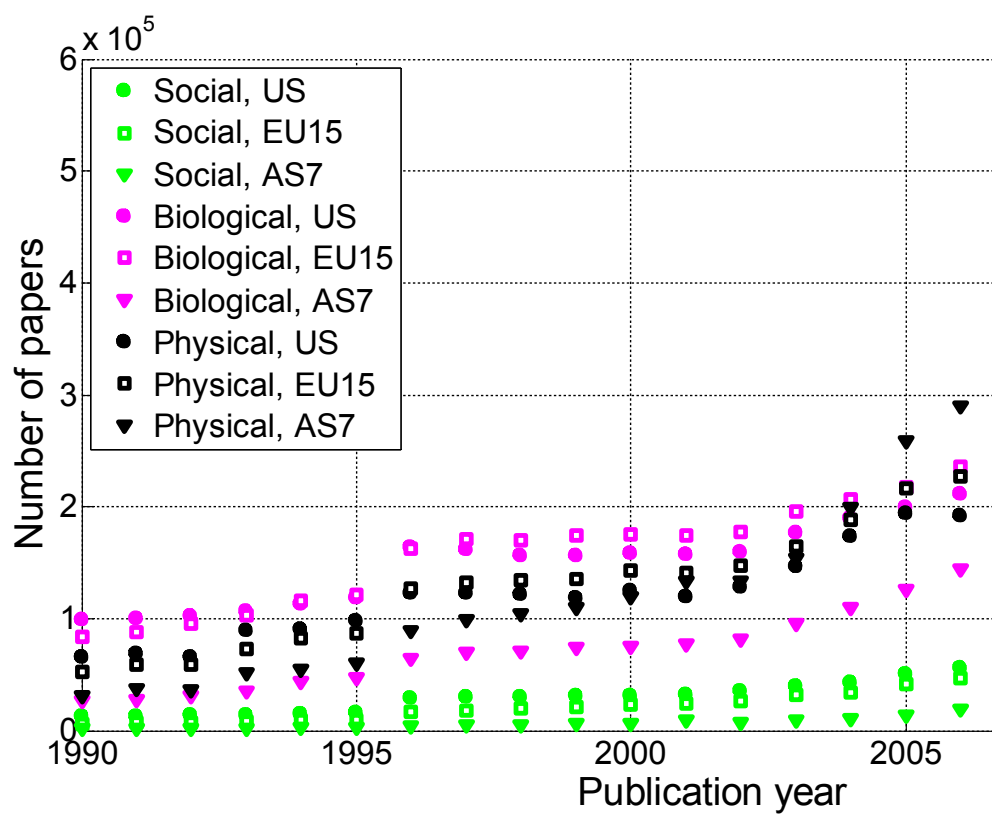

319 Figure 2. Number of papers per publication year, for three scientific disciplines and three world regions.

\section{3.2. Longitudinal trends}




\subsection{1. p-values between 0.041 and 0.049 versus p-values between 0.051 and 0.059}

Both the $p$-values between 0.041 and 0.049 and the $p$-values between 0.051 and 0.059 have increased over time (Fig. 3). In $1990,0.019 \%$ of papers (106 out of 563,023 papers) reported a $p$-value between 0.051 and 0.059 . This increased 3.6-fold to $0.067 \%$ (1,549 out of 2,317,062 papers) in 2013. Positive results increased 10.3-fold in the same period: from $0.030 \%$ (171 out of 563,023 papers) in 1990 to $0.314 \%$ (7,266 out of 2,317,062 papers) in 2013. In other words, the ratio of significant to non-significant results increased from 1.6 (i.e., 171/106 papers) in 1990 to 4.7 (i.e., 7,266/1,549 papers) in 2013 (Fig. 4).

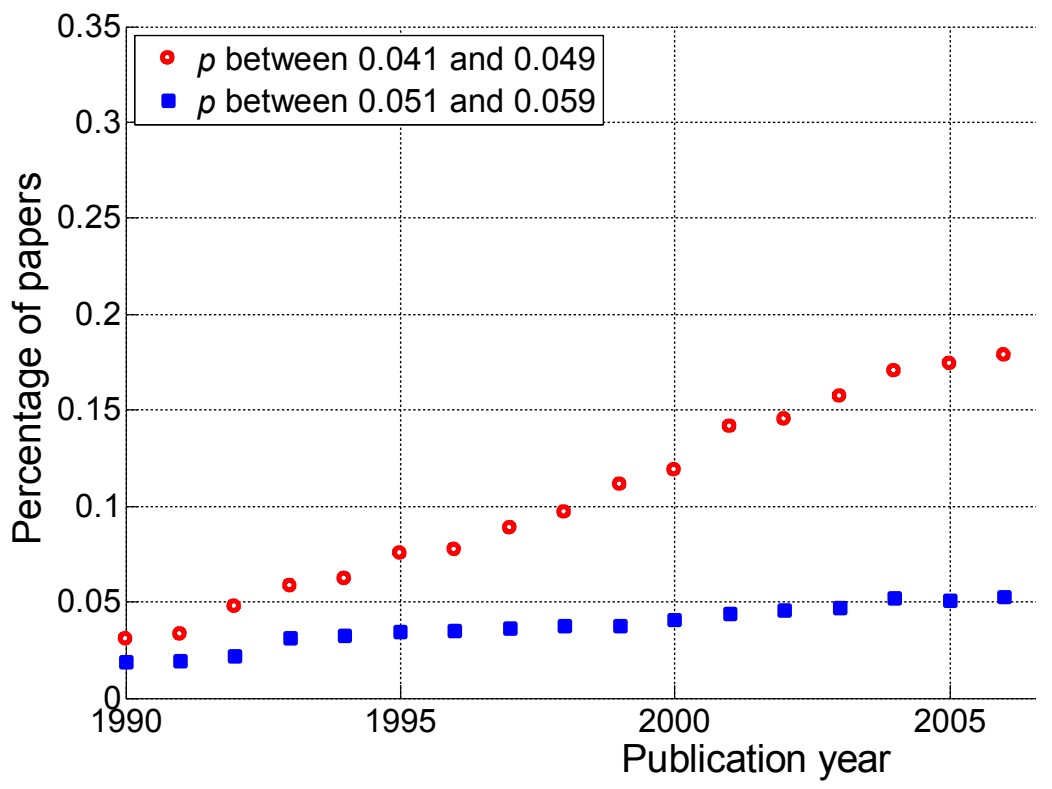

Figure 3. Percentage of papers reporting a $p$-value between 0.041 and 0.049 and percentage of papers reporting a $p$-value between 3290.051 and 0.059 per publication year.

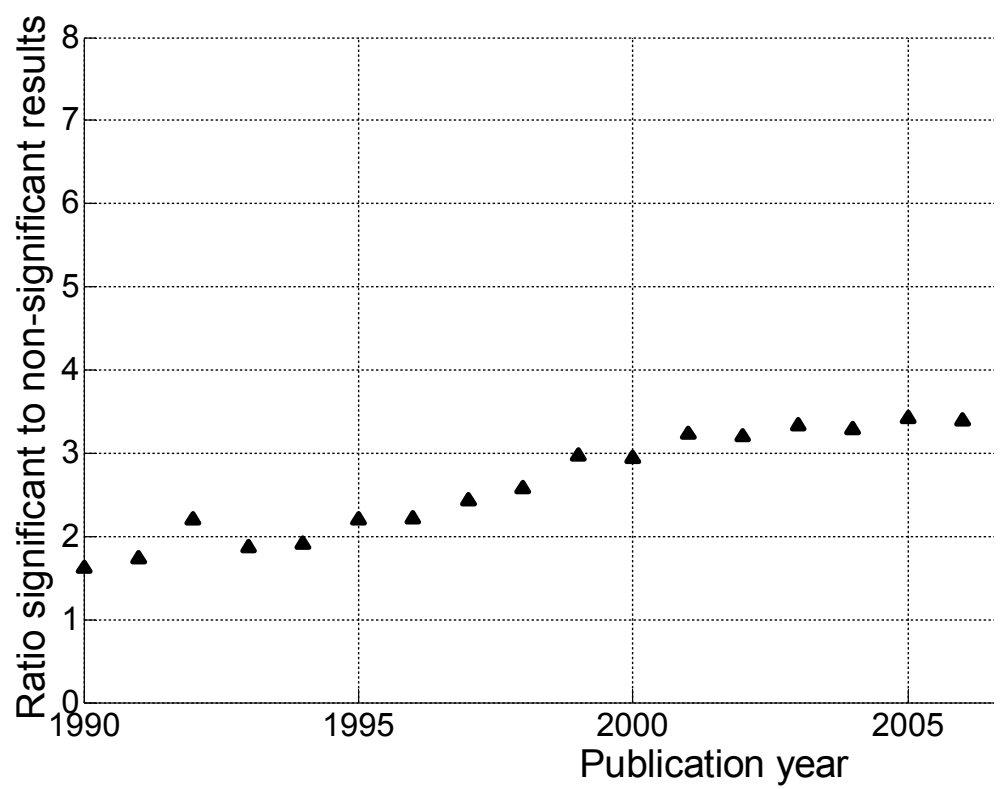

Figure 4. Ratio of $p$-values between 0.041 and 0.049 to $p$-values between 0.051 and 0.059 per publication year. The dashed line represents the result of a simple linear regression analysis.

\section{3.2.2. "Significant difference" versus "no significant difference"} papers $=1.5$ ), whereas the reporting of "no significant difference" has remained about the same (ratio $=1.1$ ). Compared to the findings on $p$-values described above, the ratio of "significant difference" to "no significant 
papers) in 2013. Averaged over the period 1990-2013, the phrase "no significant difference" was 1.4 times more

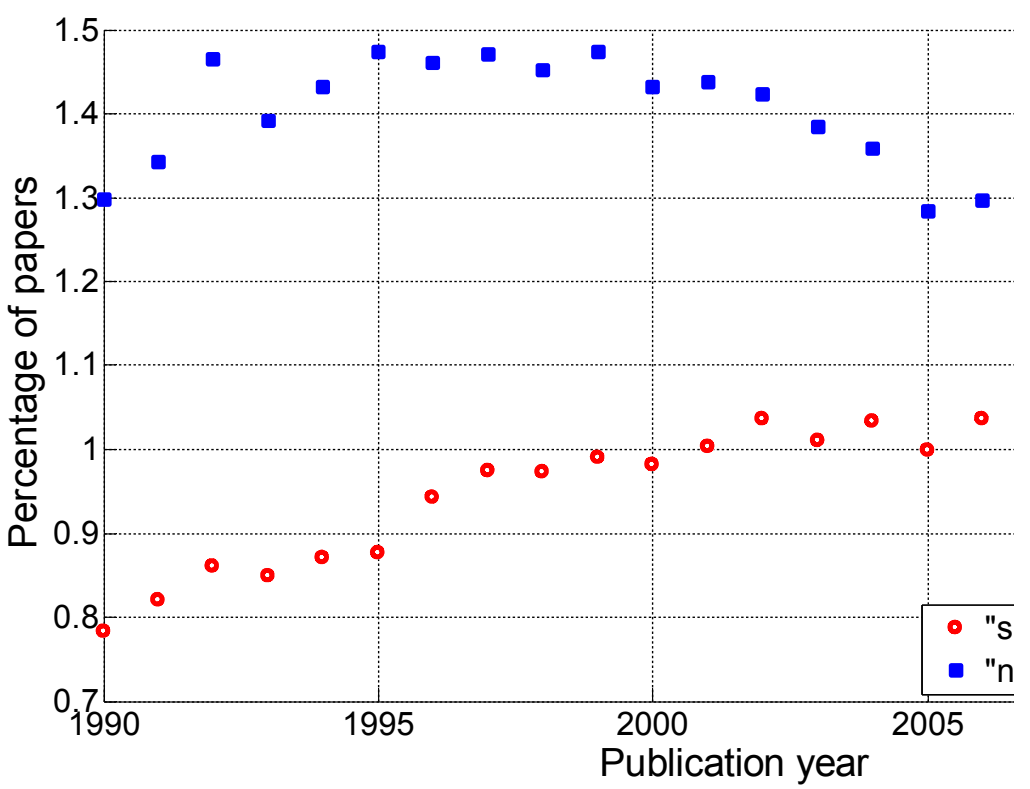

340 341

Figure 5. Percentage of papers reporting "significant difference" and percentage of papers reporting "no significant difference" per publication year.

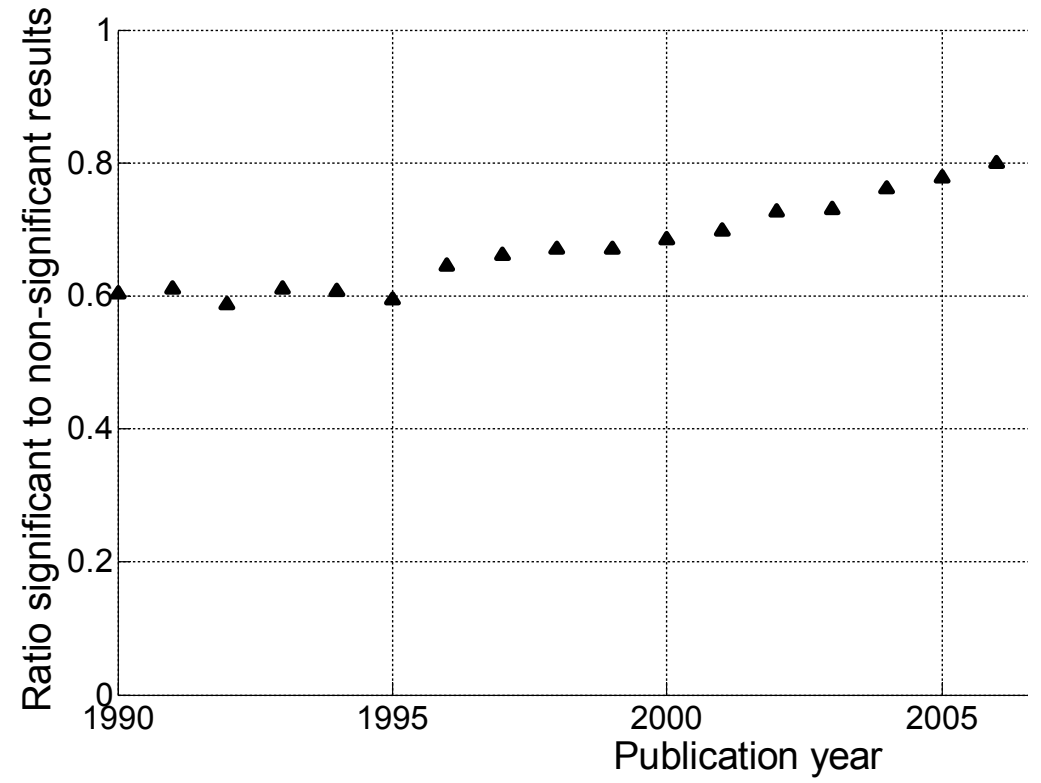

Figure 6. Ratio of "significant difference" to "no significant difference" per publication year. The dashed line represents the result of a simple linear regression analysis.

\subsection{3. $p<0.05$ versus $p>0.05$}

Both $p<0.05$ and $p>0.05$ have increased over the years, in line with the findings described in the previous two sections. The increase of reporting of $p>0.05$ however, was steeper (2013-to-1990 ratio of the percentage of papers $=4.8$ ) than that of $p<0.05$ (2013-to-1990 ratio of the percentage of papers $=1.4$; Fig. 7), opposite to the trends of $p$ values and of "significant difference" versus "no significant difference". The ratio of $p<0.05$ to $p>0.05$ decreased from 19.7 (i.e., 7,193/366 papers) in 1990 to 5.6 (i.e., 40,904/7,255 papers) in 2013 (Fig. 8). 


\section{PeerJ Reviewing Manuscript}

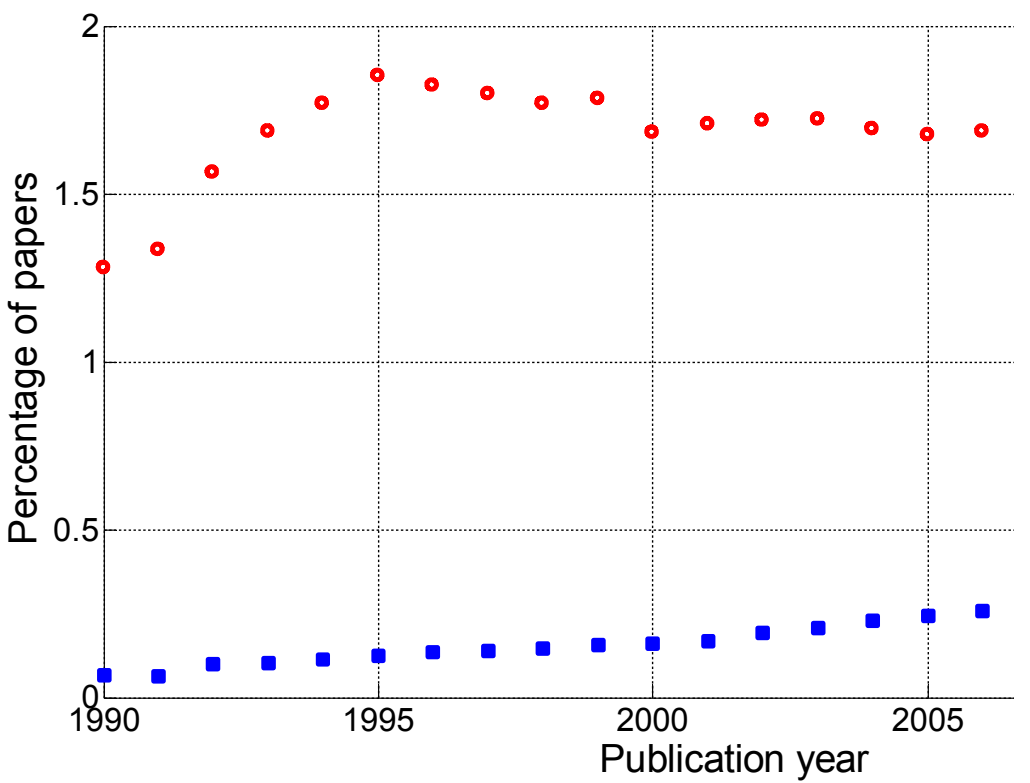

Figure 7. Percentage of papers reporting $p<0.05$ and percentage of papers reporting $p>0.05$ per publication year.

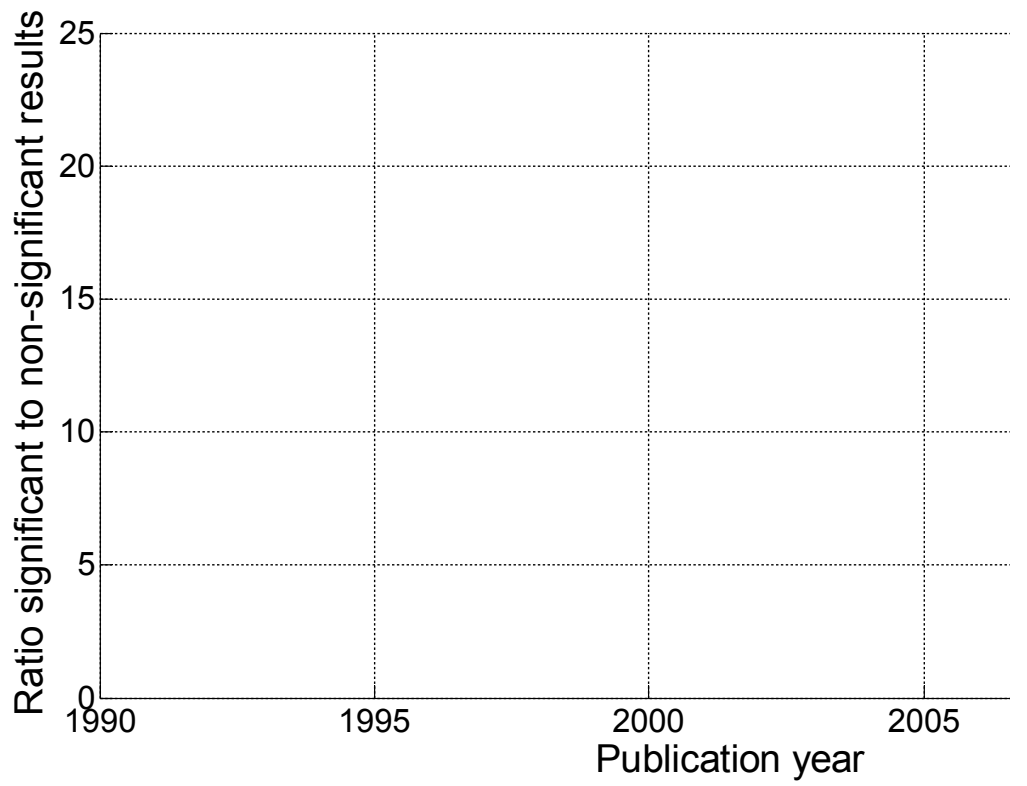

351 Figure 8. Ratio of $p<0.05$ to $p>0.05$ per publication year. The dashed line represents the result of a simple linear regression analysis.

353 In a supplementary analysis we searched for and compared abstracts containing $p<0.05$ but not $p>0.05$, abstracts containing $p>0.05$ but not $p<0.05$, and abstracts containing both $p<0.05$ and $p>0.05$. We found that the percentage of abstracts reporting only $p<0.05$ was considerably larger $(1.6 \%$ averaged over $1990-2013)$ than the percentage of abstracts reporting only $p>0.05(0.12 \%)$ and the percentage of abstracts reporting both $p<0.05$ and $p$ $>0.05(0.07 \%$; see Fig. S1 in supplementary material). The increase of reporting $p>0.05$ only was steeper (2013-to1990 ratio of the percentage of papers $=2.4)$ than that of $p<0.05$ only (2013-to-1990 ratio of the percentage of papers $=1.3$ ), in line with the results of reporting $p<0.05$ versus $p>0.05$.

\subsection{Comparison of longitudinal trends between scientific disciplines}

\section{1


8.6 times more prevalent in the biological sciences than in the social sciences. Over 1990-2013, $p$-values between 0.051 and 0.059 were respectively 47.3 and 8.7 times more prevalent in the biological sciences than in the physical and in the social sciences (Fig. 9). The regression slopes of the ratios of significant to non-significant results were similar for the three disciplines (Figs. $10 \& 16$ ).

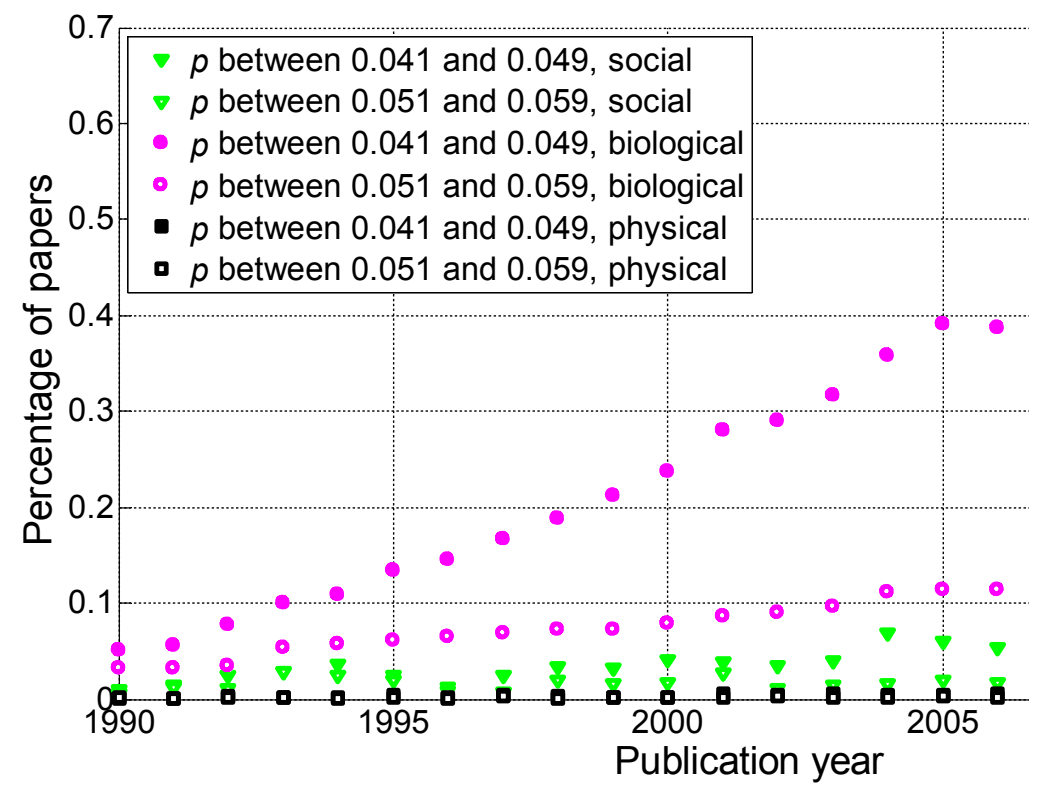

Figure 9. Percentage of papers reporting a $p$-value between 0.041 and 0.049 and percentage of papers reporting a $p$-value between 370 0.051 and 0.059 per publication year, for three scientific disciplines.

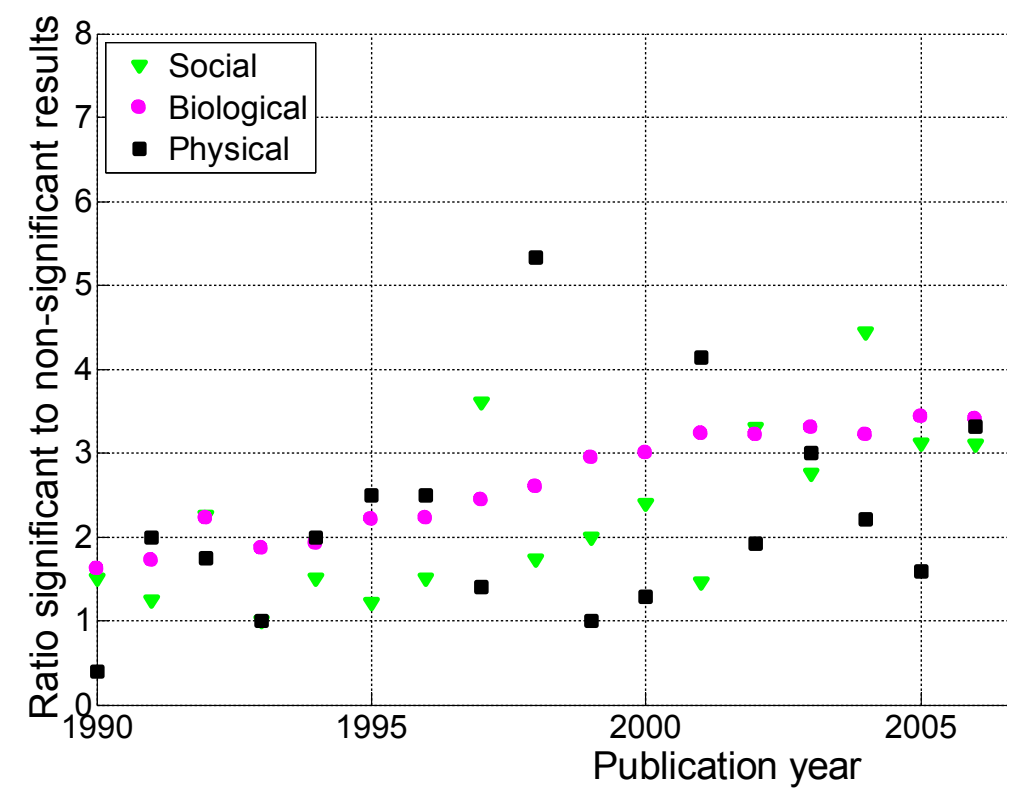

371
Figure 10. Ratio of $p$-values between 0.041 to 0.049 to $p$-values between 0.051 and 0.059 per publication year, for three scientific disciplines. The dashed lines represent the results of a simple linear regression analysis.

\subsection{2. "Significant difference" versus "no significant difference"}

Figure 11 shows that the biological sciences were more likely to use the phrases "significant difference" and "no significant difference" than the social sciences. These expressions were rare in the physical sciences, confirming the results for $p$-values in Fig. 9. Physical sciences exhibited the highest overall ratio of significant to non-significant results (Fig. 12), whereas the growth rate of the ratio of significant to non-significant results was higher in the social sciences than in the biological sciences, the growth rate of which in turn was higher than that in the physical sciences (Fig. 16). 


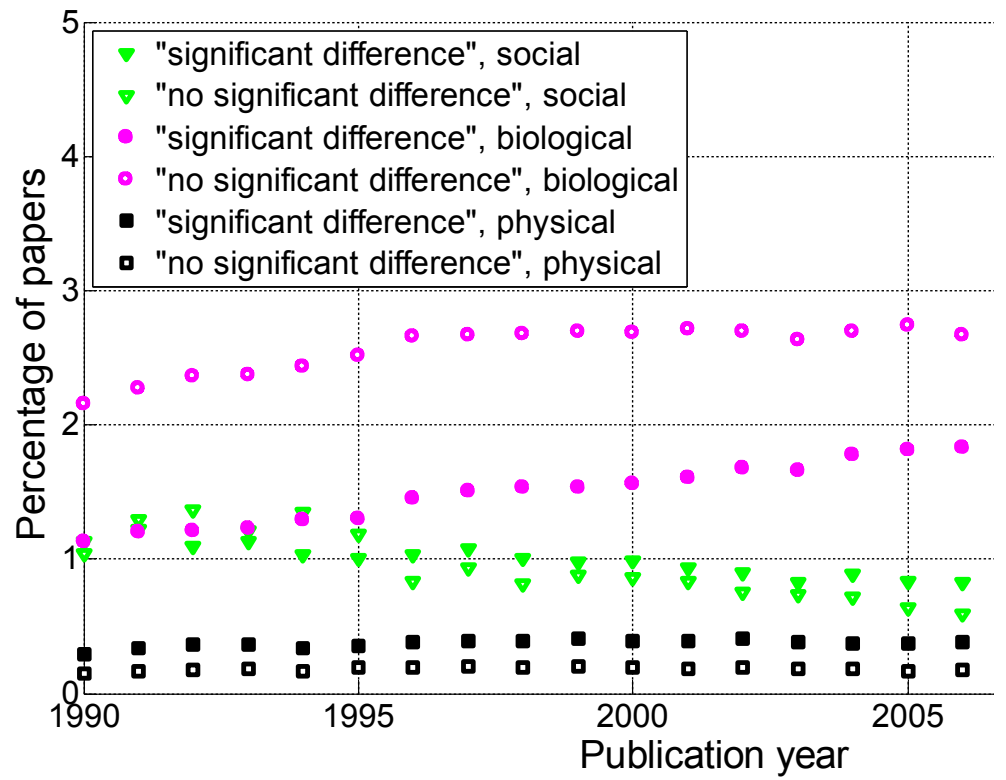

380 Figure 11. Percentage of papers reporting "significant difference" and percentage of papers reporting "no significant difference" 381 per publication year, for three scientific disciplines.

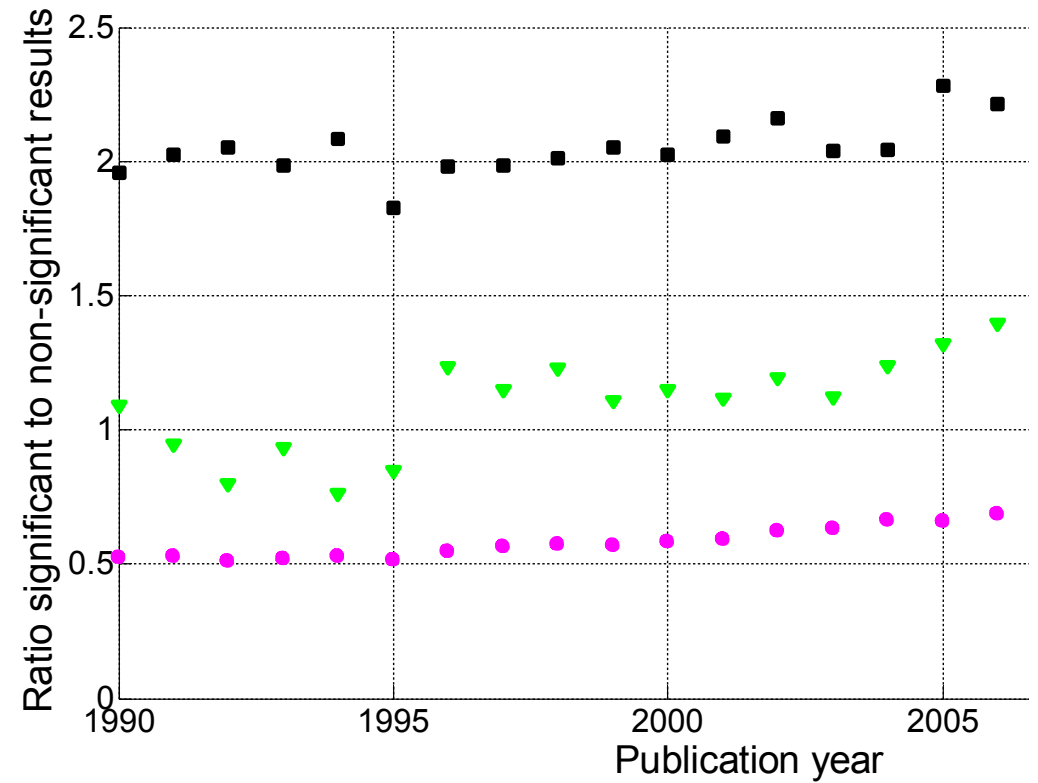

Figure 12. Ratio of "significant difference" to "no significant difference" per publication year, for three scientific disciplines. The dashed lines represent the results of a simple linear regression analysis.

384 3.3.3. $p<0.05$ versus $p>0.05$ physical sciences (Fig. 14). 


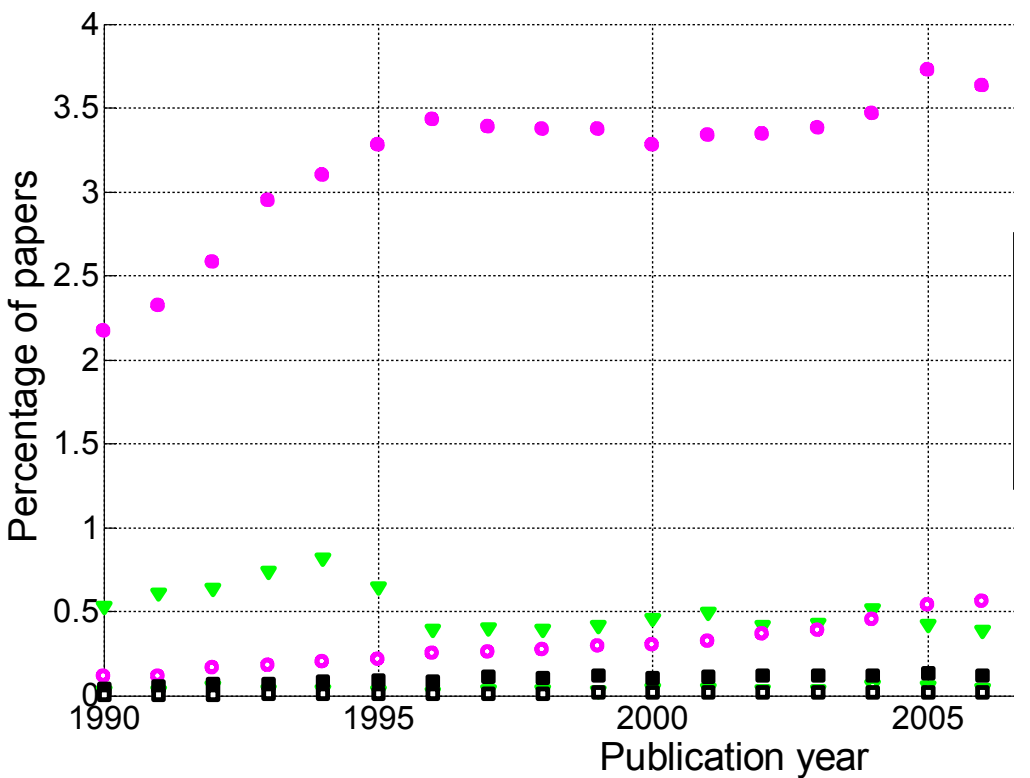

Figure 13. Percentage of papers reporting $p<0.05$ and percentage of papers reporting $p>0.05$ per publication year, for three scientific disciplines.

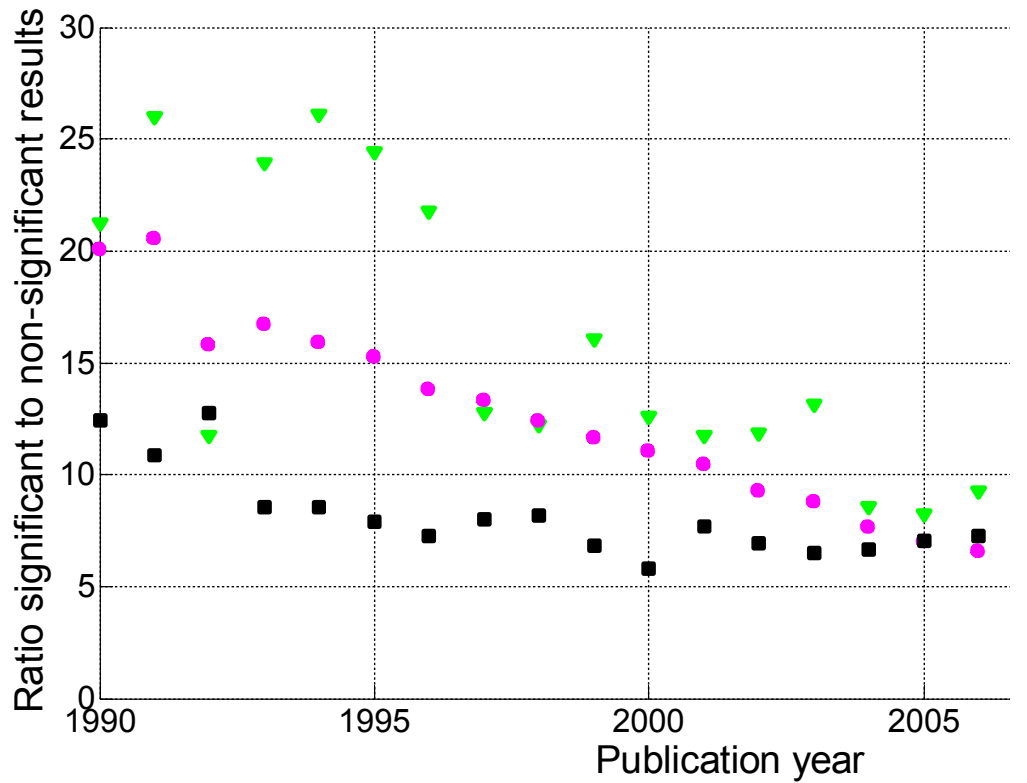

Figure 14. Ratio of $p<0.05$ to $p>0.05$ per publication year, for three scientific disciplines. The dashed lines represent the results 391 of a simple linear regression analysis.

\section{3.3.4 Pure disciplines}

The Venn diagrams in Fig. 15 show the number of papers belonging to pure disciplines, as well as the number of papers classified into two or all three disciplines. It can be seen that the greatest numbers of papers reporting $p$ values between 0.041 and 0.049 or between 0.051 and 0.059 belonged to the biological sciences; these $p$-values were rare in the pure social sciences, and even rarer in the pure physical sciences. The Venn diagrams further show that if a $p$-value were used in the physical sciences, it often occurred in papers with biological affinity (i.e., 670 out of 798 the physical sciences papers with $p$-values between 0.041 and 0.049 and 239 out the 286 physical sciences papers with $p$-values between 0.051 and 0.059 were cross-classified into the biological sciences). A large overlap also occurred between the social sciences and the biological sciences. 


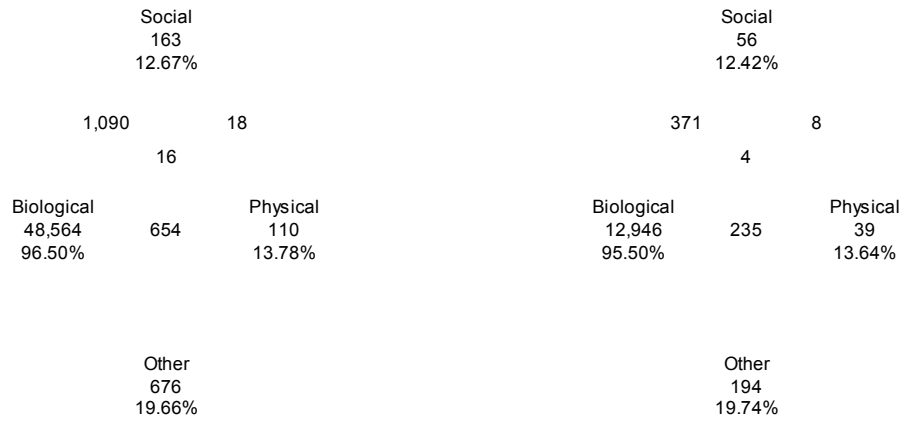

401

402

403

404

405

406

407

408

409

410

411

412

413

Figure 15. Venn diagrams showing the numbers of papers reporting a $p$-value between 0.041 and 0.049 (left), the numbers of papers reporting a $p$-value between 0.051 and 0.059 (middle), and the total number of papers (right). "Other" refers to papers purely classified into subject areas outside the three disciplines. The percentages refer to the papers that were unique to each discipline (e.g., $96.50 \%$ of biological papers with $p$-values between 0.041 and 0.049 belonged purely to biological sciences).

Figure 16 shows the slope coefficients calculated using a simple linear regression analysis for the ratios of significant to non-significant results and the percentages of significant results. These slopes were calculated for $p$-values between 0.041 and 0.049 versus $p$-values between 0.051 and 0.059 , "significant difference" versus "no significant difference", and $p<0.05$ versus $p>0.05$, for the three disciplines, both for cross-classified papers and pure disciplines. It can be seen that the results for pure disciplines were similar to the results for the cross-classified papers described in sections 3.3.1-3.3.3. The 95\% confidence intervals were wider and the trends were more erratic for the analysis of pure disciplines (and for the social and physical sciences in particular) as compared to the analysis of cross-classified papers, because the sample sizes were smaller in the former case (see also left and middle Venn diagrams in Fig. 15).
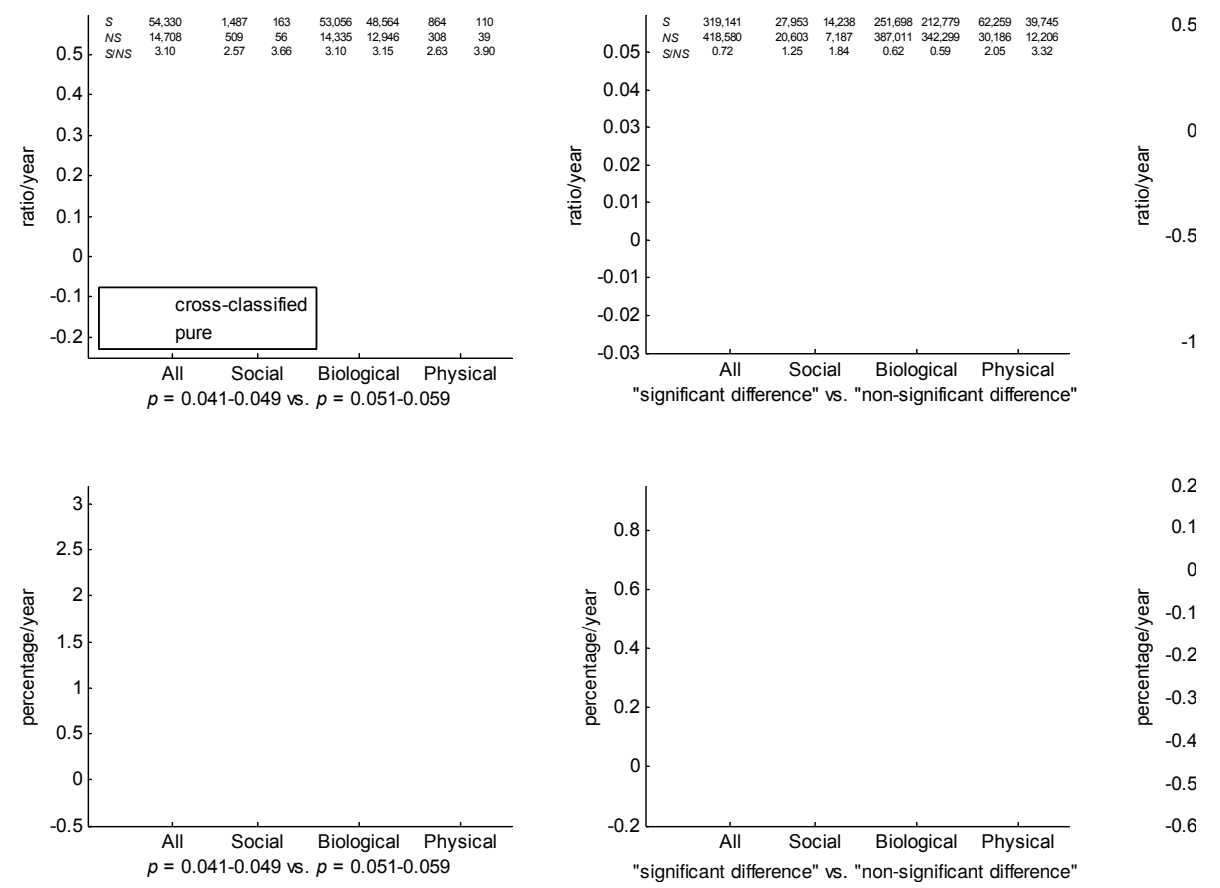

414

415

416

417

418

419

420
Figure 16. Slope coefficients calculated using a simple linear regression analysis, for the ratios of significant $(S)$ to non-significant $(N S)$ results $(S / N S$; top three figures) and the percentages of significant results $(100 \% * S /[S+N S]$; bottom three figures). The slope coefficients are reported for all papers, and for papers in three scientific disciplines, both for cross-classified papers (grey bars) and for pure disciplines (orange bars). The numbers at the top of the figure represent: (1) first row: number of papers between 1990 and 2013 reporting significant results (S); (2) second row: number of papers between 1990 and 2013 reporting nonsignificant results (NS); and (3) third row: ratio of significant to non-significant results (S/NS) calculated as the yearly $S / N S$ averaged over 1990-2013. Error bars denote 95\% confidence intervals. 


\subsection{Comparison of longitudinal trends between world regions}

\subsection{1. p-values between 0.041 and 0.049 versus p-values between 0.051 and 0.059}

For the three world regions, both $p$-values between 0.041 and 0.049 and $p$-values between 0.051 and 0.059 have increased over time (see Fig. S2 in supplementary material). The growth of the reporting significant results as compared to the reporting of non-significant results was greater in AS7 than in the US and EU15 (Fig. 17).

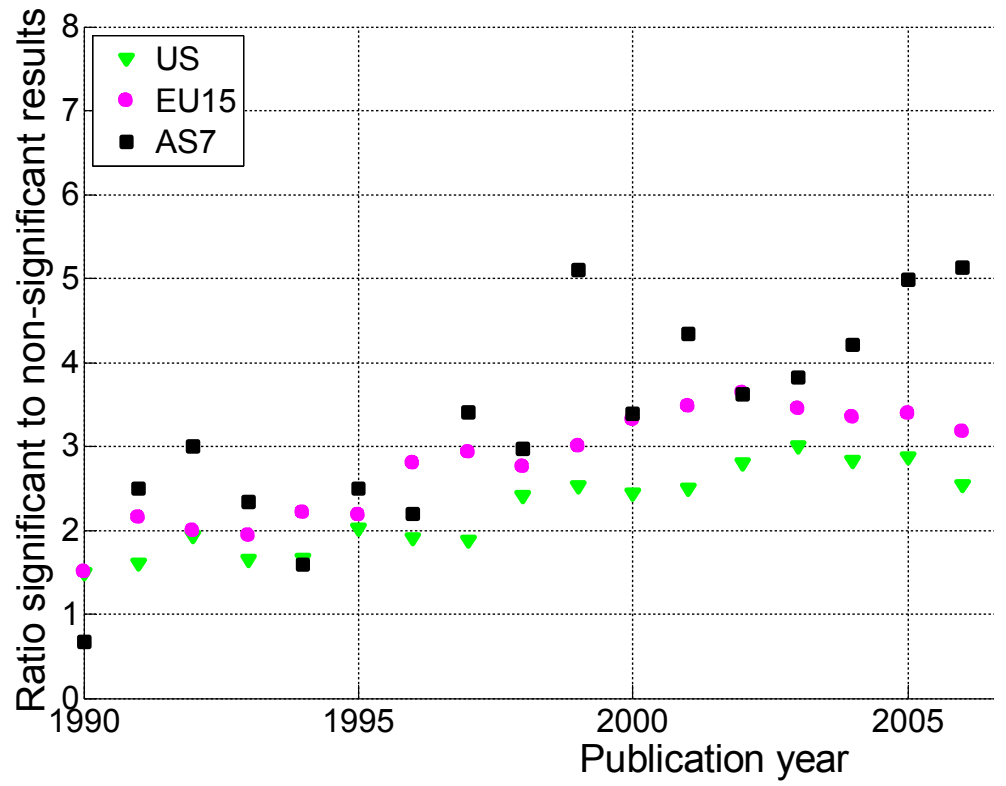

426

427

428

429

430

431

432
Figure 17. Ratio of $p$-values between 0.041 and 0.049 to $p$-values between 0.051 and 0.059 per publication year, for three world regions. The dashed lines represent the results of a simple linear regression analysis.

\subsection{2. "Significant difference" versus "no significant difference"}

The use of "significant difference" increased while the use of "no significance difference" decreased for all three world regions (Fig. S3). While AS7 exhibited the highest ratio of significant to non-significant results in terms of $p$ value reporting (Fig. 17), this region showed the lowest ratio of "significant difference" to "no significant difference" (Fig. 18).

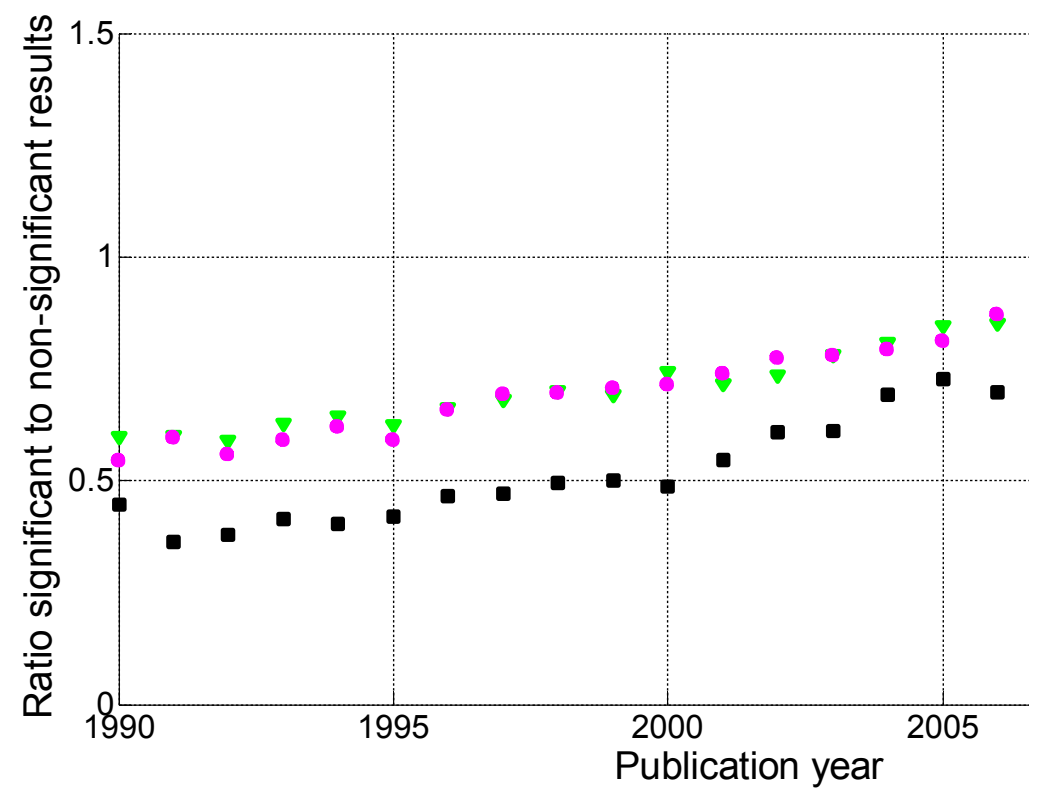

Figure 18. Ratio of "significant difference" to "no significant difference" per publication year, for three world regions. The dashed lines represent the results of a simple linear regression analysis. 
Reporting $p<0.05$ versus $p>0.05$ differed from both the reporting of $p$-values $(0.041-0.049$ versus $0.051-0.059)$ and "significant difference" versus "no significant difference", with a decrease of significant $(p<0.05)$ results for US and EU15 over time, an increase of both significant and non-significant results for AS7 (Fig. S4), and a decreasing ratio of significant to non-significant results for all three world regions (Fig. 19).

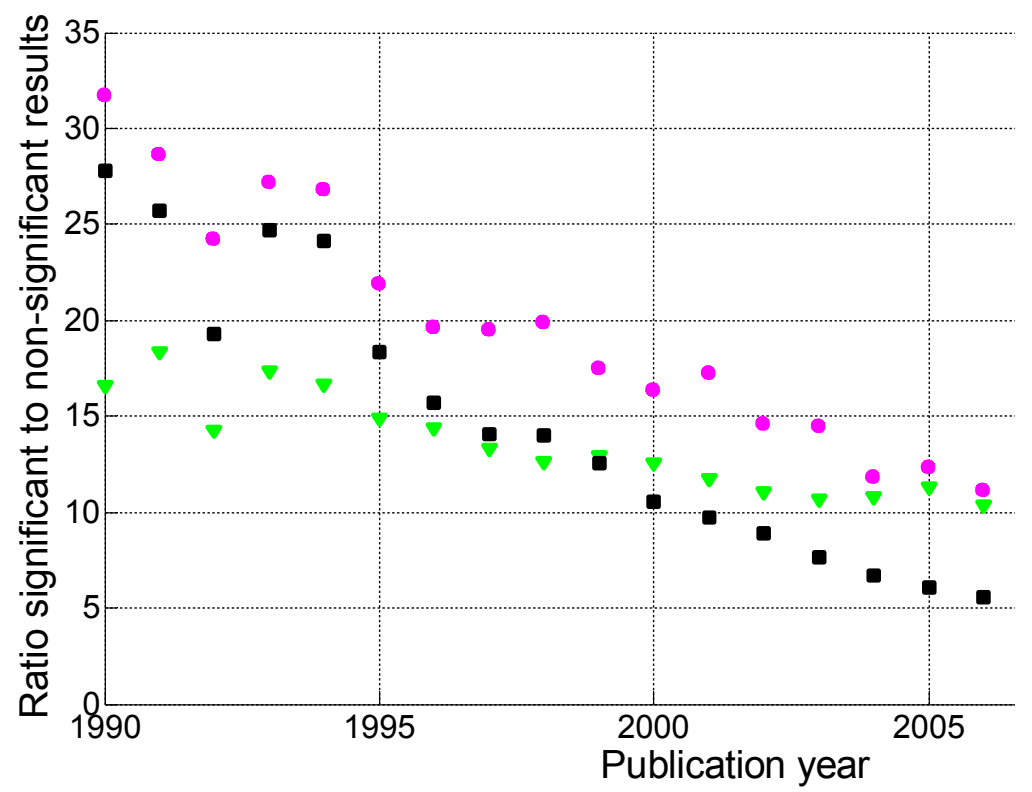

440

Figure 19. Ratio of $p<0.05$ to $p>0.05$ per publication year for three world regions. The dashed lines represent the results of a linear regression analysis.

\subsubsection{Pure world regions}

Figure 20 shows the number of papers all authors of which were affiliated with only one world region (i.e., pure world regions), as well as the number of papers with authors from different world regions. It can be seen that between $82 \%$ and $91 \%$ of all papers reporting $p$-values between 0.041 and 0.049 and between 0.051 and 0.059 were affiliated solely with one world region.

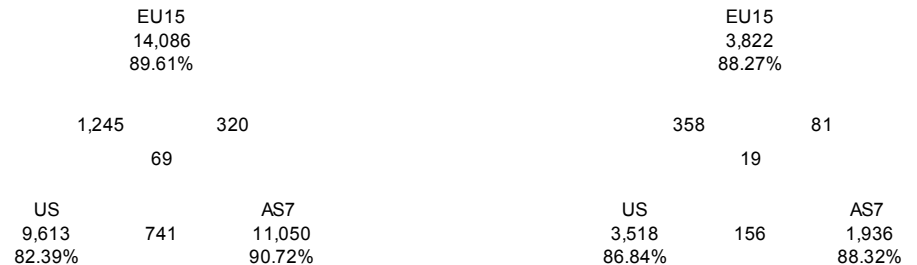

Figure 20. Venn diagrams showing the numbers of papers reporting a $p$-value between 0.041 and 0.049 (left), the numbers of papers reporting a $p$-value between 0.051 and 0.059 (middle), and the total number of papers (right). "Other" refers to papers purely affiliated with countries outside the three world regions. The percentages refer to the papers that were unique to each world region.

Figure 21 shows the slope coefficients calculated using a simple linear regression for the ratios of significant to nonsignificant results and the percentages of significant results. These slopes were calculated for $p$-values between 0.041 and 0.049 versus $p$-values between 0.051 and 0.059 , "significant difference" versus "no significant difference", and $p<0.05$ versus $p>0.05$, for the three world regions, both for cross-classified papers and pure world regions. The 
results for pure world regions were comparable to the results for the cross-classified papers described in sections 456 3.4.1-3.4.3.
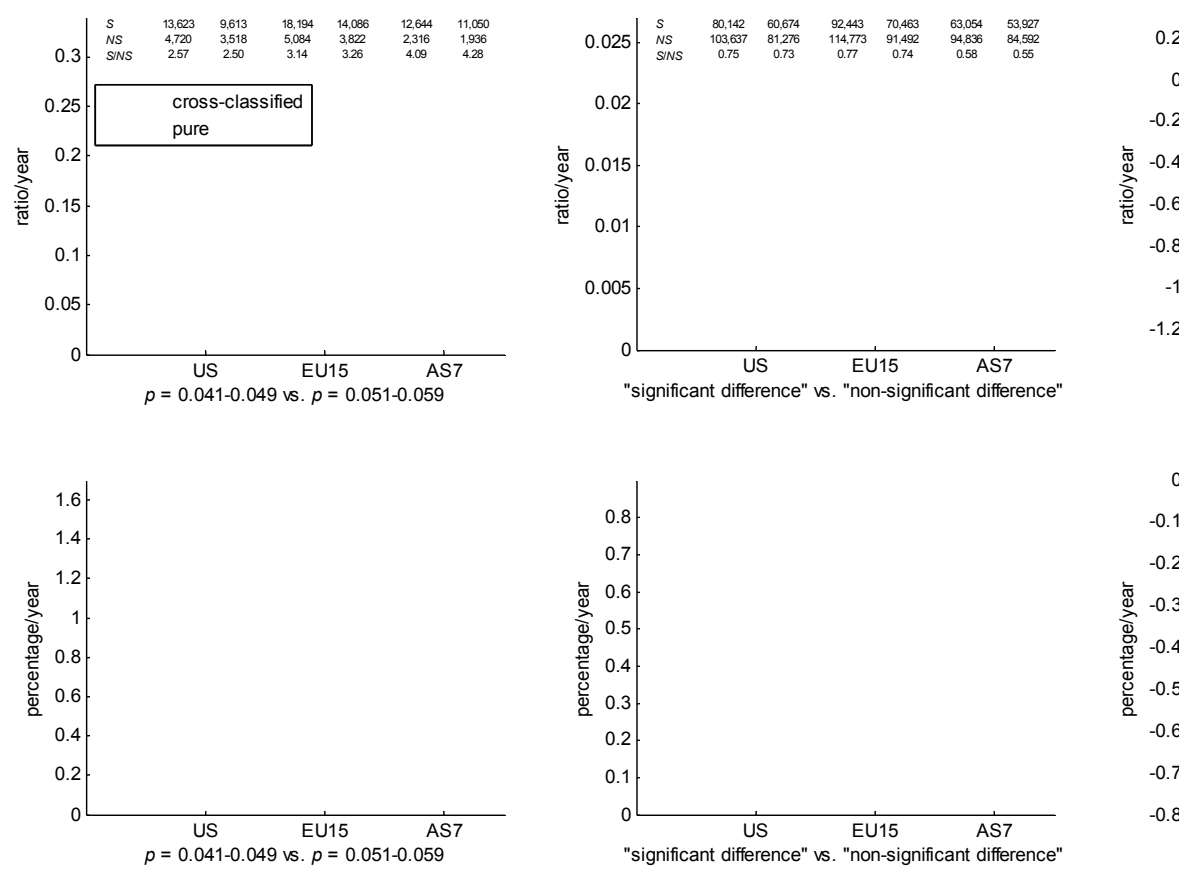

457

458

459

460

461

462

463

464

465

466

467

468

469

470

471

472

473

474

Figure 21. Slope coefficients calculated using a simple linear regression, for the ratios of significant $(S)$ to non-significant (NS) results $(S / N S$; top three figures) and the percentages of significant results $(100 \% * S /[S+N S]$; bottom three figures). The slope coefficients are reported for papers in three world regions, both for cross-classified papers (grey bars) and for pure world regions (orange bars). The numbers at the top of the figure represent: (1) first row: number of papers between 1990 and 2013 reporting significant results $(S)$; (2) second row: number of papers between 1990 and 2013 reporting non-significant results (NS); and (3) third row: ratio of significant to non-significant results $(S / N S)$ calculated as the yearly $S / N S$ averaged over 1990-2013. Error bars denote $95 \%$ confidence intervals.

\subsection{Significance versus using idiosyncratic expressions in 1990 and 2013}

Figure 22 shows the 2013-to-1990 ratio of the percentage of papers for 83 search queries. It can be seen that $p$-value reporting has increased more rapidly than the reporting of the terms "significant difference" and "no significant difference". Among all ranges of three-digit $p$-values below 0.1 tested, the 2013-to-1990 ratio was highest for $p$ values between 0.041 and 0.049 , and lowest for $p$-values between 0.051 and 0.059 . The $p$-values with two decimal numbers showed the same pattern, with the largest increases for $p=0.04$ and the smallest increases for $p=0.05$. The use of some idiosyncratic expressions related to structured reporting, such as "our aim", "the aim of", and "results showed that", has increased over the years (2013-to-1990 ratio $=8.3,5.5, \& 5.0$, respectively). Note that in terms of prevalence, the smaller the $p$-value the more frequently it was reported (see numbers at right of the bars at Fig. 22). This finding is confirmed by a supplementary analysis (Fig. 23), in which we investigated the prevalence of $p$-values between 0.001 and 0.099 with finer (0.001) intervals than the intervals in Fig. 22. 


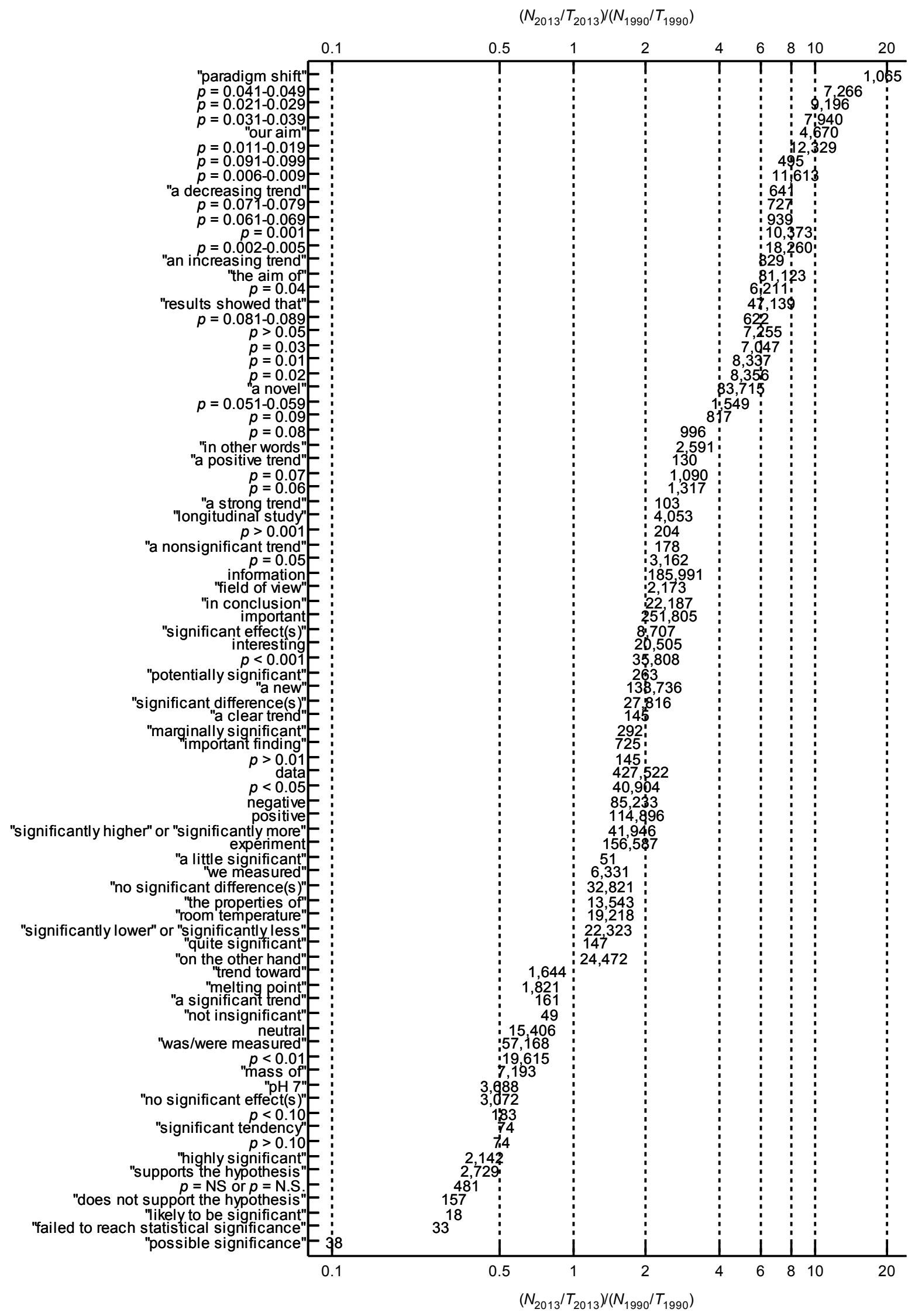


475

476

477

478

479

480

481

482

483

484

485

486

487

488

489

490

491

492

493

494

495

496

497

498

499

500

501

502

503

504

505

506

507

Figure 22. Logarithmic plot of the 2013-to-1990 ratio $\left(N_{2013} / T_{2013}\right) /\left(N_{1990} / T_{1990}\right)$, where $N$ is the number of abstracts reporting a certain expression in 2013 or 1990, and $T$ is the total number of papers with an abstract in that year. The number at the right end of each bar is $N_{2013}$. $T_{1990}=561,516$ and $T_{2013}=2,311,772$.

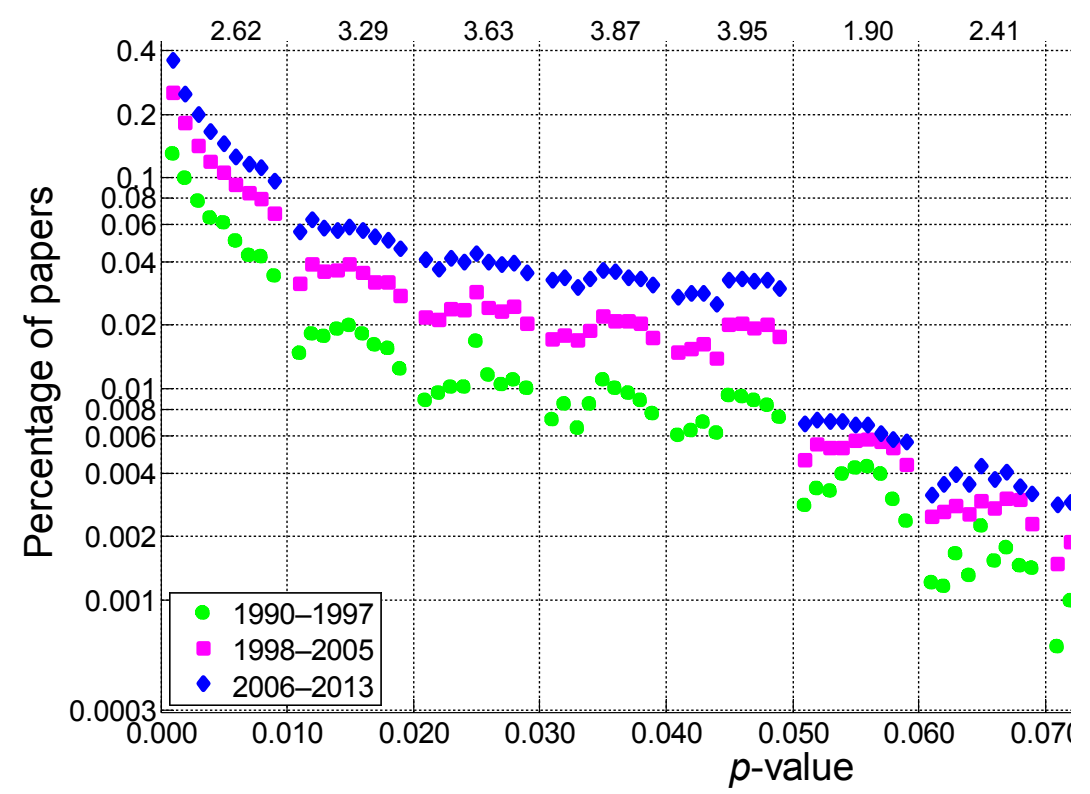

Figure 23. Percentage of papers reporting a $p$-value as a function of the size of the $p$-value for three octennia. The numbers at the top of the graph represent the ratio of the percentage of papers in 2006-2013 to the percentage of papers in 1990-1997 averaged across $0.001-0.009,0.011-0.019,0.021-0.029$, etc.

\subsection{Longitudinal trends of (non-)significance reporting}

We investigated longitudinal trends between 1990 and 2013 for $p$-values between 0.041 and 0.049 versus $p$-values between 0.051 and 0.059 , for "significant difference" versus "no significant difference", and for $p<0.05$ versus $p>$ 0.05. The longitudinal trends were compared between disciplines and between world regions. A comparison of the reporting of a variety of $p$-values, $p$-value ranges, textual reporting of significance, and idiosyncratic expressions (a total of 83 search queries) in 1990 versus 2013 was conducted as well.

The percentage of papers with $p$-values between 0.051 and 0.059 in the abstract has increased by a factor of 3.6 between 1990 and 2013, which indicates that negative results are not disappearing. Also striking is the 10.3-fold increase of $p$-values between 0.041 and 0.049 over the same time period.

For three-digit $p$-values below 0.1 , the smaller the $p$-value the more frequently it was reported (Fig. $22 \& 23$ ), in line with the right skewed distribution of $p$-values that is to be expected when the null hypothesis is false (Simonsohn et al., 2014). In other words, we did not find a peak of $p$-values just below 0.05 . We did find, however, a longitudinal change in the $p$-value distribution, with $p$-values between 0.041 and 0.049 showing the most rapid increase over the years. Among the three-digit $p$-value ranges we searched for, the 2013-to-1990 ratio of the percentage of papers was highest for $p$-values between 0.041 and 0.049 , and lowest for $p$-values between 0.051 and 0.059 . The two-digit $p$ values showed the same pattern, with $p=0.04$ exhibiting the largest increase and $p=0.05$ the smallest increase from 1990 to 2013.

Reporting of "significant difference" versus "no significant difference" displayed a more modest increase than $p$ value reporting, resembling Pautasso's (2010) findings. The use of $p>0.05$ has increased more steeply than $p<0.05$, meaning that the corresponding regression slope is negative (Figs. $16 \& 21$ ). We conclude that the prevalence and growth rates of significance and non-significance reporting strongly depend on the search term.

The use of all $p$-values has increased rapidly since 1990 (between 2 and 10 times; Fig. 22), suggesting that null hypothesis significance testing has become more widely used over the years, despite widespread criticism against the use of $p$-values (see e.g., Wagenmakers, 2007). The idiosyncratic expression "paradigm shift" was used 15.2 times more often in 2013 than in 1990 (cf. Atkin, 2002, who reported that the expression was found in 4 titles published in 1990 versus 30 in 2000 and 22 in 2001). 
508 4.2. Comparisons of longitudinal trends between scientific disciplines

509 We found no support for the hierarchy of sciences as discussed by Fanelli (2010). In our analysis, the differences in 510 the growth rates of the positive to negative results ratios between the three scientific disciplines were inconsistent 511 and dependent on the search term. For example, for the ratio of "significant difference" to "no significant 512 difference", social sciences exhibited a significantly steeper increase than the physical sciences. Contrarily, for $p<$ 5130.05 versus $p>0.05$, social sciences exhibited a significantly steeper decrease than the physical sciences (Fig. 16).

514 The more salient finding of our analysis is the enormous differences in reporting practices between disciplines, with the use of $p$-values between 0.041 and 0.049 being 65.7 times more prevalent in the biological sciences than in the physical sciences. The prevalence of $p$-values between 0.041 and 0.049 in the biological sciences is even larger when considering that many physical sciences papers reporting $p$-values had medical affinity (e.g., a new ultrasound techniques or a new radiology method being tested in a medical setting). Indeed, $84 \%$ of the physical sciences papers containing $p$-values between 0.041 and 0.049 were also classified into biological sciences by Scopus (see the left Venn diagram in Fig. 15). $p$-values between 0.041 and 0.049 were an astonishing 387 times more prevalent in the pure biological sciences than in the pure physical sciences.

The virtual absence of $p$-values in the physical sciences can be explained by the fact that researchers in the physical sciences encounter low levels of sampling and measurement error and therefore do not need $p$-values. Meehl (1978): "Multiple paths to estimating numerical point values ('consistency tests') are better, even if approximate with rough tolerances; and lacking this, ranges, orderings, second-order differences, curve peaks and valleys, and function forms should be used. Such methods are usual in developed sciences that seldom report statistical significance" (p. 806). Similarly, Mulaik et al. (1997) observed: "Another reason physicists often do not do significance tests is because they are not always testing hypotheses, but rather are trying to improve their estimates of physical constants" (p. 93). Eugene Wigner, who won the 1963 Nobel Prize in Physics for his contribution to the theory of atomic nuclei elementary particles, wrote: "if there were no phenomena which are independent of all but a manageably small set of conditions, physics would be impossible" (Wigner, 1960, p. 4, see also Hand, 2004).

532 Overlap can also be seen between the social sciences and the biological sciences, with $86 \%$ of social sciences papers with $p$-values between 0.041 and 0.049 being also classified into biological sciences. This may not be surprising since psychology is often regarded as a "hub science" (Cacioppo, 2007). Summarizing, a hierarchy of sciences (if something like that exists) is characterized by differences in the use of $p$-values in the first place, not by longitudinal trends of positive versus negative results.

537 We conducted longitudinal analyses for papers classified into multiple disciplines and for pure disciplines. The 538 analyses of cross-classified and pure papers yielded similar results. We consider the results of the analyses in which the papers were cross-classified as more trustworthy than the pure analyses. Excluding all multi-disciplinary papers limits the sample size and leaves us with a core of classical mono-disciplinary journals that are not representative of all (multi-disciplinary) research.

\section{4.3. Comparisons of longitudinal trends between world regions}

543 Previous studies have found that Asian research is more biased toward positive results than research elsewhere in the 544 world (Pan et al., 2005; Vickers et al., 1998). Others have reported that it is the United States that overestimate effect sizes, especially in softer research (Fanelli \& Ioannidis, 2013; but see Nuijten et al., 2014 questioning the robustness of the results of Fanelli \& Ioannidis). Our analysis indicated that the ratios of significant to non-significant results and corresponding growth rates depend on the search term. For reporting $p<0.05$ versus $p>0.05$, we found that AS7 had the most rapid decline of the percentage of significant results, which is inconsistent with the hierarchy of sciences (Fanelli, 2010). We also found that researchers from Asia reported $p$-values between 0.041 and 0.049 at a high level compared to $p$-values between 0.051 and 0.059 (in agreement with Fanelli, 2012), but they were considerably less likely to use the phrase "significant difference" than the other two world regions (Fig. S3). always some effect), the size and direction of the effects are currently elusive. Regional differences in significance reporting are probably obscured by important moderators such as (1) the emergence of China as the second publishing power after the US during the last decade (Leydesdorff \& Wagner, 2009), (2) that Asian researchers publish less frequently in the social sciences as compared to researchers from the US and EU15, and (3) that Asian researchers publish increasingly more over the years in the physical sciences (the least significance-oriented 
558

discipline) (see Fig. 2). Summarizing, differences between world regions in the reporting of significance are too inconsistent to draw conclusions on cross-cultural differences in significance reporting.

\subsection{Limitations \\ 4.4.1. Faulty inclusions}

Our automated string-search approach has some important limitations. First, our method is susceptible to faulty inclusions. To assess the occurrence of false positives that are unrelated to hypothesis testing, we performed a small follow-up analysis. Using a random number generator, we selected 24 papers per discipline (one per year from 1990 to 2013) that reported a $p$-value between 0.041 and 0.049 in the abstract. Inspection of the 72 abstracts revealed one clear false positive, in the physical sciences (Prandolini et al., 1998; in which " $\mathrm{P}=0.048$ " referred to a physical property rather than to a $p$-value). In the remaining 71 abstracts, $p$-values referred to a statistical test of some kind. However, the $p$-value was not always related to a clear-cut comparison between two or more groups or experimental conditions. For example, in some abstracts, the $p$-value belonged to a measure of association, to a variable contributing to a model, or to the assessment of model fit. Moreover, in our searches we made no distinction between unadjusted and adjusted $p$-values, such as those resulting from Bonferroni corrections for multiple testing. Abstracts often contain multiple $p$-values, some of which are overlapping or correlated, such as adjusted and unadjusted $p$ values of the same effect and $p$-values of subgroup analyses (Ioannidis, 2014). One strength of Fanelli's (2012) work was that he manually examined the abstracts and/or full texts of the selected 4,656 papers testing a hypothesis. His manual checking of the content of each paper may have prevented faulty inclusions, albeit at the cost of a possible loss of objectivity.

\subsubsection{Literature misses}

The papers that we assessed represent only a small fraction of all papers indexed in Scopus. For example, the papers with $p$-values between 0.041 and 0.049 and the papers with $p<0.05$ correspond to respectively $0.18 \%$ and $1.7 \%$ of all 1990-2013 papers with an abstract indexed in Scopus. Moreover, our searches only focused on the abstract of the papers and by no means provide an exhaustive analysis of the semantic content of papers (note that Fanelli's, 2012 sample was also generated by automatically searching for the sentence "test* the hypothes*" in the abstracts of papers included in the Essential Science Indicators database). Evidently, we have missed articles that report $p$-values only in the body of the article. We would argue that the abstract contains the main results and primary effects (see also Pautasso, 2010, who argues similarly), whereas many of the $p$-values that appear in the corpus of a paper are associated with secondary results. The corpus of a paper can contain a great number of $p$-values, for example associated with correlation matrices, which would not be desirable to include in the analysis. Brodeur et al. (2013), who collected 50,078 statistical tests from the full text of 641 articles in Economics journals, reported that the average number of statistical tests per article is as high as 78 (with a corresponding median of 58). Some have warned that abstracts suffer from cherry picking of significant results (e.g., Benjamini \& Hechtlinger, 2014; Gøtzsche, 2006; Ioannidis, 2014). According to Gøtzsche (2006), "significant results in abstracts should generally be disbelieved" (p. 233). Similarly, Ioannidis (2014) argued that " $P$-values reported in the abstracts of published papers... are a highly distorted, highly select sample" (p. 28) and that "most investigators report some of the bestlooking $P$-values in their abstracts" (p. 30). We argue that if selective reporting occurs in the abstracts, then focusing on the abstracts is the appropriate method to identify such behavior.

We focused our main analysis on alpha $=0.05$, the most commonly used threshold of significance and the default in many statistical software packages. A full text in ScienceDirect for " $p<0.05$ was considered" in 1990-2013 yielded 55,754 records, with the corresponding queries for $p<0.01$ and $p<0.001$ yielding only 1,221 and 299 records, respectively. In particle physics, statistical significance is typically reported in terms of 5 or 3 Sigma (Hand, 2014; Lyons, 2013; see also Hasselman's 2014 commentary on a preprint of our paper). In genomics, typical alpha levels range between $10^{-4}$ and $10^{-8}$ (see Manhattan plots in genome-wide association studies; Gibson, 2010; Gadbury \& Allison, 2012). Moreover, our search queries did not capture studies reporting of effect sizes with confidence intervals without $p$-values.

Scopus is known to be incomplete for publications prior to 1996 (Elsevier, 2014). We observed that the percentage of Scopus papers without an abstract dropped from 31.1\% (254,326 out of 817,349 papers) in 1990 to $12.6 \%$ (334,988 out of 2,652,050) in 2013 (search query for papers without abstract: ALL(\{.\}) AND NOT ABS(\{.\}); search query for all papers in the database - with and without abstract: $\operatorname{ALL}(\{\})$.$) . To overcome this limitation and avoid artefacts due$ to an increased unavailability of abstracts for older papers, we focused our searches only on papers with an abstract available in Scopus.

A reviewer raised a concern about the completeness of the 2013 data in Scopus. According to the SCImago group that defines scientific indicators and rankings based on the Scopus database, "changes after October do not affect the 
612 database of the previous year any longer seriously" (Leydesdorff et al., 2014; p. 5). Considering that our data were 613 extracted in November 2014, we expect that no major updates for 2013 are imminent and that the 2013 data are 614 complete (i.e., as incomplete as the data from earlier years, in the sense that retrospective additions, such as old

615 volumes of newly indexed journals, can always occur). During the last three months, we indeed noticed retrospective

616 additions to the Scopus database, which suggests that small numerical changes are likely to occur in any future

617 reproductions of this study. Specifically, between 28 August and 2 December, the number of papers with an abstract

618 increased between $0.30 \%$ and $0.48 \%$ for papers published in $1990-1995$, between $0.02 \%$ and $0.29 \%$ for papers

619 published in 1996-2012, and with 0.43\% for papers published in 2013.

620

621

622

623

624

625

626

627

628

629

630

631

632

633

634

635

636

637

638

639

640

641

642

643

644

645

646

647

648

649

650

651

652

653

654

655

656

657

658

659

660

661

662

663

\subsubsection{Literature representativeness}

The three defined disciplines (social, biological, physical) are broad, and differences in statistical approaches between specialties within a discipline can be expected. As a follow-up analysis, we searched for $p$-values between 0.041 and 0.049 and $p$-values between 0.051 and 0.059 in three research fields of biological sciences: psychiatry, surgery, and cardiovascular medicine. A comparison between these three fields showed that the use of $p$-values between 0.041 and 0.049 were more prevalent in cardiovascular/heart journals, followed by surgery journals, and psychiatry journals (Fig. S5). We found no difference in growth rates between the three fields (Fig. S6). Of course, comparisons between other fields could have given different results.

\subsubsection{Automated versus manual searches}

We opted for automated searches. Automated searches have been fiercely criticized in the past. Ioannidis (2014) stated that "the abstracts of the crème de la crème of the biomedical literature are a mess. No fancy informatics script can sort out that mess. One still needs to read the papers" (p. 34).

We argue that - provided that one uses a great number of diverse search terms and search strategies-an automated search should render a representative cross-sectional estimate of the trends in scientific publishing. Our manual inspection of the 72 abstracts mentioned in section 4.4.1 made it clear to us how difficult it really is to assess whether a paper supports a specific null hypothesis or not. We ran into three types of problems: (1) Issues of accessibility: Despite the fact that our university has 17,300 journal subscriptions, a large proportion of the full-text articles are hidden behind paywalls, which introduces serious availability bias (indicatively, for the 72 random abstracts, we did not have access to the full texts of 3/24 [13\%] of papers in the biological sciences, 10/24 [42\%] papers of papers in the physical sciences, and 10/24 [42\%] of papers in the social sciences). (2) Issues of interpretation, especially when judging papers containing specialized terminology outside one's field. (3) The fact that many papers do not explicitly report on a hypothesis or might test multiple hypotheses at the same time. All three issues lead to problems of reproducibility. The results of an automated search, on the other hand, are highly reproducible.

For manual searches a sample size of 3,000 to 5,000 articles seems to be the maximum achieved so far (cf. $N=4,656$ in Fanelli, 2012; $N=3,701$ in Leggett et al., 2013; $N=3,627$ in Masicampo \& Lalande, 2012), and these relatively small sample sizes imply relatively low statistical power and reliability. Masicampo and Lalande (2012) investigated the distribution of $p$-values between 0.01 and 0.10 retrieved from 2007/2008 issues of three psychological journals, Psychological Science (PS), Journal of Experimental Psychology: General (JEP) and Journal of Personality and Social Psychology (JPSP). The $p$-values from PS were also re-collected and re-analyzed by a blind assessor, who found a distinctive peak of $p$-values just below the 0.05 threshold for this journal. Recently, Lakens (in press) reanalyzed Masicampo and Lalande's (2012) datasets and concluded that the peak identified by the blind assessor, as well as the peak of $p$-values just below the 0.05 threshold found by Leggett et al. (2013) for JPSP, do "not replicate" and that "clearly, more data is needed". Prompted by Masicampo and Lalande' study, Mathôt (2013) automatically extracted 2,063 $p$-values associated with $t$-tests and ANOVA from the Journal of Vision and found no peak in the $p$ value distribution just below the 0.05 threshold. Our automated searches allowed us to retrieve 54,330 papers with $p$ values between 0.041 and $0.049,14,708$ papers with $p$-values between 0.051 and $0.059,319,141$ papers with "significant difference", 418,580 papers with "no significant difference", 523,175 papers with $p<0.05$, and 69,758 papers with $p>0.05$. Hence, sample size is an important advantage of automated searches.

\subsection{Conclusions and interpretations}

We investigated longitudinal trends of positive versus negative results reported in the literature and compared these trends between scientific disciplines and between world regions. We found that both positive and negative results have become more prevalent and that the growth rates of both positive and negative results strongly depend on the search terms. The increase from 1990 to 2013 was evident for all $p$-value ranges, but strongest for $p$-values between 0.041 and 0.049 . 
664 The fact that $p$-values just below 0.05 exhibited the fastest increase among all $p$-value ranges we searched for

665 suggests (but does not prove) that questionable research practices have increased over the past 25 years. This

666 interpretation should be regarded with some caution, since a change of the $p$-value distribution can occur for various

667 reasons, including changes in the file drawer effect and changes in the number of studies investigating a true effect

668 (see also Lakens, in press).

669 In addition to questionable statistical practices, positive explanations for the observed trends are possible, 670 particularly when one considers that not only significant but also non-significant results have increased. First, 671 scientists may have become more knowledgeable, and therefore better able to formulate accurate predictions and 672 design statistically powerful experiments that disprove a null hypothesis. Second, scientists may have become more 673 likely to use, and report the results of, statistical significance testing. The observed longitudinal trends of the 674 reporting of $p$-values might thus occur because of science becoming more empirical, organized, and quantitative.

675 Structured reporting in abstracts is getting preferred (and recommended in journal instructions for authors) over a 676 narrative summary of research findings (see Ripple et al., 2011, who analyzed about 5.5 million MEDLINE records 677 and found that the frequency of structured abstracts increased from $2.5 \%$ in 1992 to $20.3 \%$ in 2005 ). The growing 678 popularity of expressions such as "the aim of", "our aim", and "results showed that" is consistent with the notion that 679 structured reporting in abstracts has been embraced by journals. Moreover, as reminded by Low (2014) in a reaction 680 to the preprint of our paper, the increase of $p$-values may be associated with the fact that people nowadays do not use 681 lookup tables, but report numeric $p$-values instead (Sterne, 2002). Third, the observed increase of negative results

682 (Fig. 3) may be caused by a growing replication movement providing a counterforce to positive results (cf. mega683 journals such as PLOS ONE which judges papers based on their technical soundness rather than statistical 684 significance; Binfield, 2009), and the increasing use of $p$-values might be a manifestation of dynamic exchange of 685 information within the scientific network. Besides, as indicated by Popper (1959), theories are "in an asymmetrical 686 way, falsifiable only: they are statements which are tested by being submitted to systematic attempts to falsify them" 687 (italics in the original). In this line, a single falsification can be worth more than numerous confirmations of an 688 established null hypothesis. So, perhaps some asymmetry between positives and negatives results in innovative 689 research fields is expectable, or even desirable.

\section{References}

691 Asendorpf, J. B., Conner, M., De Fruyt, F., De Houwer, J., Denissen, J. J., Fiedler, K., ... \& Wicherts, J. M. (2013).

692 Recommendations for increasing replicability in psychology. European Journal of Personality, 27, $108-119$.

693 Atkin, P. A. (2002). A paradigm shift in the medical literature. British Medical Journal, 325, 1450-1451.

694 Bakker, M., \& Wicherts, J. M. (2014). Outlier removal, sum scores, and the inflation of the type I error rate in 695 independent samples t tests: The power of alternatives and recommendations. Psychological Methods, $19,409-427$.

696 Basu, S., \& Park, H. U. (2014). Publication bias in recent empirical accounting research. Available at SSRN 6972379889.

698 Benjamini, Y., \& Hechtlinger, Y. (2014). Discussion: An estimate of the science-wise false discovery rate and 699 applications to top medical journals by Jager and Leek. Biostatistics, 15, 13-16.

700 Binfield, P. (2009). PLoS One: background, future development, and article-level metrics. Rethinking Electronic

701 Publishing: Innovation in Communication Paradigms and Technologies, 69-86.

702 Boutron, I., Dutton, S., Ravaud, P., \& Altman, D. G. (2010). Reporting and interpretation of randomized controlled 703 trials with statistically nonsignificant results for primary outcomes. JAMA, 303, 2058-2064.

704 Brodeur, A., Lé, M., Sangnier, M., \& Zylberberg, Y. (2013). Star wars: The empirics strike back (Discussion Paper

705 No. 7268). Discussion Paper Series. Bonn: Forschungsinstitut zur Zukunft der Arbeit.

706 Cacioppo, J. T. (2007). Psychology is a hub science. APS Observer, 20, 5.

707 Camfield, L., Duvendack, M., \& Palmer-Jones, R. (2014). Things you wanted to know about bias in evaluations but 708 never dared to think. IDS Bulletin, 45, 49-64. 
709 Chabris, C. F., Hebert, B. M., Benjamin, D. J., Beauchamp, J., Cesarini, D., van der Loos, M., ... \& Laibson, D.

710 (2012). Most reported genetic associations with general intelligence are probably false positives. Psychological

711 Science, 23, 1314-1323.

712 Chan, A. W., Song, F., Vickers, A., Jefferson, T., Dickersin, K., Gøtzsche, P. C., ... \& Van der Worp, H. B. (2014).

713 Increasing value and reducing waste: addressing inaccessible research. The Lancet, 383, 257-266.

714 Cumming, G., \& Finch, S. (2005). Inference by eye: Confidence intervals and how to read pictures of data.

715 American Psychologist, 60, 170-180.

716 De Angelis, C., Drazen, J. M., Frizelle, F. A., Haug, C., Hoey, J., Horton, R., ... \& Weyden, M. B. V. D. (2004). 717 Clinical trial registration: a statement from the International Committee of Medical Journal Editors. New England

718 Journal of Medicine, 351, 1250-1251.

719 De Rond, M., \& Miller, A. N. (2005). Publish or perish. Bane or boon of academic life? Journal of Management 720 Inquiry, 14, 321-329.

721 De Winter, J. C. F., Zadpoor, A. A., \& Dodou, D. (2014). The expansion of Google Scholar versus Web of Science: a 722 longitudinal study. Scientometrics, 98, 1547-1565.

723 Dirnagl, U., \& Lauritzen, M. (2010). Fighting publication bias: introducing the Negative Results section. Journal of 724 Cerebral Blood Flow and Metabolism, 30, 1263-1264.

725 Djulbegovic, B., Lacevic, M., Cantor, A., Fields, K. K., Bennett, C. L., Adams, J. R., ... \& Lyman, G. H. (2000). The 726 uncertainty principle and industry-sponsored research. The Lancet, 356, 635-638.

727 Duval, S., \& Tweedie, R. (2000). Trim and fill: a simple funnel-plot-based method of testing and adjusting for 728 publication bias in meta-analysis. Biometrics, 56, 455-463.

729 Dwan, K., Altman, D. G., Arnaiz, J. A., Bloom, J., Chan, A. W., Cronin, E., ... \& Williamson, P. R. (2008).

730 Systematic review of the empirical evidence of study publication bias and outcome reporting bias. PloS One, 3 , 731 e3081.

732 Elsevier (2014). Printing and exporting citation overviews. Retrieved from 733 http://help.scopus.com/Content/h_citovrdoc.htm

734 Fanelli, D. (2009). How many scientists fabricate and falsify research? A systematic review and meta-analysis of 735 survey data. PloS One, 4, e5738.

736 Fanelli, D. (2010). "Positive" results increase down the hierarchy of the sciences. PLOS ONE, 5 , e10068.

737 Fanelli, D. (2012). Negative results are disappearing from most disciplines and countries. Scientometrics, 90, 891738904.

739 Fanelli, D. (2014). Reply to de Winter and Dodou (2014): Growing bias and the hierarchy are actually supported, 740 despite different design, errors, and disconfirmation-biases. Retrieved from 741 https://peerj.com/preprints/447/\#feedback

742 Fanelli, D., \& Ioannidis, J. P. (2013). US studies may overestimate effect sizes in softer research. Proceedings of the

743 National Academy of Sciences, 110, 15031-15036.

744 Ferguson, C. J., \& Heene, M. (2012). A vast graveyard of undead theories publication bias and psychological 745 science's aversion to the null. Perspectives on Psychological Science, 7, 555-561.

746 Fern, E. F., \& Monroe, K. B. (1996). Effect-size estimates: Issues and problems in interpretation. Journal of 747 Consumer Research, 23, 89-105.

748 Fiedler, K., Kutzner, F., \& Krueger, J. I. (2012). The long way from $\alpha$-error control to validity proper. Problems with 749 a short-sighted false-positive debate. Perspectives on Psychological Science, 7, 661-669. 
750 Finkel, E. J., Eastwick, P. W., \& Reis, H. T. (in press). Best research practices in psychology: Illustrating

751 epistemological and pragmatic considerations with the case of relationship science. Journal of Personality and

752 Social Psychology.

753 Francis, G. (2013). Replication, statistical consistency, and publication bias. Journal of Mathematical Psychology,

$75457,153-169$.

755 Francis, G. (2014). The frequency of excess success for articles in Psychological Science. Psychonomic Bulletin \&

756 Review, 21, 1180-1187.

757 Franco, A., Malhotra, N., \& Simonovits, G. (2014). Publication bias in the social sciences: unlocking the file drawer.

758 Science, 345, 1502-1505.

759 Gadbury, G. L., \& Allison, D. B. (2012). Inappropriate fiddling with statistical analyses to obtain a desirable p-value:

760 tests to detect its presence in published literature. PLOS ONE, 7, e46363.

761 Gerber, A. S., \& Malhotra, N. (2008a). Publication bias in empirical sociological research. Do arbitrary significance

762 levels distort published results? Sociological Methods \& Research, 37, 3-30.

763 Gerber, A., \& Malhotra, N. (2008b). Do statistical reporting standards affect what is published? Publication bias in

764 two leading political science journals. Quarterly Journal of Political Science, 3, 313-326.

765 Gibson, G. (2010). Hints of hidden heritability in GWAS. Nature Genetics, 42, 558-560.

766 Goodman, S. N. (2014). Discussion: An estimate of the science-wise false discovery rate and application to the top

767 medical literature. Biostatistics, 15, 23-27.

768 Google Scholar (2014). Search tips. Retrieved from http://scholar.google.com/intl/en/scholar/help.html\#export

769 Gøtzsche, P. C. (2006). Believability of relative risks and odds ratios in abstracts: cross sectional study. BMJ, 333,

770 231-234.

771 Hand, D. J. (2004). Measurement: theory and practice. London: Arnold.

772 Hand, D. (2014). The improbability principle: Why coincidences, miracles and rare events happen all the time.

773 Random House.

774 Hankins, M. (2013, April 21). Still not significant [blog post]. Retrieved from

775 http://mchankins.wordpress.com/2013/04/21/still-not-significant-2/?

776 utm_content=buffer0fa47\&utm medium=social\&utm_source=twitter.com\&utm_campaign=buffer

777 Hankins, M. [mc_hankins] (2014, May 17). Also search was abstract only (!), p to 3dp only (not 2 or 4+), 'p=' but not

778 ' $\mathrm{p}<$ ' or ' $\mathrm{p}>$ ' [Tweet]. Retrieved from https://twitter.com/mc hankins/status/493125467290238976

779 Hasselman, F. (2014). Feedback on De Winter and Dodou (2014). A surge of p-values between 0.040 and 0.049 in

780 recent decades (but negative results are increasing rapidly too). Retrieved from

781 https://peerj.com/preprints/447/\#feedback

782 Hopewell, S., Loudon, K., Clarke, M. J., Oxman, A. D., \& Dickersin, K. (2009). Publication bias in clinical trials due

783 to statistical significance or direction of trial results. Cochrane Database of Systematic Reviews, 1.

784 Hunter, J. E., \& Schmidt, F. L. (1996). Cumulative research knowledge and social policy formulation: The critical

785 role of meta-analysis. Psychology, Public Policy, and Law, 2, 324-347.

786 Ioannidis, J. (2003). Genetic associations: false or true? Trends in Molecular Medicine, 9, 135-138.

787 Ioannidis, J. P. (2005). Why most published research findings are false. PLoS Medicine, 2, e124.

788 Ioannidis, J. (2008). Calibration of credibility of agnostic genome-wide associations. American Journal of Medical

789 Genetics Part B: Neuropsychiatric Genetics, 147, 964-972. 
790 Ioannidis, J. P. (2014). Discussion: Why "An estimate of the science-wise false discovery rate and application to the 791 top medical literature" is false. Biostatistics, 15, 28-36.

792 Ioannidis, J., Munafò, M. R., Fusar-Poli, P., Nosek, B. A., \& David, S. P. (2014). Publication and other reporting 793 biases in cognitive sciences: detection, prevalence, and prevention. Trends in Cognitive Sciences, 18, $235-241$.

794 Jacsó, P. (2008). Google scholar revisited. Online Information Review, 32, 102-114.

795 Jager, L. R., \& Leek, J. T. (2014). An estimate of the science-wise false discovery rate and application to the top 796 medical literature. Biostatistics, 15, 1-12.

797 Jennings, R. G., \& Van Horn, J. D. (2012). Publication bias in neuroimaging research: implications for meta798 analyses. Neuroinformatics, 10, 67-80.

799 Jennions, M. D., \& Møller, A. P. (2002). Publication bias in ecology and evolution: an empirical assessment using the

800 'trim and fill' method. Biological Reviews of the Cambridge Philosophical Society, 77, 211-222.

801 Joober, R., Schmitz, N., Annable, L., \& Boksa, P. (2012). Publication bias: What are the challenges and can they be 802 overcome? Journal of Psychiatry \& Neuroscience, 37, 149-152.

803 Kirkham, J. J., Dwan, K. M., Altman, D. G., Gamble, C., Dodd, S., Smyth, R., \& Williamson, P. R. (2010). The 804 impact of outcome reporting bias in randomised controlled trials on a cohort of systematic reviews. BMJ, 340 , c365.

805 Kühberger, A., Fritz, A., \& Scherndl, T. (2014). Publication bias in psychology: a diagnosis based on the correlation

806 between effect size and sample size. PLOS ONE, 9, e105825.

807 Kyzas, P. A., Denaxa-Kyza, D., \& Ioannidis, J. (2007). Almost all articles on cancer prognostic markers report 808 statistically significant results. European Journal of Cancer, 43, 2559-2579.

809 Lakens, D. (in press). What p-hacking really looks like: A comment on Masicampo \& Lalande (2012). Quarterly 810 Journal of Experimental Psychology.

811 Larsen, P. O., \& Von Ins, M. (2010). The rate of growth in scientific publication and the decline in coverage

812 provided by Science Citation Index. Scientometrics, 84, 575-603.

813 Laws, K. R. (2013). Negativland-a home for all findings in psychology. BMC Psychology, 1, 2.

814 Leggett, N. C., Thomas, N. A., Loetscher, T., \& Nicholls, M. E. (2013). The life of $p$ : “Just significant” results are on 815 the rise. The Quarterly Journal of Experimental Psychology, 66, 2303-2309.

816 Lexchin, J., Bero, L. A., Djulbegovic, B., \& Clark, O. (2003). Pharmaceutical industry sponsorship and research

817 outcome and quality: systematic review. BMJ, 326, 1167-1170.

818 Leydesdorff, L., De Moya-Anegón, F., \& De Nooy, W. (2014). Aggregated journal-journal citation relations in

819 Scopus and Web-of-Science matched and compared in terms of networks, maps, and interactive overlays.

820 arXiv:1404.2505.

821 Leydesdorff, L., \& Wagner, C. (2009). Is the United States losing ground in science? A global perspective on the

822 world science system. Scientometrics, 78, 23-36.

823 Low, N. [nicolamlow] (2014, July 21). @PeerJPrePrints @thePeerJ \#nearlysignificant Might it just be because

824 people don't use lookup tables for $p$ values but give exact values? [Tweet]. Retrieved from

825 https://twitter.com/nicolamlow/status/491460395216171008

826 Lyons, L. (2013). Discovering the Significance of 5 $\sigma$. arXiv preprint arXiv:1310.1284.

827 Masicampo, E. J., \& Lalande, D. R. (2012). A peculiar prevalence of $p$ values just below .05. The Quarterly Journal 828 of Experimental Psychology, 65, 2271-2279.

829 Mathôt, S. (2013). No particular prevalence of $\mathrm{p}$ values just below .05 [blog post]. Retrieved from 830 http://www.cogsci.nl/blog/miscellaneous/221-no-particular-prevalence-of-p-values-just-below-05 
831 Meehl, P. E. (1978). Theoretical risks and tabular asterisks: Sir Karl, Sir Ronald, and the slow progress of soft 832 psychology. Journal of Consulting and Clinical Psychology, 46, 806-834.

833 Michel, J. B., Shen, Y. K., Aiden, A. P., Veres, A., Gray, M. K., Pickett, J. P., ... \& Aiden, E. L. (2011). Quantitative 834 analysis of culture using millions of digitized books. Science, 331, 176-182.

835 Mulaik, S. A., Raju, N. S., \& Harshman, R. A. (1997). There is a time and place for significance testing. In L. L. 836 Harlow, S. A. Mulaik, \& J. H. Steiger (Eds.), What if there were no significance tests? (pp. 65-116). Hillsdale, NJ: 837 Erlbaum.

838 Nuijten, M. B., Van Assen, M. A., Van Aert, R. C., \& Wicherts, J. M. (2014). Standard analyses fail to show that US 839 studies overestimate effect sizes in softer research. Proceedings of the National Academy of Sciences, 111, E712840 E713.

841 Pan, Z., Trikalinos, T. A., Kavvoura, F. K., Lau, J., \& Ioannidis, J. P. (2005). Local literature bias in genetic 842 epidemiology: an empirical evaluation of the Chinese literature. PLoS Medicine, 2, e334.

843 Pashler, H., \& Harris, C. R. (2012). Is the replicability crisis overblown? Three arguments examined. Perspectives on 844 Psychological Science, 7, 531-536.

845 Pautasso, M. (2010). Worsening file-drawer problem in the abstracts of natural, medical and social science 846 databases. Scientometrics, 85, 193-202.

847 Pocock, S. J., Collier, T. J., Dandreo, K. J., De Stavola, B. L., Goldman, M. B., Kalish, L. A., ... \& McCormack, V. A. 848 (2004). Issues in the reporting of epidemiological studies: a survey of recent practice. BMJ, 329.

849 Popper, K. R. (1959). The logic of scientific discovery. London: Hutchinson.

850 Prandolini, M. J., Hutchison, W. D., Leib, J., Chaplin, D. H., \& Bowden, G. J. (1998). NMRON studies of MnBr 2 . $8514 \mathrm{H}_{2} \mathrm{O}$ in applied magnetic fields. Hyperfine Interactions, 116, 83-89.

852 Ridley, J., Kolm, N., Freckelton, R. P., \& Gage, M. J. G. (2007). An unexpected influence of widely used 853 significance thresholds on the distribution of reported P-values. Journal of Evolutionary Biology, $20,1082-1089$.

854 Ripple, A. M., Mork, J. G., Knecht, L. S., \& Humphreys, B. L. (2011). A retrospective cohort study of structured 855 abstracts in MEDLINE, 1992-2006. Journal of the Medical Library Association, 99, 160-163.

856 Rothstein, H. R., Sutton, A. J., \& Borenstein, M. (Eds.). (2006). Publication bias in meta-analysis: Prevention, 857 assessment and adjustments. West Sussex, England: John Wiley \& Sons.

858 Rouder, J. N., Morey, R. D., Verhagen, J., Province, J. M., Wagenmakers, E. J., \& Rouder, J. (2014). The p<. 05 rule 859 and the hidden costs of the free lunch in inference. Unpublished manuscript. Retrieved from: 860 http://pcl.missouri.edu/sites/default/files/p_5.pdf

861 Rücker, G., Schwarzer, G., \& Carpenter, J. (2008). Arcsine test for publication bias in meta-analyses with binary 862 outcomes. Statistics in Medicine, 27, 746-763.

863 Schmidt, F. L., \& Hunter, J. E. (1996). Measurement error in psychological research: Lessons from 26 research 864 scenarios. Psychological Methods, 1, 199-233.

865 Sherman, R. [RyneSherman] (2014, July 29). I thought $\mathrm{p}<.10$ was "marginally sig." Why not look for increases in $p$ $866>$.10? That would be more convincing. [Tweet]. Retrieved from 867 https://twitter.com/RyneSherman/status/494112263200968704

868 Simmons, J. P., Nelson, L. D., \& Simonsohn, U. (2011). False-positive psychology: undisclosed flexibility in data 869 collection and analysis allows presenting anything as significant. Psychological Science, 22, 1359-1366.

870 Simonsohn, U., Nelson, L. D., \& Simmons, J. P. (2014). P-curve: A key to the file-drawer. Journal of Experimental 871 Psychology: General, 143, 534-547. 
872 Sismondo, S. (2008). Pharmaceutical company funding and its consequences: a qualitative systematic review. 873 Contemporary Clinical Trials, 29, 109-113.

874 Smart, R. G. (1964). The importance of negative results in psychological research. Canadian 875 Psychologist/Psychologie Canadienne, 5, 225-232.

876 Sterling, T. D., Rosenbaum, W. L., \& Weinkam, J. J. (1995). Publication decisions revisited: The effect of the 877 outcome of statistical tests on the decision to publish and vice versa. The American Statistician, 49, $108-112$.

878 Sterne, J. A. (2002). Teaching hypothesis tests-time for significant change? Statistics in Medicine, 21, 985-994.

879 Strube, M. J. (2006). SNOOP: A program for demonstrating the consequences of premature and repeated null 880 hypothesis testing. Behavior Research Methods, 38, 24-27.

881 Terrin, N., Schmid, C. H., Lau, J., \& Olkin, I. (2003). Adjusting for publication bias in the presence of heterogeneity. 882 Statistics in Medicine, 22, 2113-2126.

883 The Thomson Cooperation (2008). Essential Science Indicators. Retrieved from

884 http://esi.webofknowledge.com/help/h_datjrn.htm

885 Thomson Reuters (2014). Methodology for Sciencewatch.com. Retrieved from

886 http://archive.sciencewatch.com/about/met/

887 Thornton, A., \& Lee, P. (2000). Publication bias in meta-analysis: its causes and consequences. Journal of Clinical 888 Epidemiology, 53, 207-216.

889 Vickers, A., Goyal, N., Harland, R., \& Rees, R. (1998). Do certain countries produce only positive results? A 890 systematic review of controlled trials. Controlled Clinical Trials, 19, 159-166.

891 Wagenmakers, E. J. (2007). A practical solution to the pervasive problems of $p$ values. Psychonomic Bulletin \& 892 Review, 14, 779-804.

893 Wigner, E. P. (1960). The unreasonable effectiveness of mathematics in the natural sciences. Richard courant lecture 894 in mathematical sciences delivered at New York University, May 11, 1959. Communications on Pure and Applied 895 Mathematics, 13, 1-14.

896 Yong, E. (2012). Replication studies: Bad copy. Nature, 485, 298-300.

897 Young, N. S., Ioannidis, J. P., \& Al-Ubaydli, O. (2008). Why current publication practices may distort science. PLoS 898 Medicine, 5, e201. 
Table 1. All search queries and corresponding syntaxes in Scopus.

\begin{tabular}{|c|c|c|}
\hline 1. & All abstracts & $\operatorname{ABS}(\{\})$. \\
\hline 2. & $<0.001$ & $\operatorname{ABS}(\{\mathrm{p}<0.001\}$ OR $\{\mathrm{p}<.001\}$ OR $\{\mathrm{p}<=0.001\}$ OR $\{\mathrm{p}<=.001\}$ OR $\{\mathrm{p} \leq 0.001\}$ OR $\{\mathrm{p} \leq .001\})$ \\
\hline 3. & $>0.001$ & $\operatorname{ABS}(\{\mathrm{p}>0.001\}$ OR $\{\mathrm{p}>.001\})$ \\
\hline 4. & $<0.01$ & $\operatorname{ABS}(\{\mathrm{p}<0.01\}$ OR $\{\mathrm{p}<.01\}$ OR $\{\mathrm{p}<=0.01\}$ OR $\{\mathrm{p}<=.01\}$ OR $\{\mathrm{p} \leq 0.01\}$ OR $\{\mathrm{p} \leq .01\})$ \\
\hline 5. & $>0.01$ & $\operatorname{ABS}(\{\mathrm{p}>0.01\}$ OR $\{\mathrm{p}>.01\})$ \\
\hline 6. & $<0.05$ & $\operatorname{ABS}(\{\mathrm{p}<0.05\}$ OR $\{\mathrm{p}<.05\}$ OR $\{\mathrm{p}<=0.05\}$ OR $\{\mathrm{p}<=.05\}$ OR $\{\mathrm{p} \leq 0.05\}$ OR $\{\mathrm{p} \leq .05\})$ \\
\hline 7. & $>0.05$ & $\operatorname{ABS}(\{\mathrm{p}>0.05\}$ OR $\{\mathrm{p}>.05\})$ \\
\hline 8. & $<0.10$ & $\operatorname{ABS}(\{\mathrm{p}<0.10\}$ OR $\{\mathrm{p}<.10\}$ OR $\{\mathrm{p}<=0.10\}$ OR $\{\mathrm{p}<=.10\}$ OR $\{\mathrm{p} \leq 0.10\}$ OR $\{\mathrm{p} \leq .10\})$ \\
\hline 9. & $>0.10$ & $\operatorname{ABS}(\{\mathrm{p}>0.10\}$ OR $\{\mathrm{p}>.10\})$ \\
\hline 10. & $=0.001$ & $\operatorname{ABS}(\{\mathrm{p}=0.001\}$ OR $\{\mathrm{p}=.001\})$ \\
\hline 11. & $0.002-0.005$ & $\operatorname{ABS}(\{\mathrm{p}=0.002\}$ OR $\{\mathrm{p}=.002\}$ OR $\{\mathrm{p}=0.003\}$ OR $\{\mathrm{p}=.003\}$ OR $\{\mathrm{p}=0.004\}$ OR $\{\mathrm{p}=.004\}$ OR $\{\mathrm{p}=0.005\}$ \\
\hline 12. & $0.006-0.009$ & $\operatorname{ABS}(\{\mathrm{p}=0.006\}$ OR $\{\mathrm{p}=.006\}$ OR $\{\mathrm{p}=0.007\}$ OR $\{\mathrm{p}=.007\}$ OR $\{\mathrm{p}=0.008\}$ OR $\{\mathrm{p}=.008\}$ OR $\{\mathrm{p}=0.009\}$ \\
\hline 13. & $0.011-0.019$ & $\begin{array}{l}\text { ABS }(\{\mathrm{p}=0.011\} \text { OR }\{\mathrm{p}=.011\} \text { OR }\{\mathrm{p}=0.012\} \text { OR }\{\mathrm{p}=.012\} \text { OR }\{\mathrm{p}=0.013\} \text { OR }\{\mathrm{p}=.013\} \text { OR }\{\mathrm{p}=0.014\} \mathrm{O} \\
=.015\} \text { OR }\{\mathrm{p}=0.016\} \text { OR }\{\mathrm{p}=.016\} \text { OR }\{\mathrm{p}=0.017\} \text { OR }\{\mathrm{p}=.017\} \text { OR }\{\mathrm{p}=0.018\} \text { OR }\{\mathrm{p}=.018\} \text { OR }\{\mathrm{p}=0\end{array}$ \\
\hline 14. & $0.021-0.029$ & $\begin{array}{l}\text { ABS }(\{\mathrm{p}=0.021\} \text { OR }\{\mathrm{p}=.021\} \text { OR }\{\mathrm{p}=0.022\} \text { OR }\{\mathrm{p}=.022\} \text { OR }\{\mathrm{p}=0.023\} \text { OR }\{\mathrm{p}=.023\} \text { OR }\{\mathrm{p}=0.024\} \\
=.025\} \text { OR }\{\mathrm{p}=0.026\} \text { OR }\{\mathrm{p}=.026\} \text { OR }\{\mathrm{p}=0.027\} \text { OR }\{\mathrm{p}=.027\} \text { OR }\{\mathrm{p}=0.028\} \text { OR }\{\mathrm{p}=.028\} \text { OR }\{\mathrm{p}=0 .\end{array}$ \\
\hline 15. & $0.031-0.039$ & $\begin{array}{l}\text { ABS }(\{\mathrm{p}=0.031\} \text { OR }\{\mathrm{p}=.031\} \text { OR }\{\mathrm{p}=0.032\} \text { OR }\{\mathrm{p}=.032\} \text { OR }\{\mathrm{p}=0.033\} \text { OR }\{\mathrm{p}=.033\} \text { OR }\{\mathrm{p}=0.034\} \\
=.035\} \text { OR }\{\mathrm{p}=0.036\} \text { OR }\{\mathrm{p}=.036\} \text { OR }\{\mathrm{p}=0.037\} \text { OR }\{\mathrm{p}=.037\} \text { OR }\{\mathrm{p}=0.038\} \text { OR }\{\mathrm{p}=.038\} \text { OR }\{\mathrm{p}=0 .\end{array}$ \\
\hline 16. & $0.041-0.049$ & $\begin{array}{l}\text { ABS }(\{p=0.041\} \text { OR }\{p=.041\} \text { OR }\{p=0.042\} \text { OR }\{p=.042\} \text { OR }\{p=0.043\} \text { OR }\{p=.043\} \text { OR }\{p=0.044\} \\
=.045\} \text { OR }\{p=0.046\} \text { OR }\{p=.046\} \text { OR }\{p=0.047\} \text { OR }\{p=.047\} \text { OR }\{p=0.048\} \text { OR }\{p=.048\} \text { OR }\{p=0\end{array}$ \\
\hline 17. & $0.051-0.059$ & $\begin{array}{l}\text { ABS }(\{\mathrm{p}=0.051\} \text { OR }\{\mathrm{p}=.051\} \text { OR }\{\mathrm{p}=0.052\} \text { OR }\{\mathrm{p}=.052\} \text { OR }\{\mathrm{p}=0.053\} \text { OR }\{\mathrm{p}=.053\} \text { OR }\{\mathrm{p}=0.054\} \\
=.055\} \text { OR }\{\mathrm{p}=0.056\} \text { OR }\{\mathrm{p}=.056\} \text { OR }\{\mathrm{p}=0.057\} \text { OR }\{\mathrm{p}=.057\} \text { OR }\{\mathrm{p}=0.058\} \text { OR }\{\mathrm{p}=.058\} \text { OR }\{\mathrm{p}=0 .\end{array}$ \\
\hline 18. & $0.061-0.069$ & $\begin{array}{l}\text { ABS }(\{p=0.061\} \text { OR }\{p=.061\} \text { OR }\{p=0.062\} \text { OR }\{p=.062\} \text { OR }\{p=0.063\} \text { OR }\{p=.063\} \text { OR }\{p=0.064\} 0 \\
=.065\} \text { OR }\{p=0.066\} \text { OR }\{p=.066\} \text { OR }\{p=0.067\} \text { OR }\{p=.067\} \text { OR }\{p=0.068\} \text { OR }\{p=.068\} \text { OR }\{p=0\end{array}$ \\
\hline 19. & $0.071-0.079$ & $\begin{array}{l}\text { ABS }(\{\mathrm{p}=0.071\} \text { OR }\{\mathrm{p}=.071\} \text { OR }\{\mathrm{p}=0.072\} \text { OR }\{\mathrm{p}=.072\} \text { OR }\{\mathrm{p}=0.073\} \text { OR }\{\mathrm{p}=.073\} \text { OR }\{\mathrm{p}=0.074\} \\
=.075\} \text { OR }\{\mathrm{p}=0.076\} \text { OR }\{\mathrm{p}=.076\} \text { OR }\{\mathrm{p}=0.077\} \text { OR }\{\mathrm{p}=.077\} \text { OR }\{\mathrm{p}=0.078\} \text { OR }\{\mathrm{p}=.078\} \text { OR }\{\mathrm{p}=0 .\end{array}$ \\
\hline 20. & $0.081-0.089$ & $\begin{array}{l}\text { ABS }(\{\mathrm{p}=0.081\} \text { OR }\{\mathrm{p}=.081\} \text { OR }\{\mathrm{p}=0.082\} \text { OR }\{\mathrm{p}=.082\} \text { OR }\{\mathrm{p}=0.083\} \text { OR }\{\mathrm{p}=.083\} \text { OR }\{\mathrm{p}=0.084\} \\
=.085\} \text { OR }\{\mathrm{p}=0.086\} \text { OR }\{\mathrm{p}=.086\} \text { OR }\{\mathrm{p}=0.087\} \text { OR }\{\mathrm{p}=.087\} \text { OR }\{\mathrm{p}=0.088\} \text { OR }\{\mathrm{p}=.088\} \text { OR }\{\mathrm{p}=0\end{array}$ \\
\hline 21. & $0.091-0.099$ & $\begin{array}{l}\text { ABS }(\{\mathrm{p}=0.091\} \text { OR }\{\mathrm{p}=.091\} \text { OR }\{\mathrm{p}=0.092\} \text { OR }\{\mathrm{p}=.092\} \text { OR }\{\mathrm{p}=0.093\} \text { OR }\{\mathrm{p}=.093\} \text { OR }\{\mathrm{p}=0.094\} \\
=.095\} \text { OR }\{\mathrm{p}=0.096\} \text { OR }\{\mathrm{p}=.096\} \text { OR }\{\mathrm{p}=0.097\} \text { OR }\{\mathrm{p}=.097\} \text { OR }\{\mathrm{p}=0.098\} \text { OR }\{\mathrm{p}=.098\} \text { OR }\{\mathrm{p}=0 .\end{array}$ \\
\hline 22. & 0.01 & $\operatorname{ABS}(\{\mathrm{p}=0.010\}$ OR $\{\mathrm{p}=.010\}$ OR $\{\mathrm{p}=0.01\}$ OR $\{\mathrm{p}=.01\})$ \\
\hline 23. & 0.02 & $\operatorname{ABS}(\{\mathrm{p}=0.020\}$ OR $\{\mathrm{p}=.020\}$ OR $\{\mathrm{p}=0.02\}$ OR $\{\mathrm{p}=.02\})$ \\
\hline 24. & 0.03 & $\operatorname{ABS}(\{\mathrm{p}=0.030\}$ OR $\{\mathrm{p}=.030\}$ OR $\{\mathrm{p}=0.03\}$ OR $\{\mathrm{p}=.03\})$ \\
\hline 25. & 0.04 & $\operatorname{ABS}(\{\mathrm{p}=0.040\}$ OR $\{\mathrm{p}=.040\}$ OR $\{\mathrm{p}=0.04\}$ OR $\{\mathrm{p}=.04\})$ \\
\hline 26. & 0.05 & $\operatorname{ABS}(\{\mathrm{p}=0.050\}$ OR $\{\mathrm{p}=.050\}$ OR $\{\mathrm{p}=0.05\}$ OR $\{\mathrm{p}=.05\})$ \\
\hline 27. & 0.06 & $\operatorname{ABS}(\{\mathrm{p}=0.060\}$ OR $\{\mathrm{p}=.060\}$ OR $\{\mathrm{p}=0.06\}$ OR $\{\mathrm{p}=.06\})$ \\
\hline 28. & 0.07 & $\operatorname{ABS}(\{\mathrm{p}=0.070\}$ OR $\{\mathrm{p}=.070\}$ OR $\{\mathrm{p}=0.07\}$ OR $\{\mathrm{p}=.07\})$ \\
\hline 29. & 0.08 & $\operatorname{ABS}(\{\mathrm{p}=0.080\}$ OR $\{\mathrm{p}=.080\}$ OR $\{\mathrm{p}=0.08\}$ OR $\{\mathrm{p}=.08\})$ \\
\hline 30. & 0.09 & $\operatorname{ABS}(\{\mathrm{p}=0.090\}$ OR $\{\mathrm{p}=.090\}$ OR $\{\mathrm{p}=0.09\}$ OR $\{\mathrm{p}=.09\})$ \\
\hline 31. & $\mathrm{p}=\mathrm{NS}$ or $\mathrm{p}=\mathrm{N} . \mathrm{S}$. & $\operatorname{ABS}(\{\mathrm{p}=\mathrm{NS}\}$ OR $\{\mathrm{p}=\mathrm{N} . \mathrm{S}\})$. \\
\hline 32. & "significant difference(s)" & $\begin{array}{l}\text { ABS }((\{\text { significant difference }\} \text { OR \{significant differences\} OR \{significantly different }\} \text { OR \{differed significantly } \\
\text { difference\} OR \{no significant differences\} OR \{no statistically significant difference\} OR \{no statistically signific } \\
\text { different }\} \text { OR \{did not differ significantly\}) }\end{array}$ \\
\hline 33. & "no significant difference(s)" & $\begin{array}{l}\text { ABS( \{no significant difference }\} \text { OR \{no significant differences\} OR \{no statistically significant difference }\} \text { OR \{n } \\
\text { OR \{not significantly different }\} \text { OR \{did not differ significantly\}) }\end{array}$ \\
\hline 34. & "significant effect(s)" & $\begin{array}{l}\text { ABS }((\{\text { significant effect }\} \text { OR }\{\text { significant effects\}) AND NOT ( } \text { no significant effect }\} \text { OR \{no significant effects\} } \\
\text { OR \{no statistically significant effects\} OR \{not a significant effect }\} \text { OR \{not a statistically significant effect }\}))\end{array}$ \\
\hline 35. & "no significant effect(s)" & $\begin{array}{l}\text { ABS(\{no significant effect\} OR \{no significant effects\} OR \{no statistically significant effect\} OR \{no statistically } \\
\text { significant effect\} OR \{not a statistically significant effect\}) }\end{array}$ \\
\hline 36. & "supports the hypothesis" & $\begin{array}{l}\text { ABS((\{supports the hypothesis\} OR \{support the hypothesis\} OR \{supports our hypothesis\} OR \{support our hypc } \\
\text { support the hypothesis\} OR \{do not support the hypothesis\} OR \{does not support our hypothesis\} OR \{do not sup }\end{array}$ \\
\hline 37. & "does not support the hypothesis" & ABS(\{does not support the hypothesis\} OR \{do not support the hypothesis\} OR \{does not support our hypothesis\} \\
\hline 38. & "significantly higher/more" & ABS(\{significantly higher\} OR \{significantly more\}) \\
\hline 39. & "significantly lower/less" & ABS(\{significantly lower\} OR \{significantly less\}) \\
\hline 40. & "marginally significant" & ABS("marginally significant") \\
\hline 41. & "important finding" & ABS("important finding" OR "important findings") \\
\hline 42. & "pH 7" & ABS("ph 7") \\
\hline 43. & "mass of" & ABS("mass of") \\
\hline 44. & "room temperature" & ABS("room temperature") \\
\hline 45. & "melting point" & ABS("melting point") \\
\hline 46. & "field of view" & ABS("field of view") \\
\hline 47. & "the properties of" & ABS("the properties of") \\
\hline 48. & "the aim of" & ABS("the aim of") \\
\hline
\end{tabular}




\begin{tabular}{|c|c|c|}
\hline 49. & "our aim" & ABS("our aim") \\
\hline 50. & "results showed that" & ABS("results showed that") \\
\hline 51. & "in conclusion" & ABS("in conclusion") \\
\hline 52. & "longitudinal study" & ABS("longitudinal study") \\
\hline 53. & "in other words" & ABS("in other words") \\
\hline 54. & "on the other hand" & ABS("on the other hand") \\
\hline 55. & "a novel" & ABS("a novel") \\
\hline 56. & "a new" & ABS("a new") \\
\hline 57. & "was/were measured" & ABS("was measured" OR "were measured") \\
\hline 58. & "we measured" & ABS("we measured") \\
\hline 59. & "paradigm shift" & ABS("paradigm shift") \\
\hline 60. & data & ABS(data) \\
\hline 61. & information & ABS(information) \\
\hline 62. & experiment & ABS(experiment) \\
\hline 63. & important & ABS(important) \\
\hline 64. & interesting & ABS(interesting) \\
\hline 65. & neutral & ABS(neutral) \\
\hline 66. & positive & $\mathrm{ABS}$ (positive) \\
\hline 67. & negative & ABS(negative) \\
\hline 68. & "highly significant" & ABS("highly significant" AND NOT "not highly significant") \\
\hline 69. & "trend toward" & ABS("trend toward") \\
\hline 70. & "an increasing trend" & ABS("an increasing trend") \\
\hline 71. & "a decreasing trend" & ABS("a decreasing trend") \\
\hline 72. & "potentially significant" & ABS("potentially significant") \\
\hline 73. & "a nonsignificant trend" & ABS("a nonsignificant trend" OR "a non significant trend") \\
\hline 74. & "a significant trend" & ABS("a significant trend") \\
\hline 75. & "quite significant" & ABS("quite significant") \\
\hline 76. & "a clear trend" & ABS("a clear trend") \\
\hline 77. & "a positive trend" & ABS("a positive trend") \\
\hline 78. & "a strong trend" & ABS("a strong trend") \\
\hline 79. & "significant tendency" & ABS("significant tendency") \\
\hline 80. & "a little significant" & ABS("a little significant") \\
\hline 81. & "not insignificant" & ABS("not insignificant") \\
\hline 82. & "possible significance" & ABS("possible significance") \\
\hline 83. & $\begin{array}{l}\text { "failed to reach statistical } \\
\text { significance" }\end{array}$ & ABS("failed to reach statistical significance") \\
\hline 84. & "likely to be significant" & ABS("likely to be significant") \\
\hline
\end{tabular}


Supplementary material

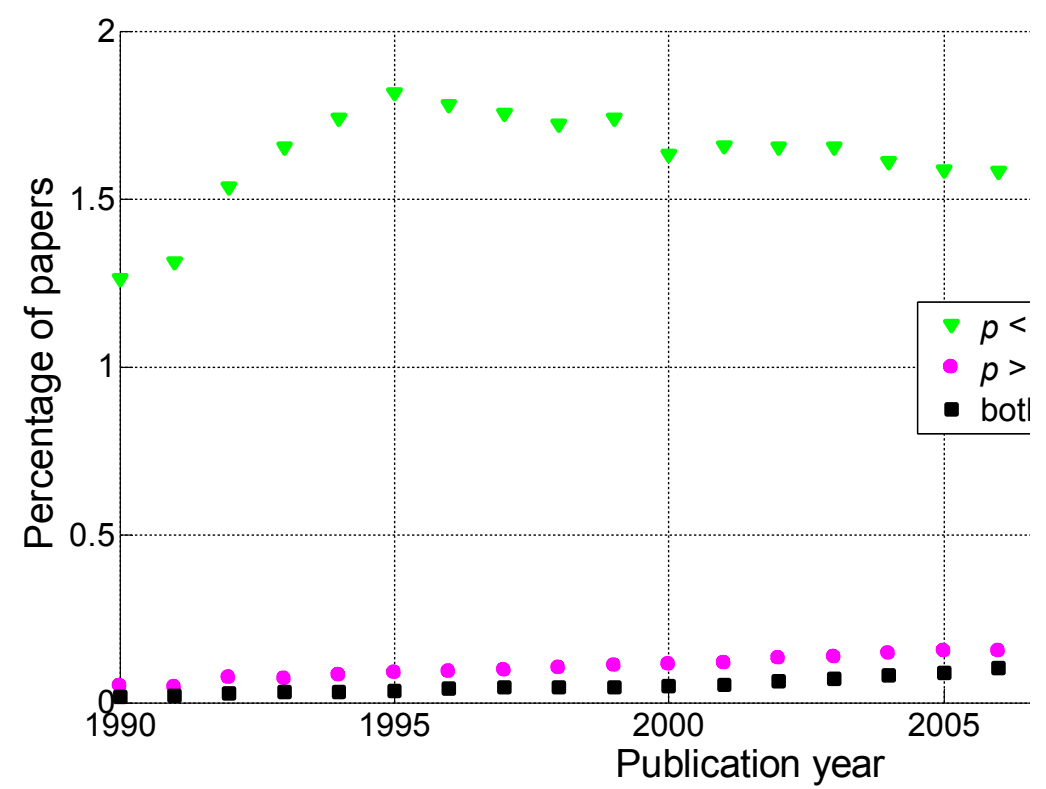

901 Figure S1. Percentage of papers reporting $p<0.05$ and not $p>0.05$, percentage of papers reporting $p<0.05$ and not $p>0.05$, and 902 percentage of papers reporting both $p<0.05$ and $p>0.05$ per publication year.

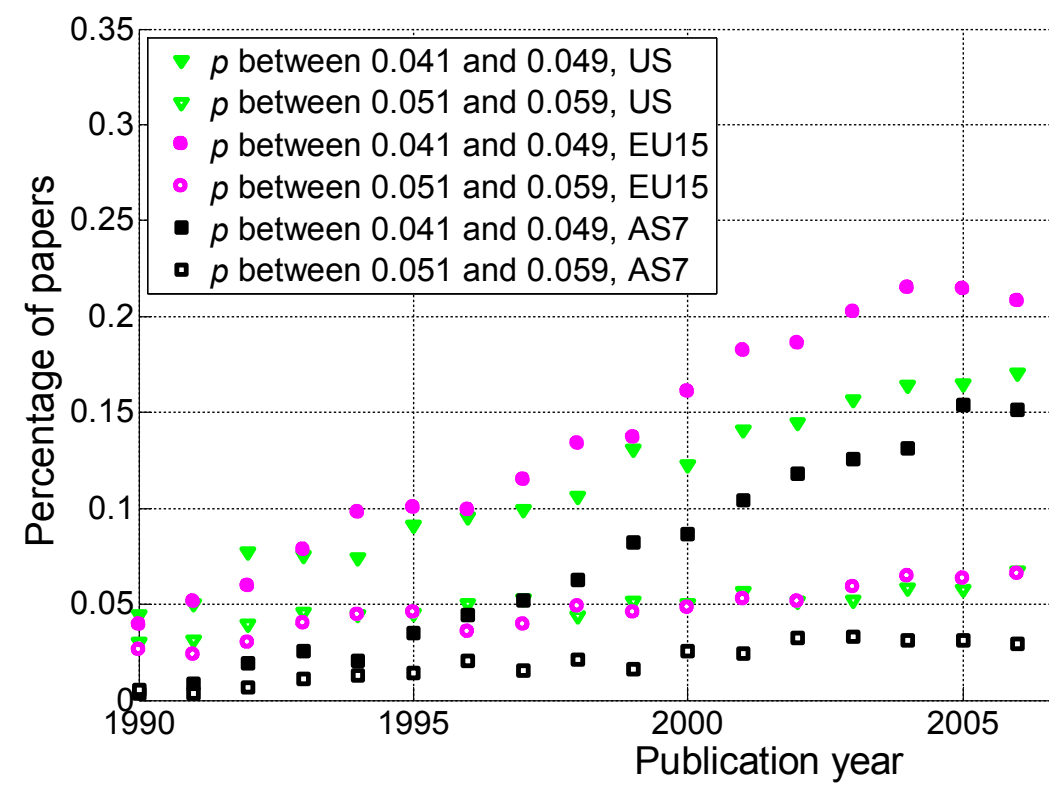

Figure S2. Percentage of papers reporting a $p$-value between 0.041 and 0.049 and percentage of papers reporting a $p$-value between 0.051 and 0.059 per publication year, for three world regions. 


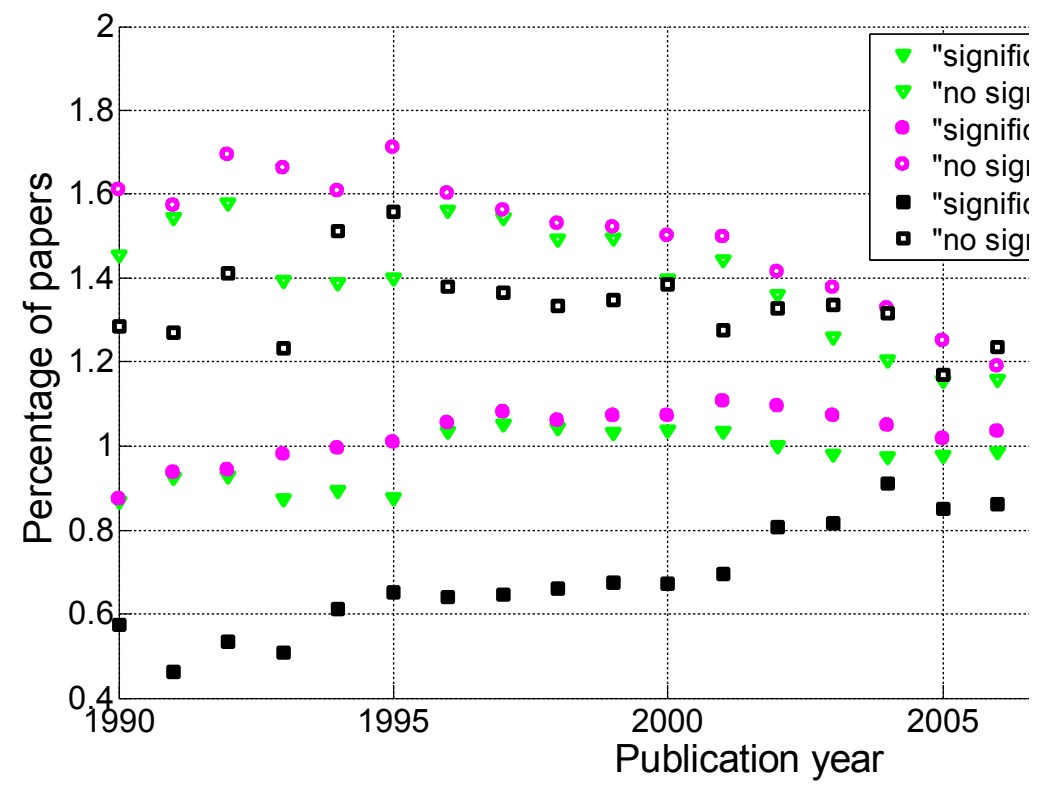

905 Figure S3. Percentage of papers reporting "significant difference" and percentage of papers reporting "no significant difference" 906 per publication year, for three world regions.

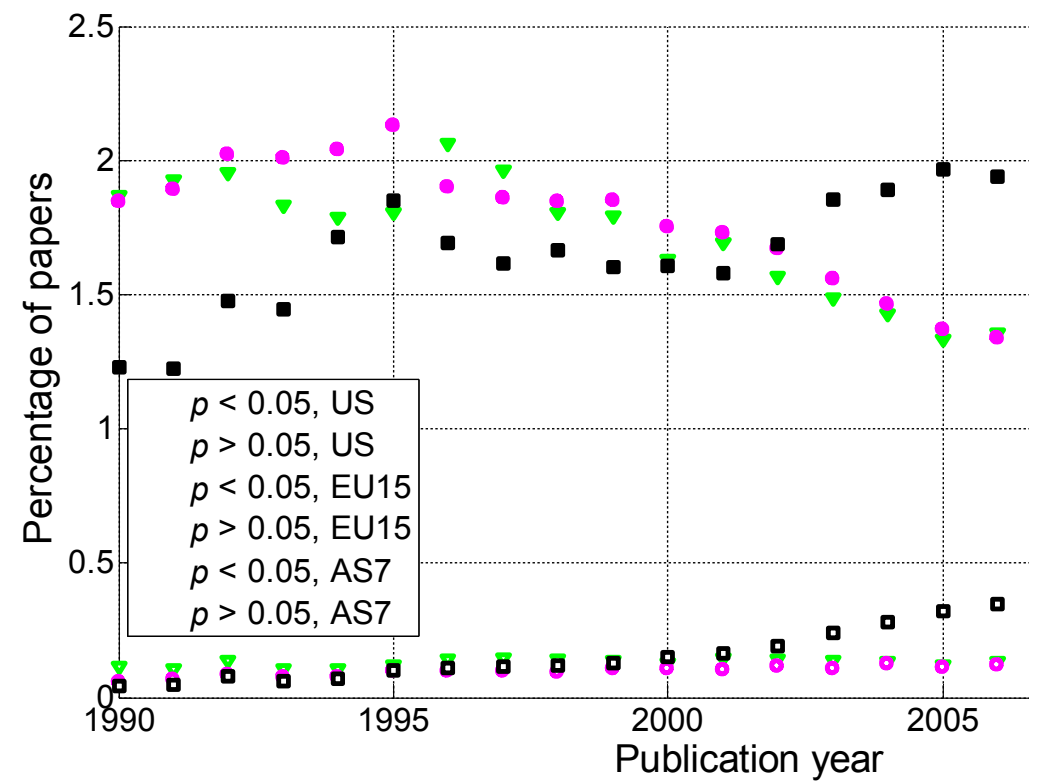

907 Figure S4. Percentage of papers reporting $p<0.05$ and percentage of papers reporting $p>0.05$ per publication year, for three 908 world regions. 


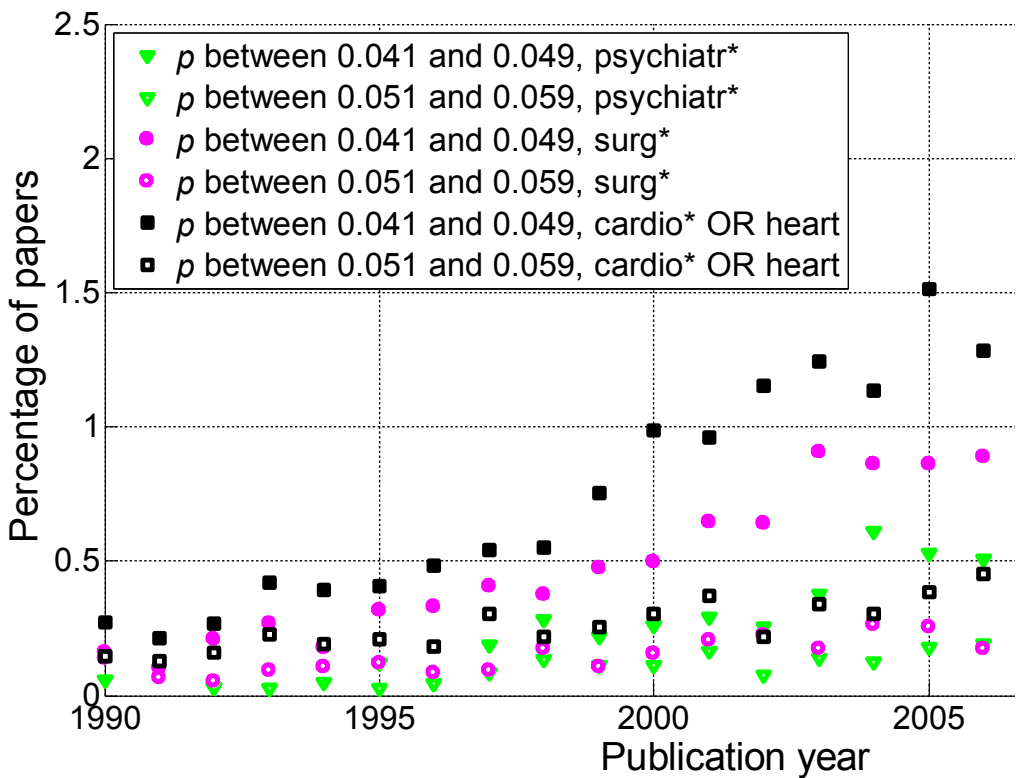

909 Figure S5. Percentage of papers reporting a $p$-value between 0.041 and 0.049 and percentage of papers reporting a $p$-value 910 between 0.051 and 0.059 per publication year, for three indicative subfields of biological sciences.

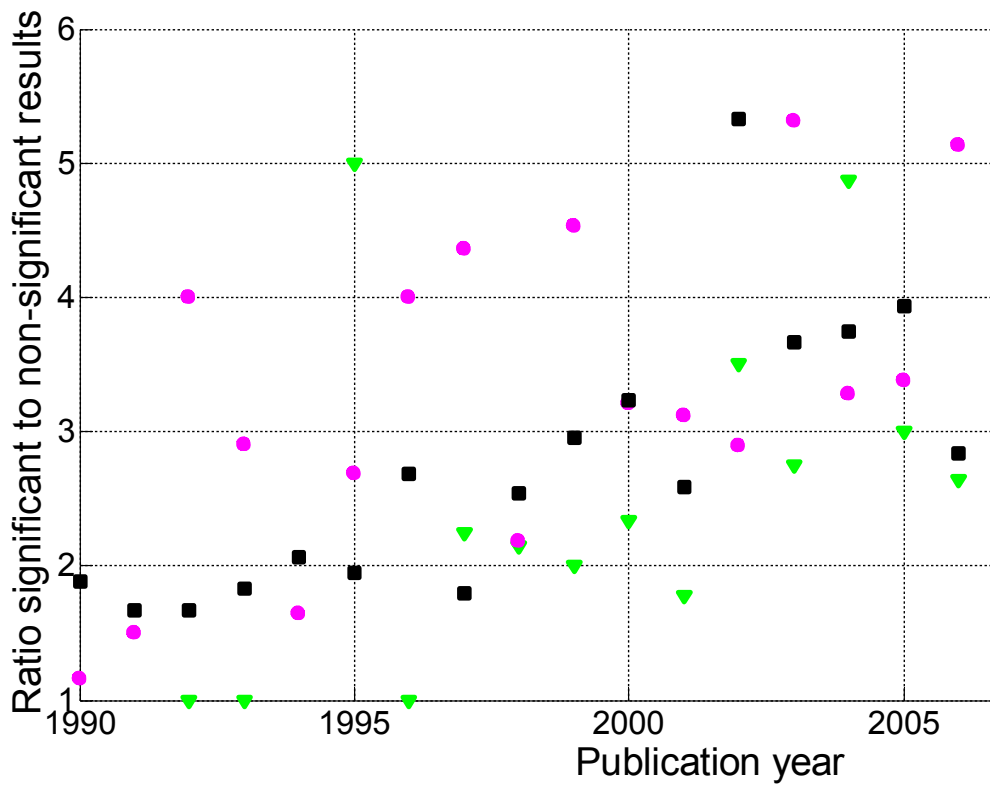

911 Figure S6. Ratio of $p$-values between 0.041 and 0.049 to $p$-values between 0.051 and 0.059 per publication year, for three indicative subfields of biological sciences. The dashed lines represent the results of a linear regression analysis. 


\section{1}

Figure 1

Number of papers reporting a positive result divided by the total number of papers examined (i.e., papers reporting a positive result + papers reporting a negative result) per publication year, for three scientific disciplines. The figure was created by graphically extracting the data shown in Fanelli's (2012) figures. The dashed lines represent the results of a simple linear regression analysis.

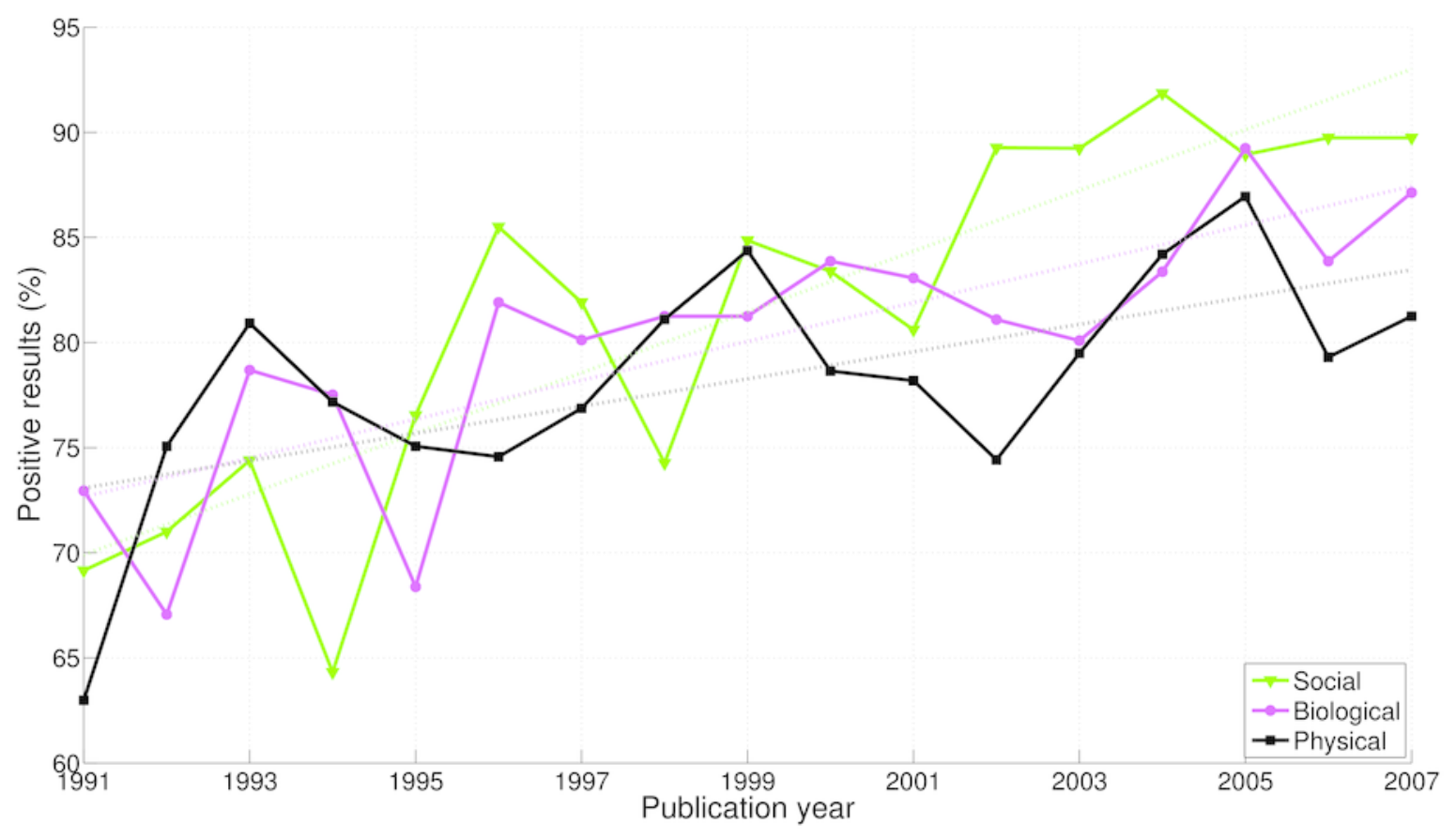


2

Figure 2

Number of papers per publication year, for three scientific disciplines and three world regions.

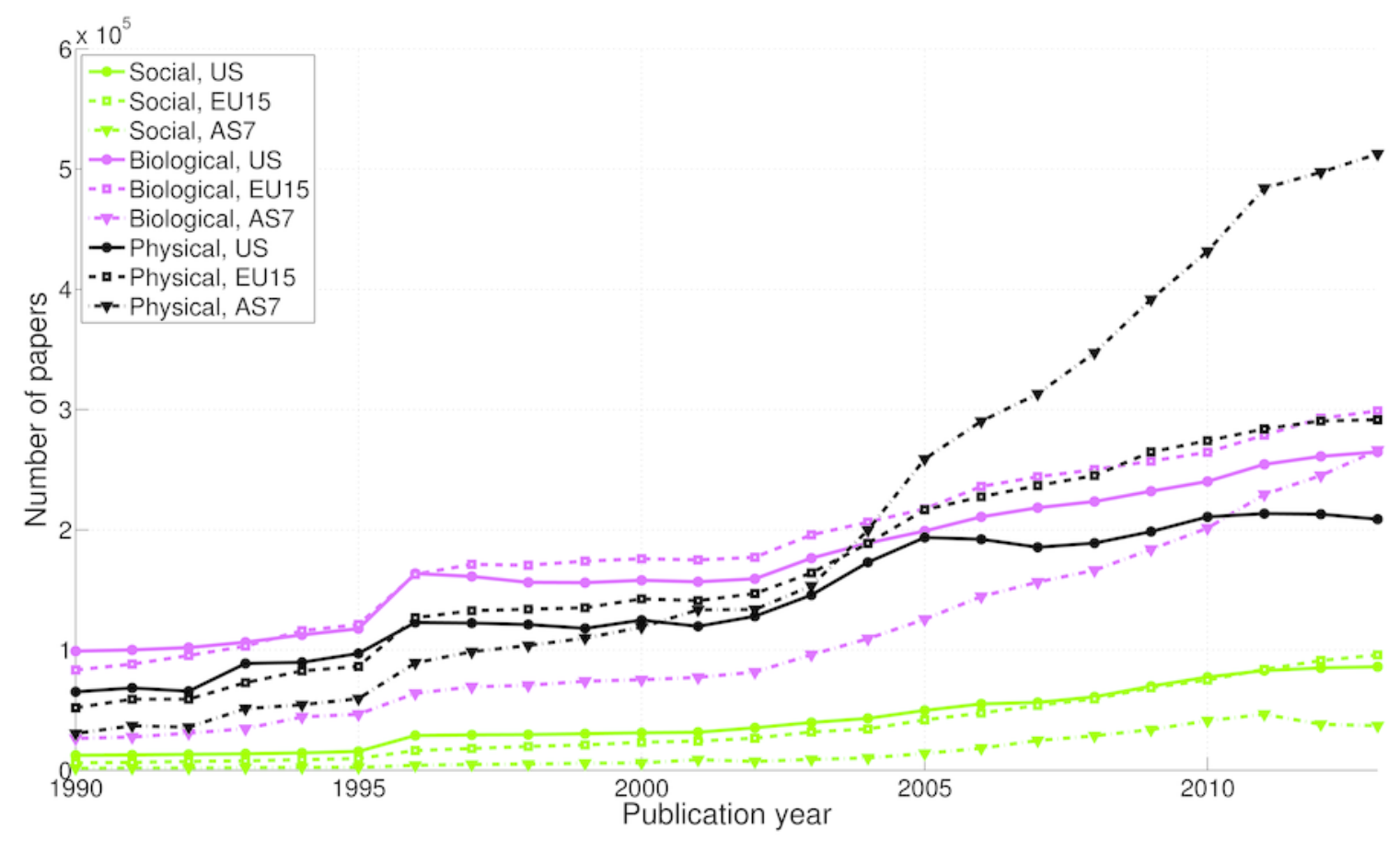




\section{3}

Figure 3

Percentage of papers reporting a p-value between 0.041 and 0.049 and percentage of papers reporting a $p$-value between 0.051 and 0.059 per publication year.

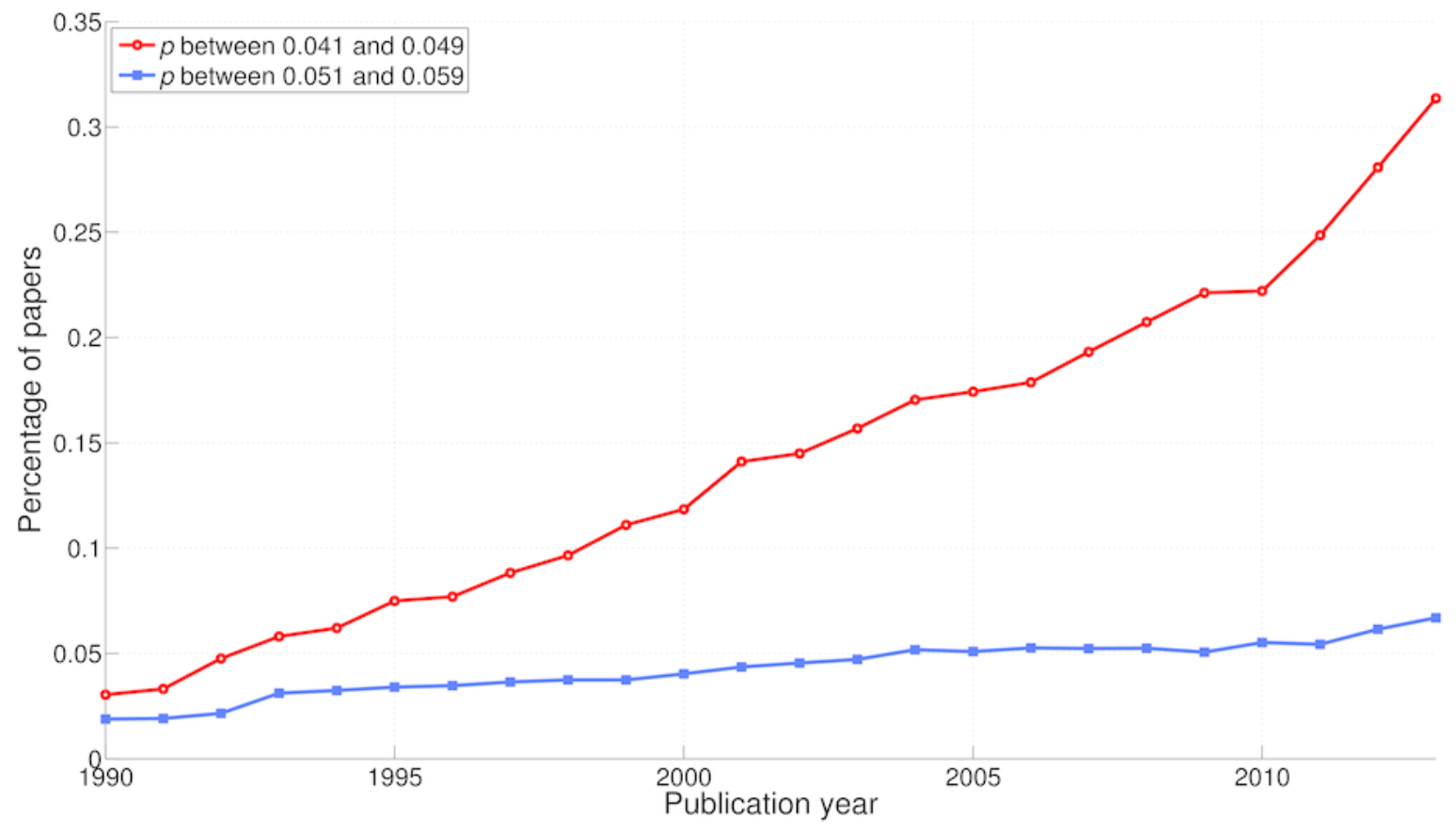


4

Figure 4

Ratio of $p$-values between 0.041 and 0.049 to $p$-values between 0.051 and 0.059 per publication year. The dashed line represents the result of a simple linear regression analysis.

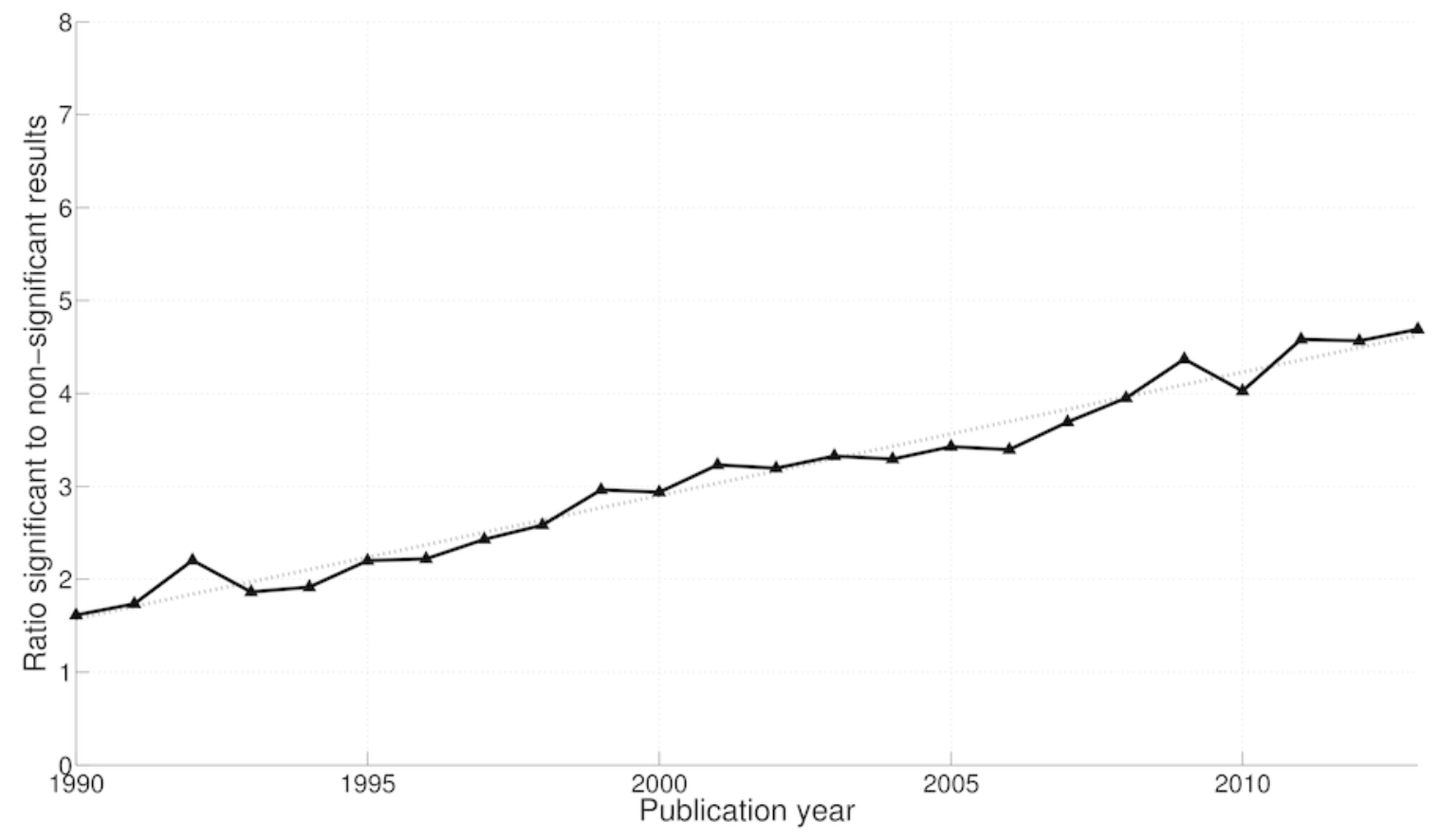




\section{5}

Figure 5

Percentage of papers reporting "significant difference" and percentage of papers reporting "no significant difference" per publication year.

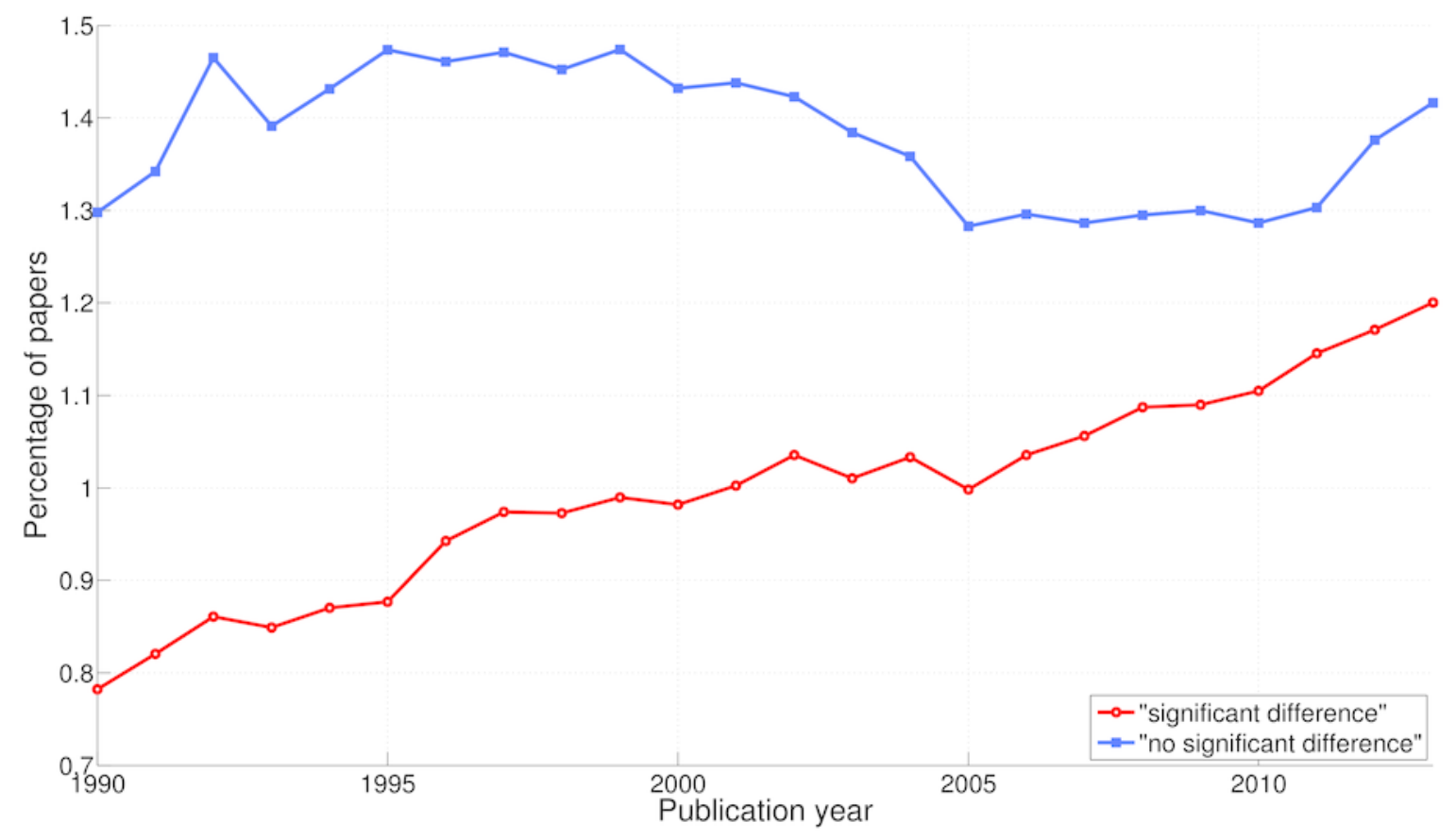




\section{6}

Figure 6

Ratio of "significant difference" to "no significant difference" per publication year. The dashed line represents the result of a simple linear regression analysis.

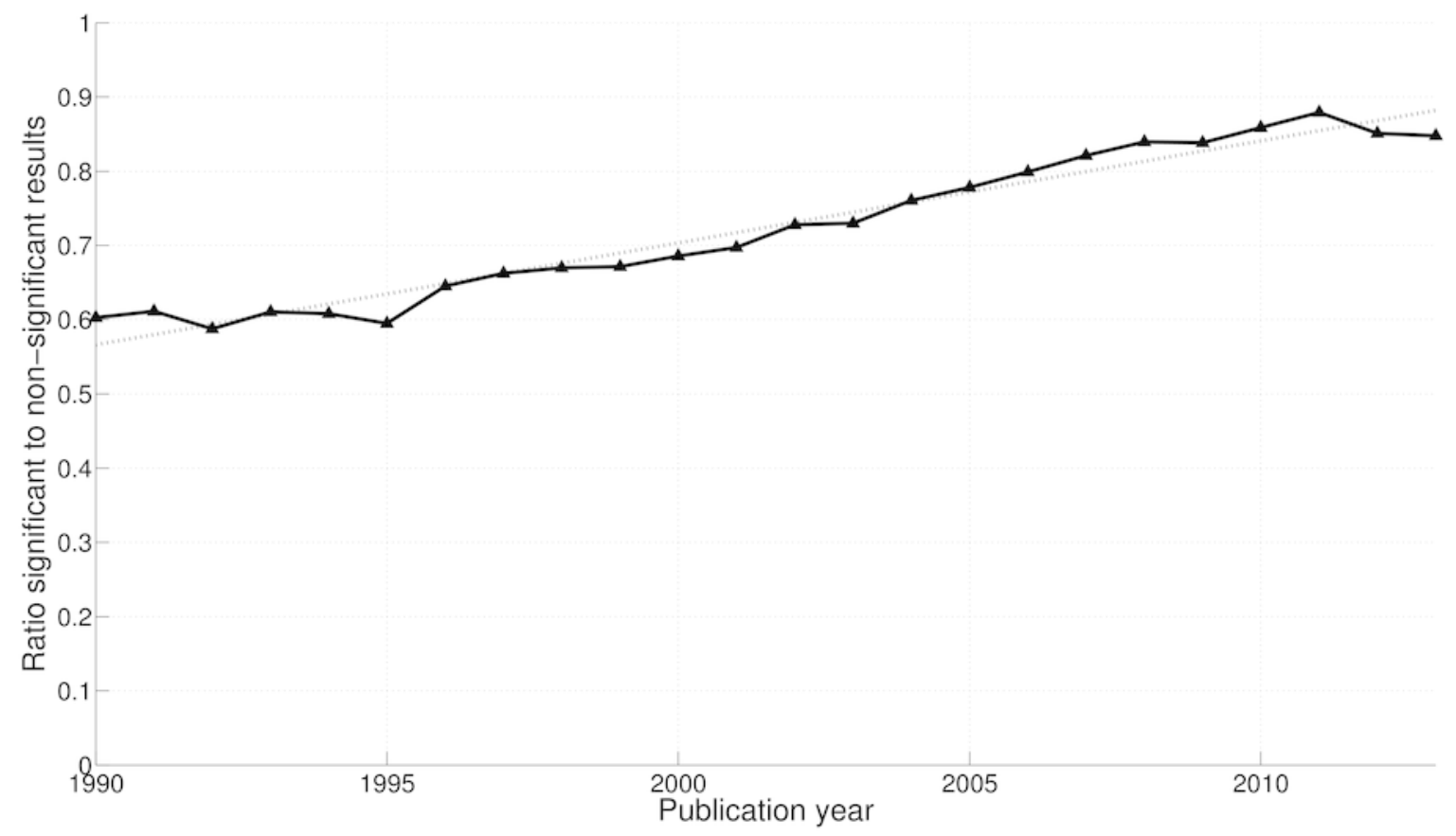




\section{7}

Figure 7

Percentage of papers reporting $p<0.05$ and percentage of papers reporting $p>0.05$ per publication year.

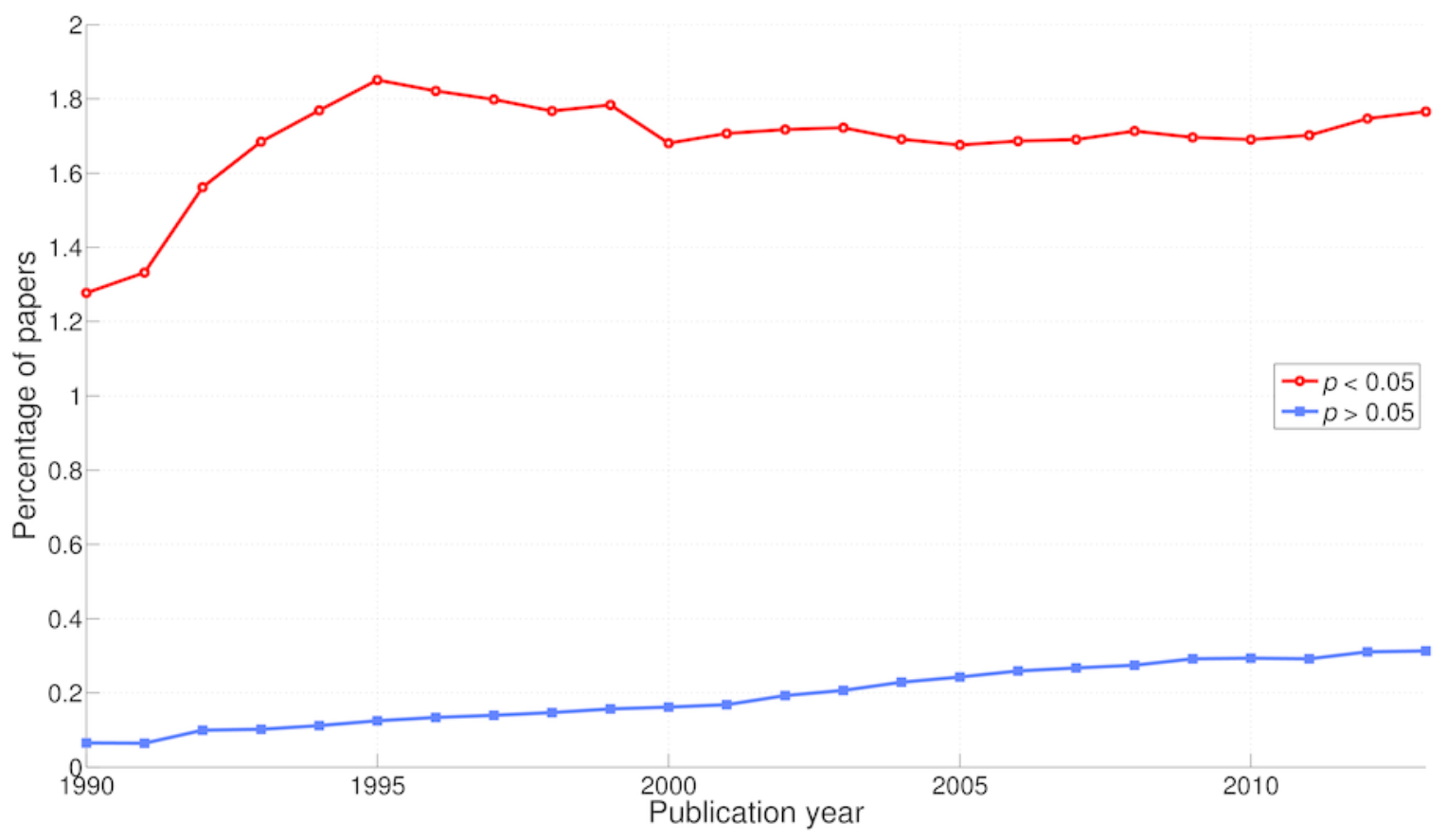


8

Figure 8

Ratio of $p<0.05$ to $p>0.05$ per publication year. The dashed line represents the result of a simple linear regression analysis.

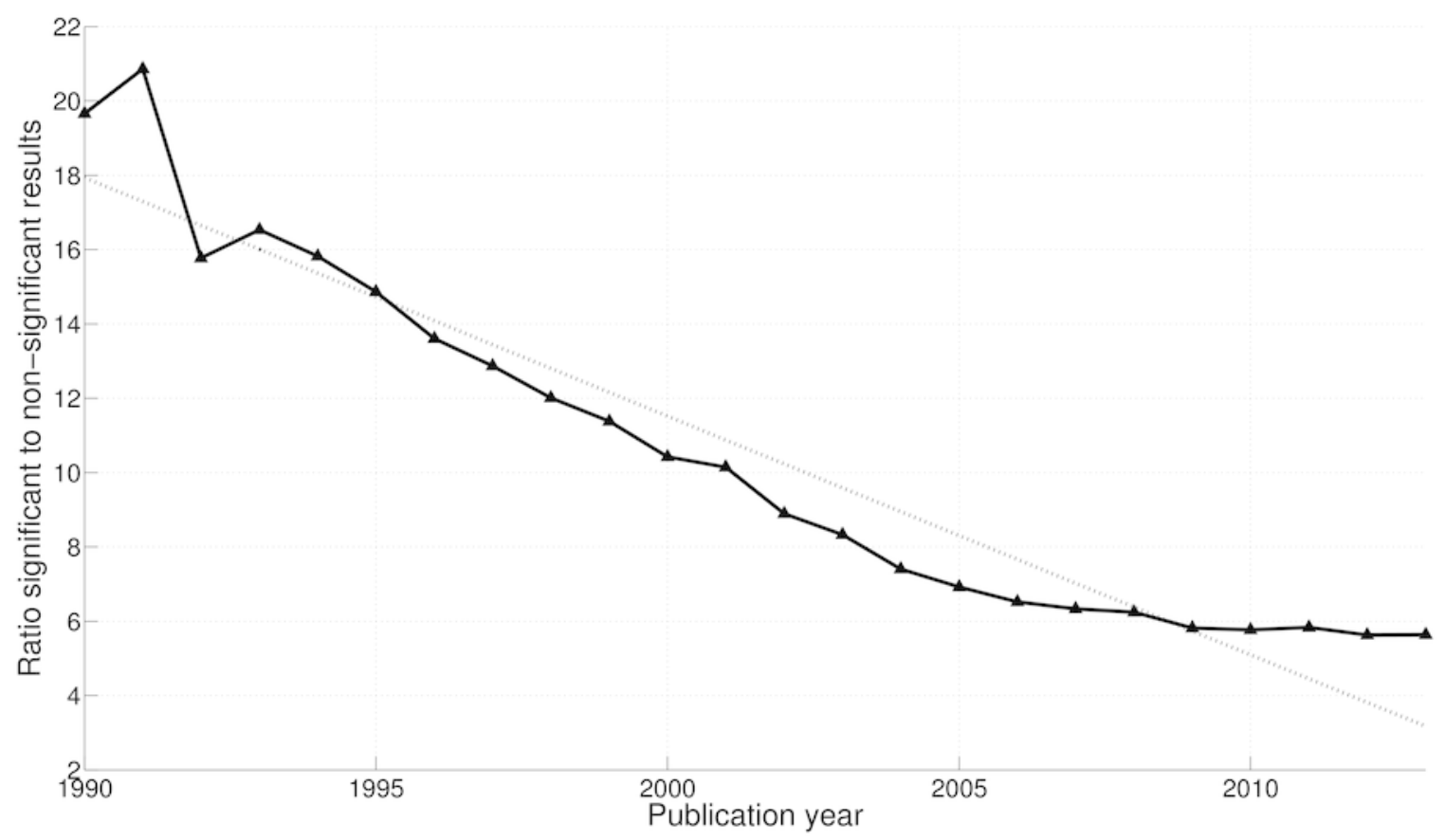


9

Figure 9

Percentage of papers reporting a p-value between 0.041 and 0.049 and percentage of papers reporting a p-value between 0.051 and 0.059 per publication year, for three scientific disciplines.

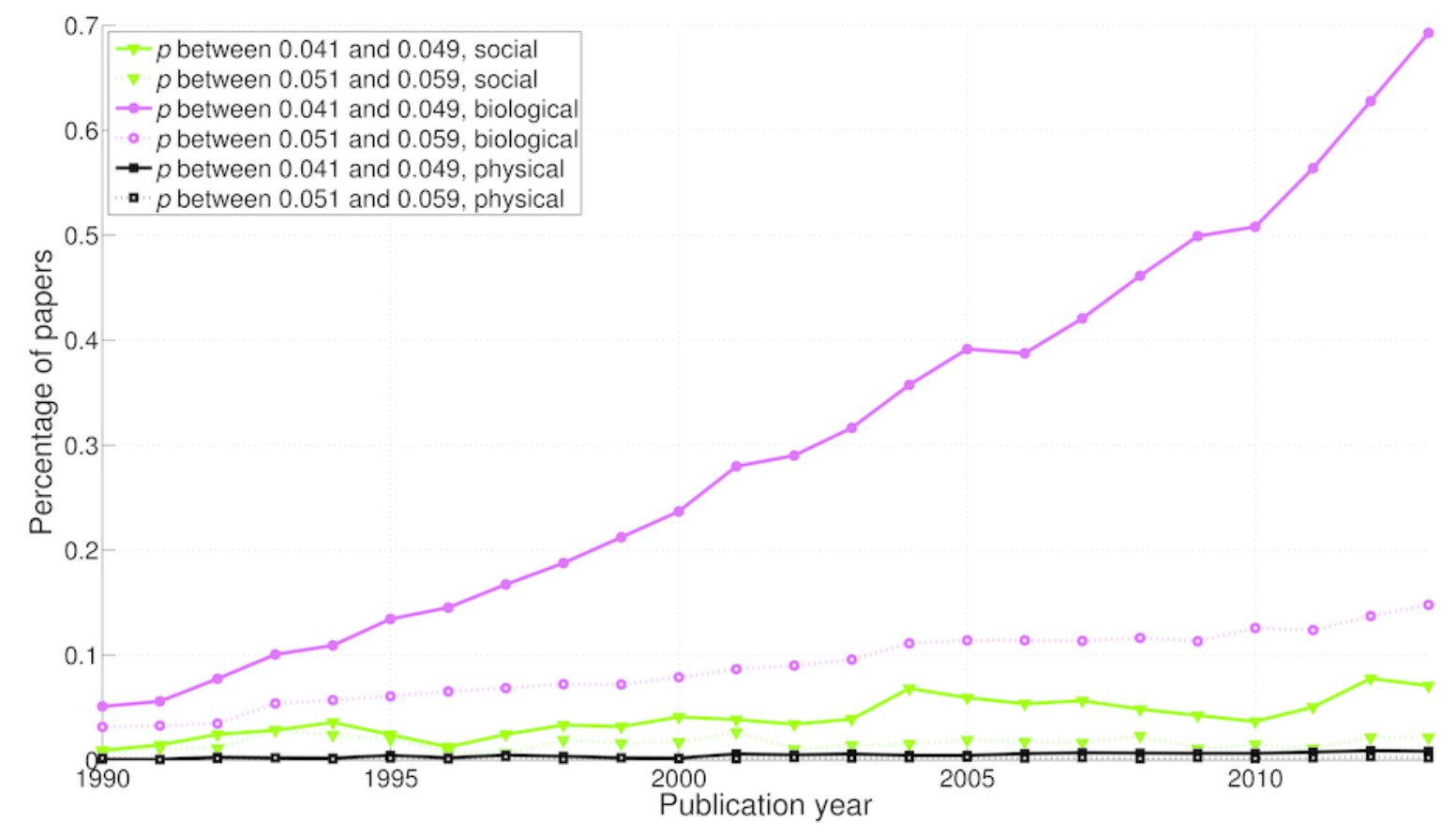


10

Figure 10

Ratio of $p$-values between 0.041 to 0.049 to $p$-values between 0.051 and 0.059 per publication year, for three scientific disciplines. The dashed lines represent the results of a simple linear regression analysis.

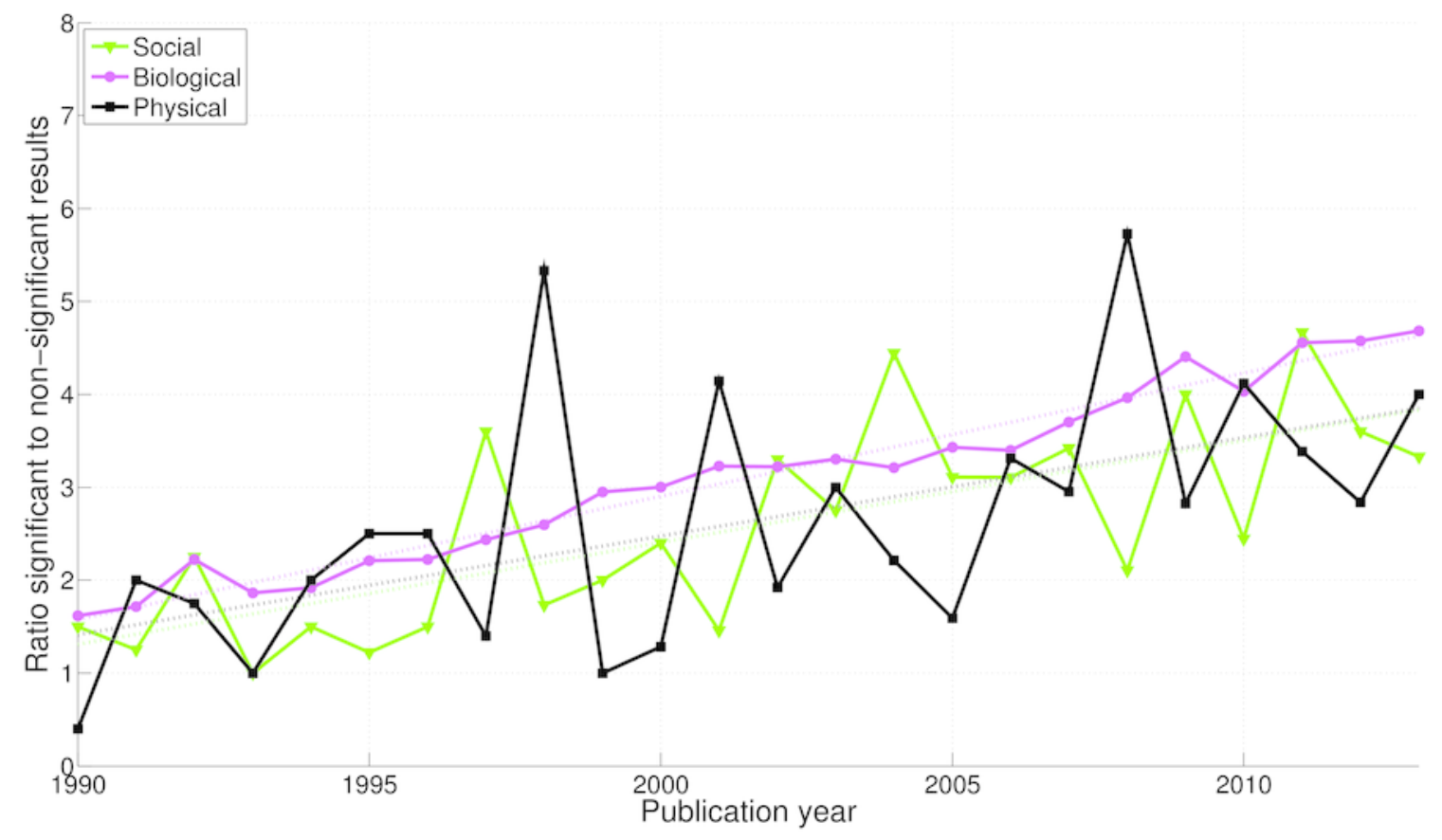




\section{1}

Figure 11

Percentage of papers reporting "significant difference" and percentage of papers reporting "no significant difference" per publication year, for three scientific disciplines.

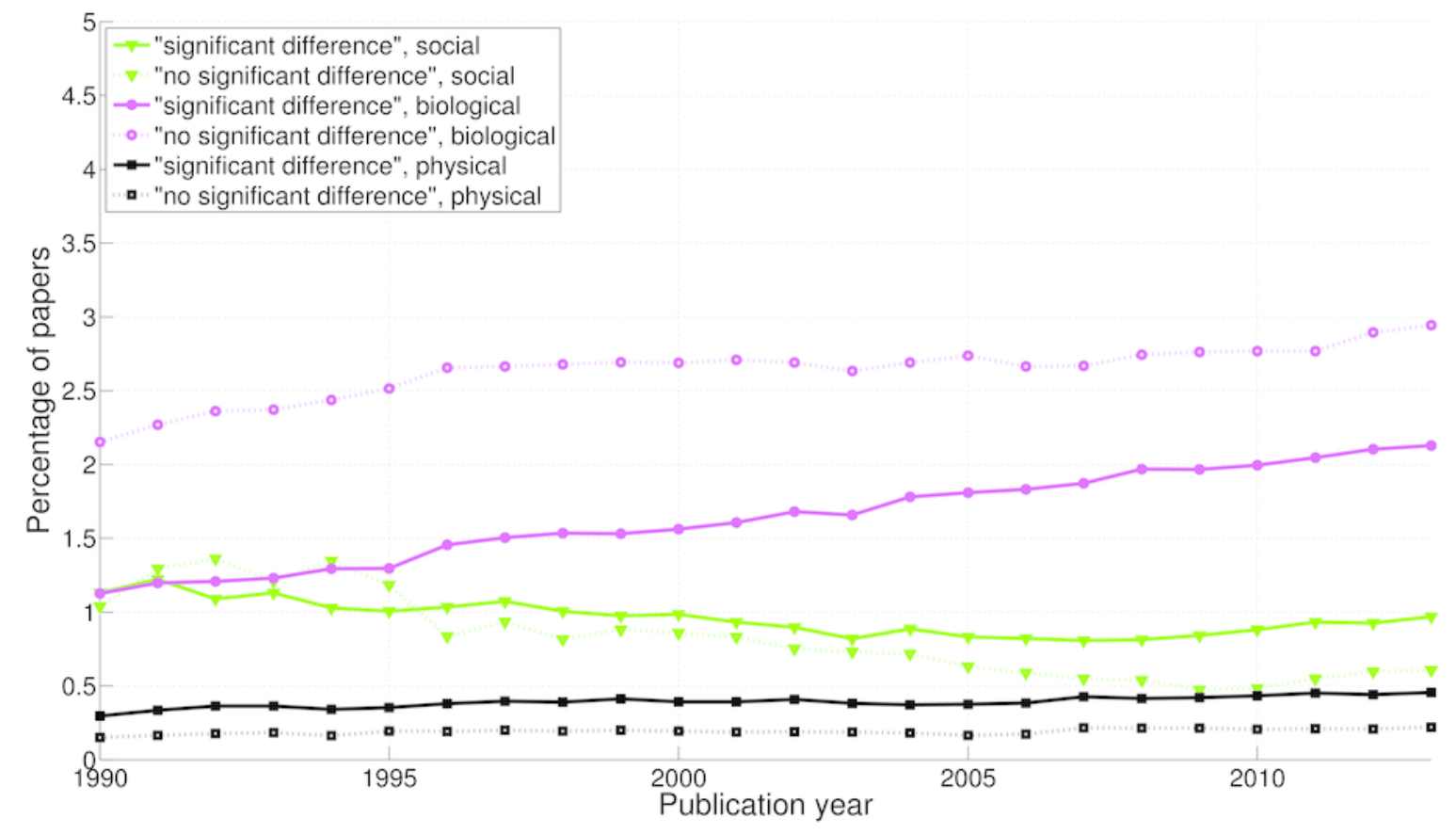


12

Figure 12

Ratio of "significant difference" to "no significant difference" per publication year, for three scientific disciplines. The dashed lines represent the results of a simple linear regression analysis.

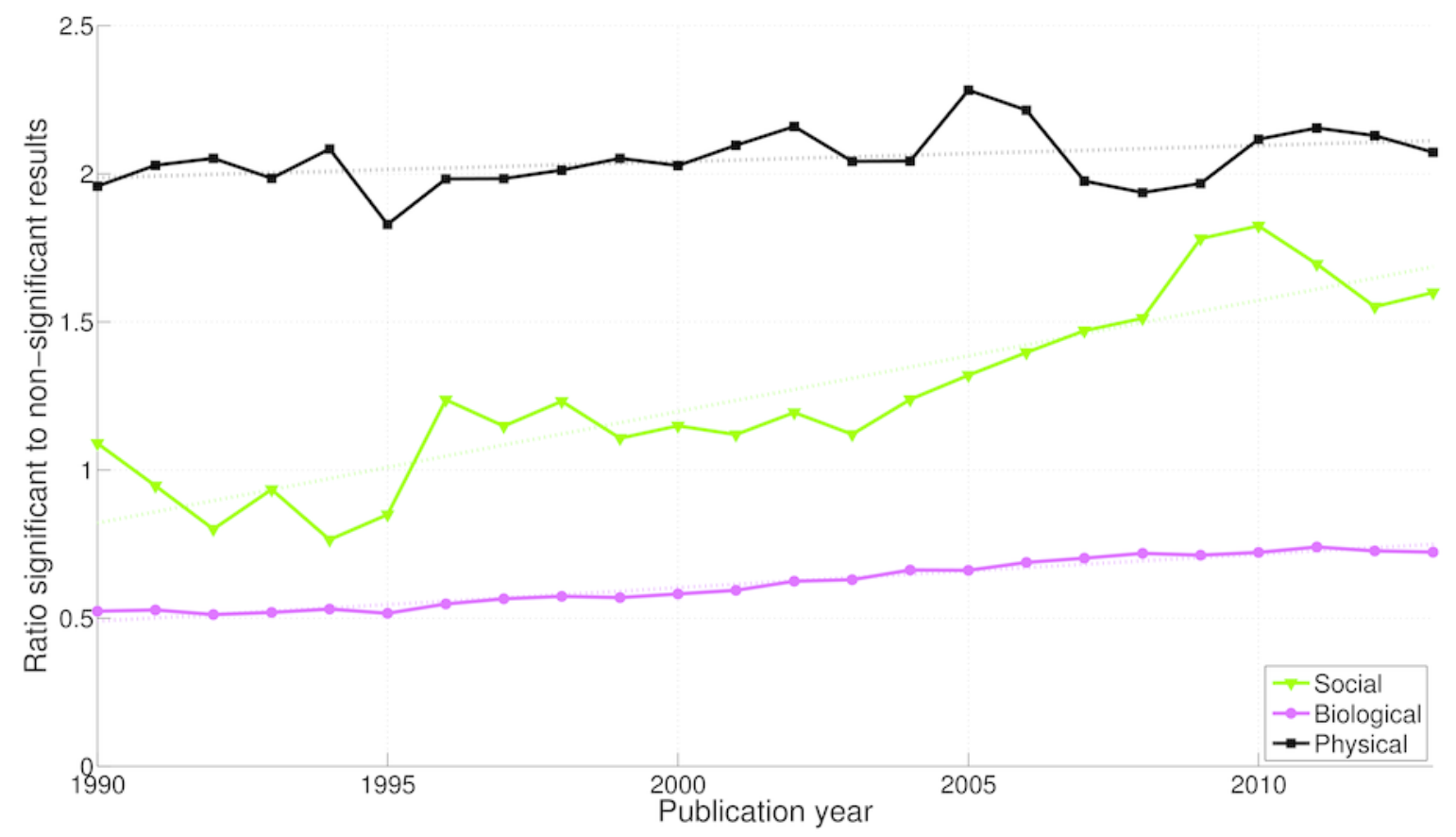




\section{3}

Figure 13

Percentage of papers reporting $p<0.05$ and percentage of papers reporting $p>0.05$ per publication year, for three scientific disciplines.

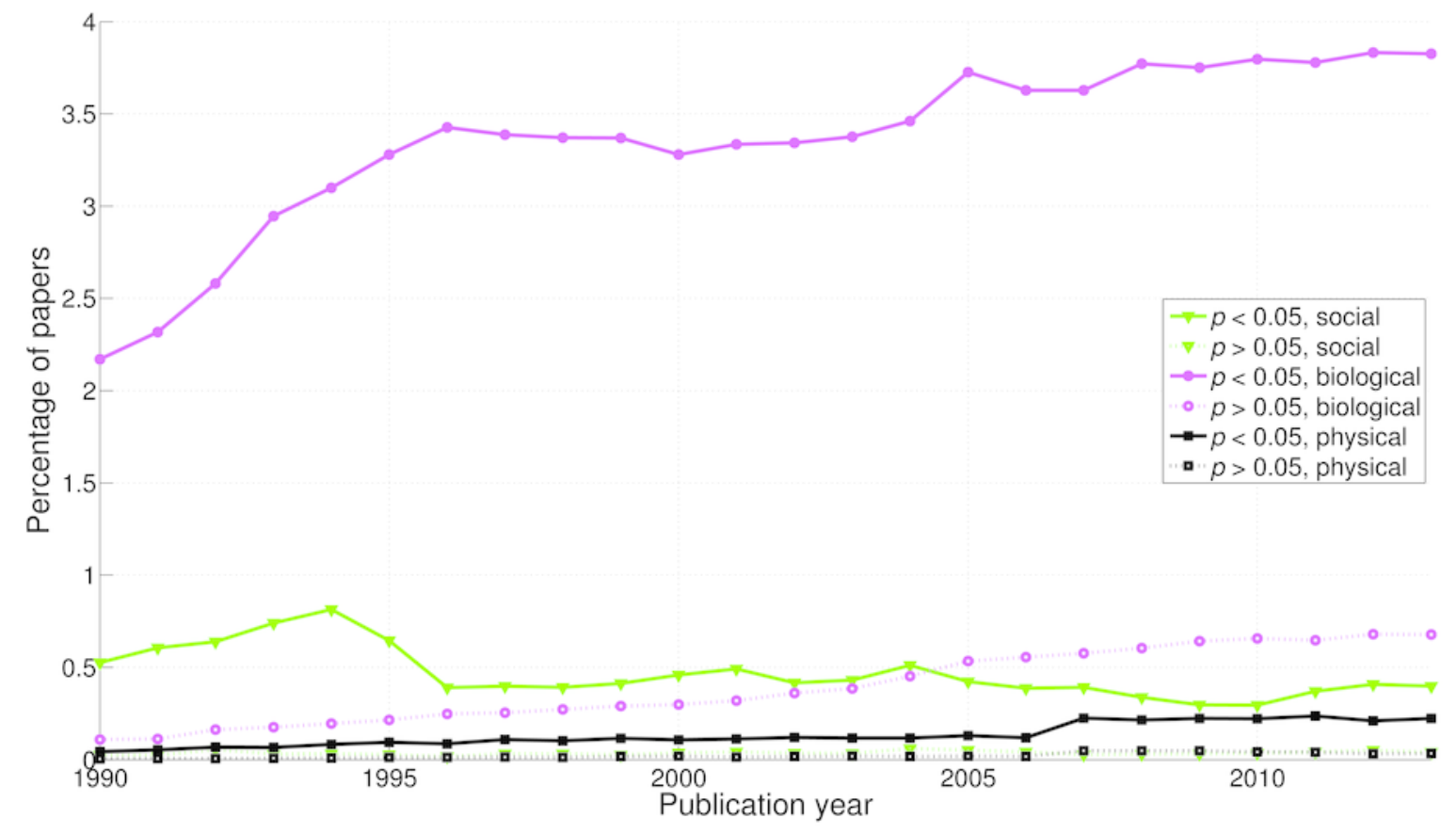




\section{4}

Figure 14

Ratio of $p<0.05$ to $p>0.05$ per publication year, for three scientific disciplines. The dashed lines represent the results of a simple linear regression analysis.

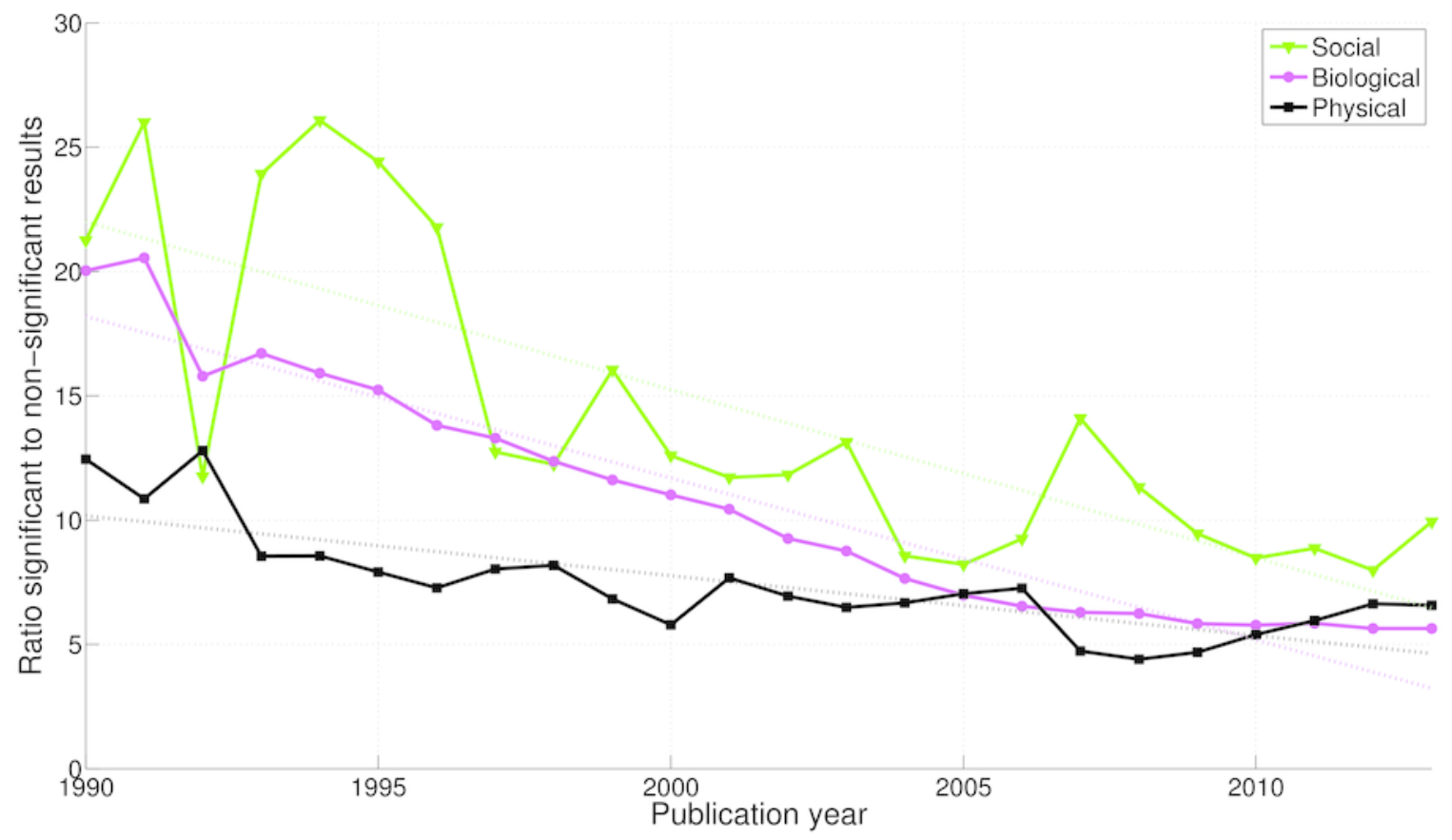


15

Figure 15

Venn diagrams showing the numbers of papers reporting a $p$-value between 0.041 and 0.049 $(A)$, the numbers of papers reporting a $p$-value between 0.051 and $0.059(B)$, and the total number of papers (C). "Other" refers to papers purely classified into subject areas outside the three disciplines. The percentages refer to the papers that were unique to each discipline (e.g., $96.50 \%$ of biological papers with $p$-values between 0.041 and 0.049 belonged purely to biological sciences).
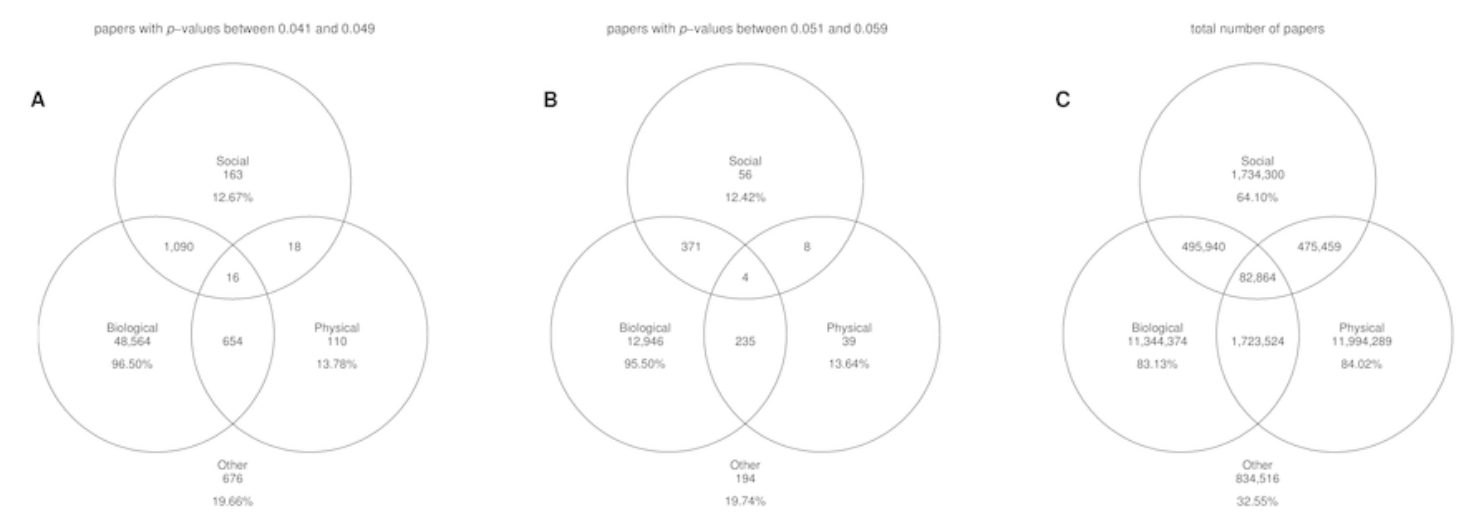


\section{6}

Figure 16

Slope coefficients calculated using a simple linear regression analysis, for the ratios of significant (S) to non-significant (NS) results (S/NS; A, B, C) and the percentages of significant results $(100 \% * S /[S+N S] ; D, E, F)$. The slope coefficients are reported for all papers, and for papers in three scientific disciplines, both for cross-classified papers (grey bars) and for pure disciplines (orange bars). The numbers at the top of the figure represent: (1) first row: number of papers between 1990 and 2013 reporting significant results (S); (2) second row: number of papers between 1990 and 2013 reporting non-significant results (NS); and (3) third row: ratio of significant to non-significant results (S/NS) calculated as the yearly S/NS averaged over 1990-2013. Error bars denote 95\% confidence intervals.

A

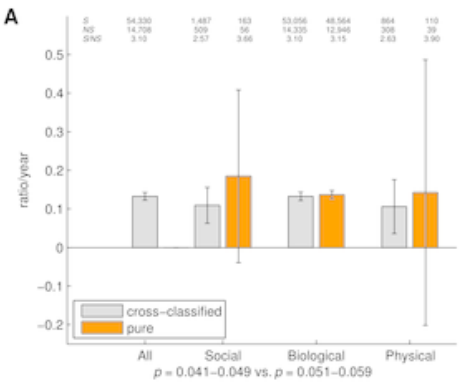

D

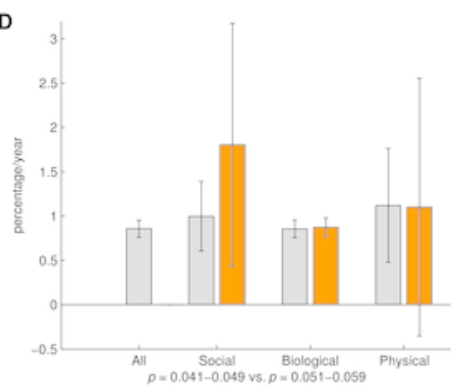

B

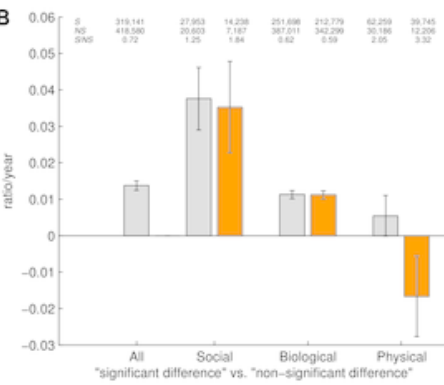

E

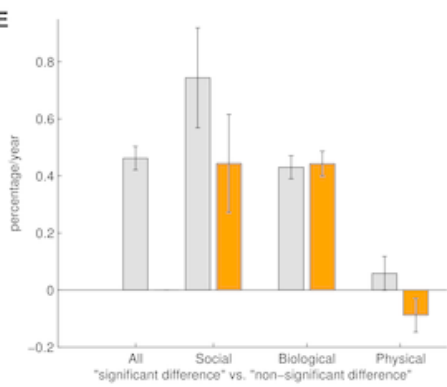

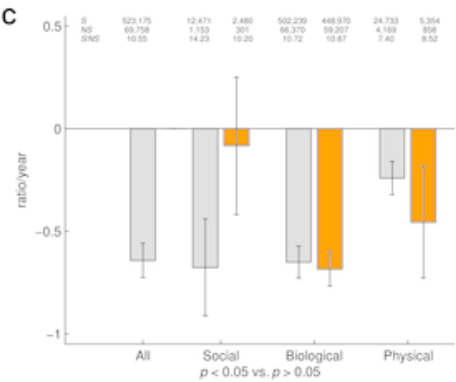

F

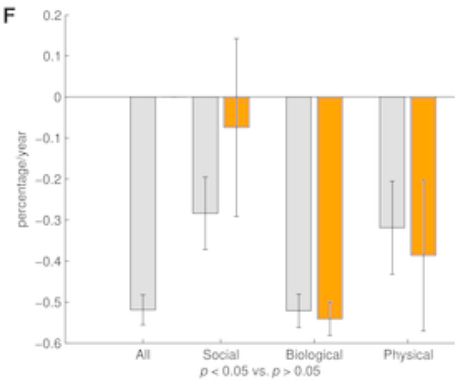


17

Figure 17

Ratio of $p$-values between 0.041 and 0.049 to $p$-values between 0.051 and 0.059 per publication year, for three world regions. The dashed lines represent the results of a simple linear regression analysis.

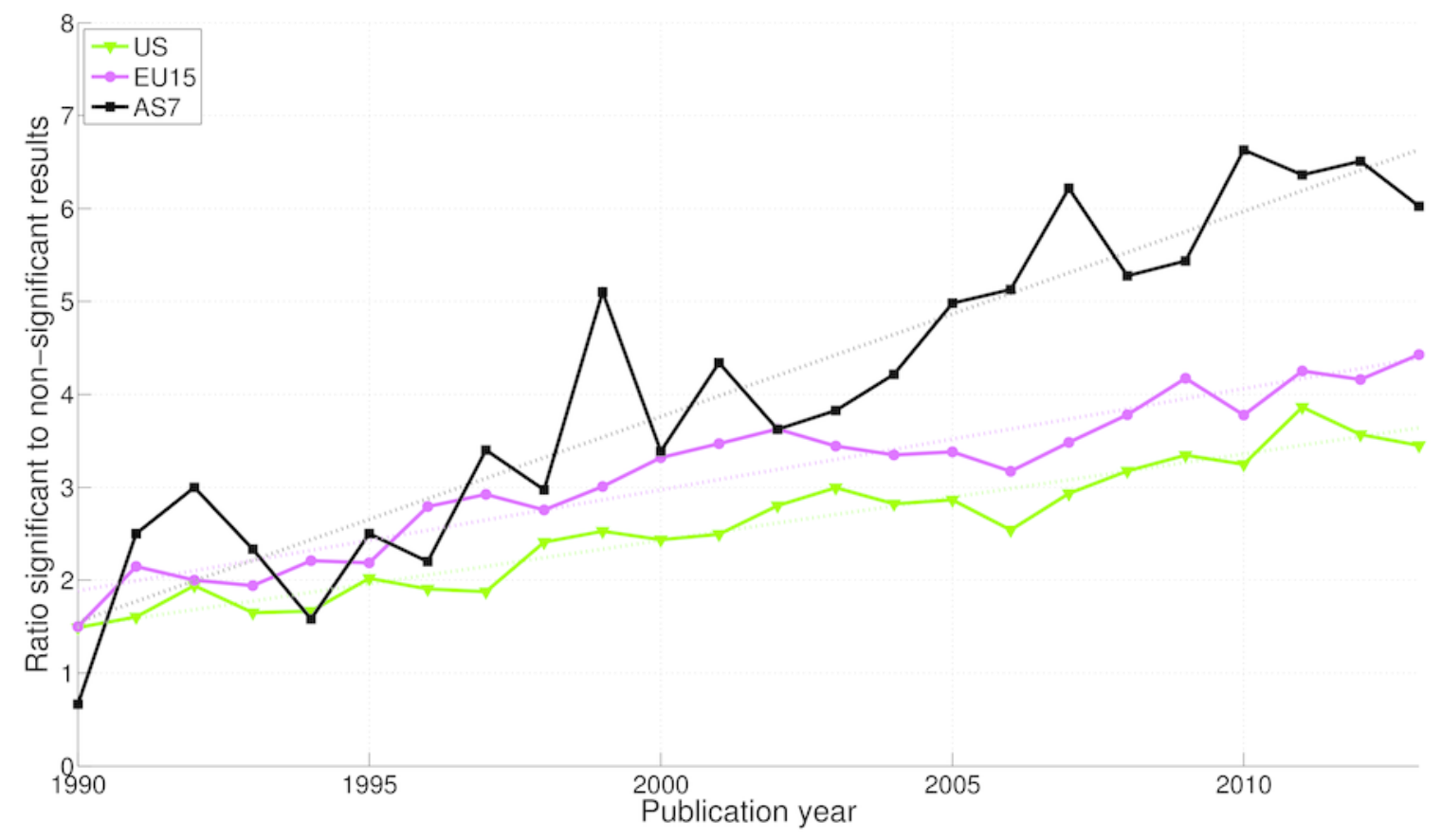


18

Figure 18

Ratio of "significant difference" to "no significant difference" per publication year, for three world regions. The dashed lines represent the results of a simple linear regression analysis.

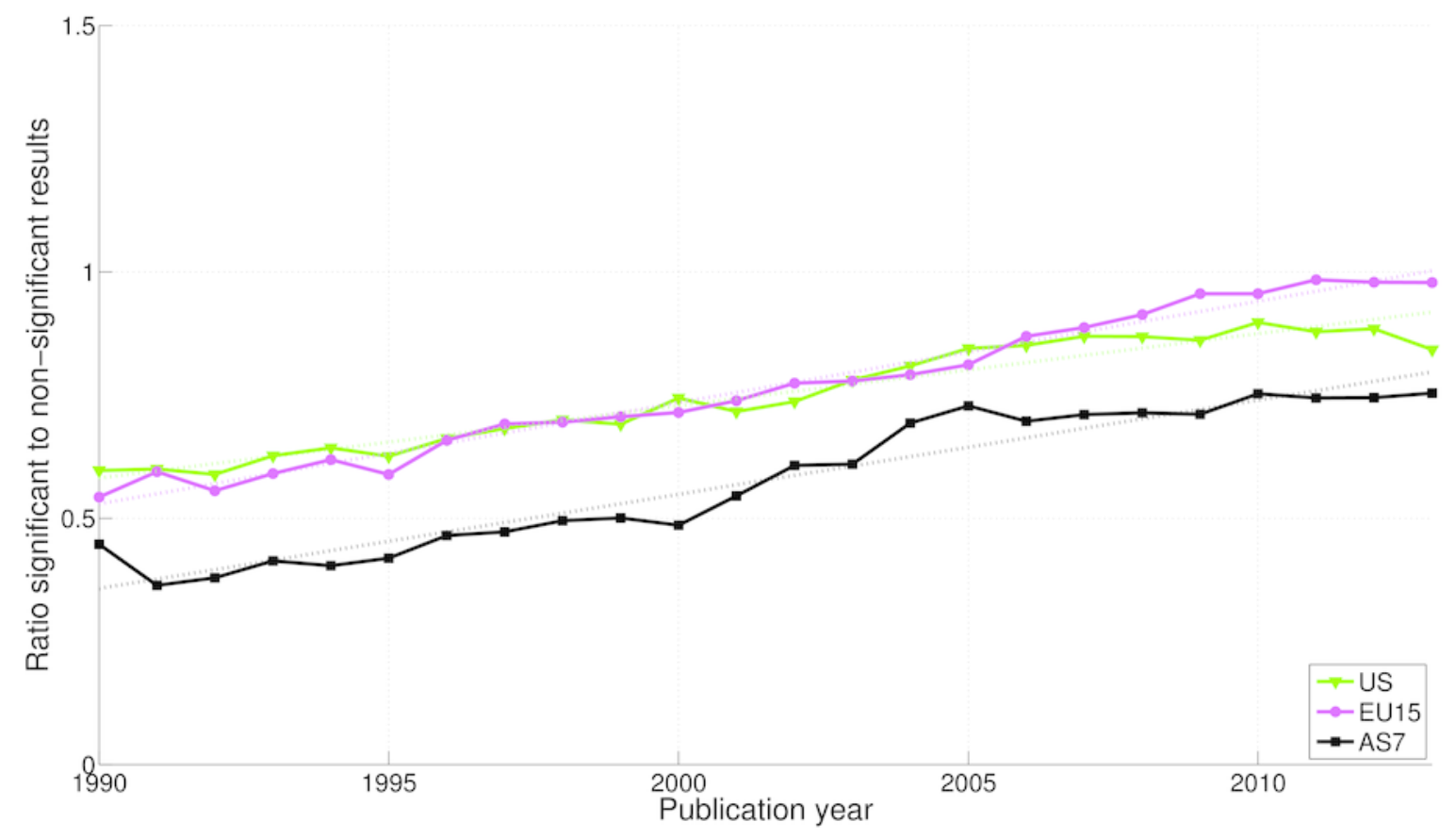




\section{9}

Figure 19

Ratio of $p<0.05$ to $p>0.05$ per publication year for three world regions. The dashed lines represent the results of a linear regression analysis.

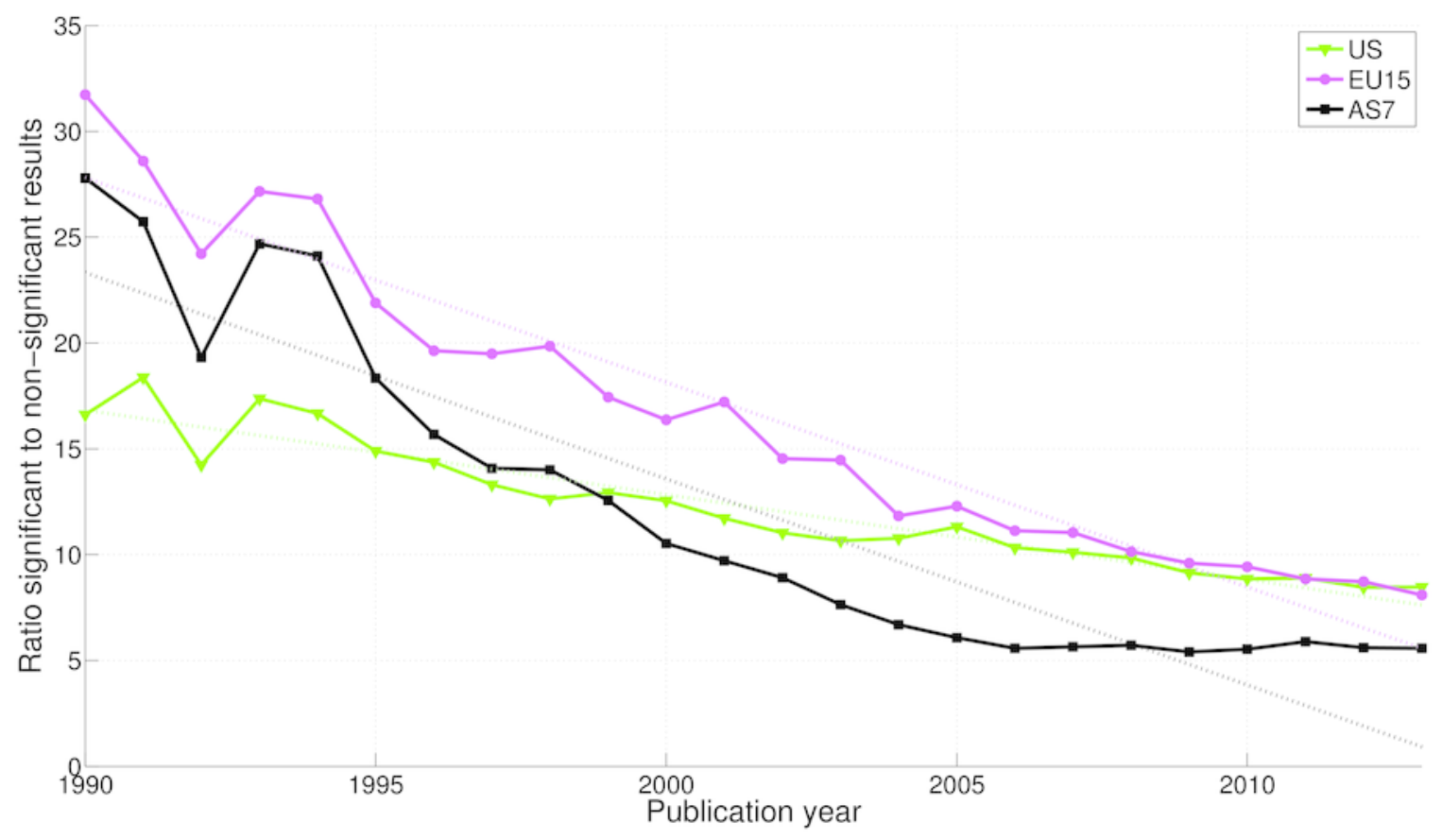


20

Figure 20

Venn diagrams showing the numbers of papers reporting a $p$-value between 0.041 and 0.049 $(A)$, the numbers of papers reporting a $p$-value between 0.051 and $0.059(B)$, and the total number of papers $(C)$. "Other" refers to papers purely affiliated with countries outside the three world regions. The percentages refer to the papers that were unique to each world region.
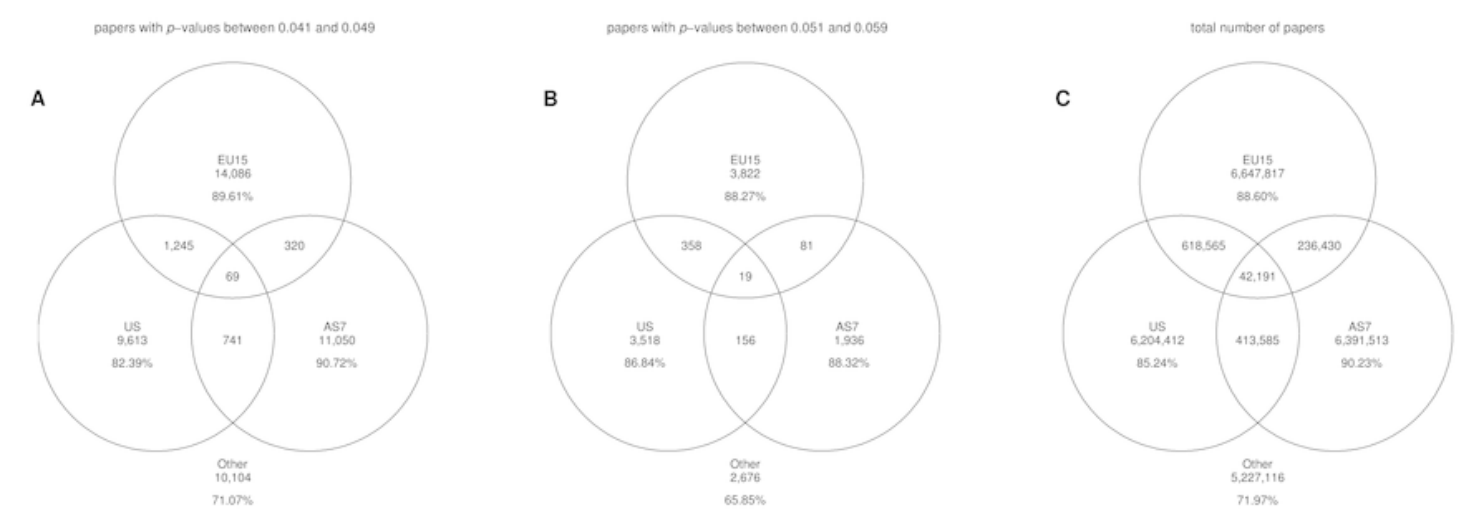
21

Figure 21

Slope coefficients calculated using a simple linear regression, for the ratios of significant $(S)$ to non-significant (NS) results ( $S / N S ; A, B, C)$ and the percentages of significant results $(100 \% * S /[S+N S] ; D, E, F)$. The slope coefficients are reported for papers in three world regions, both for cross-classified papers (grey bars) and for pure world regions (orange bars). The numbers at the top of the figure represent: (1) first row: number of papers between 1990 and 2013 reporting significant results (S); (2) second row: number of papers between 1990 and 2013 reporting non-significant results (NS); and (3) third row: ratio of significant to nonsignificant results (S/NS) calculated as the yearly S/NS averaged over 1990-2013. Error bars denote $95 \%$ confidence intervals.

A
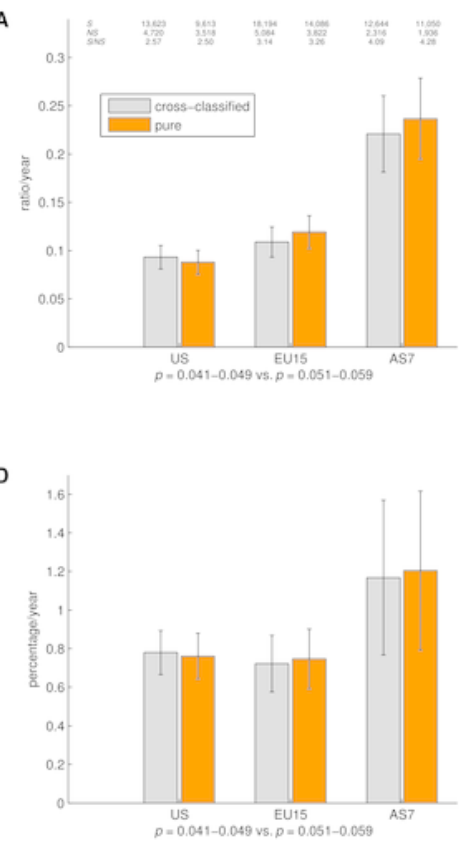

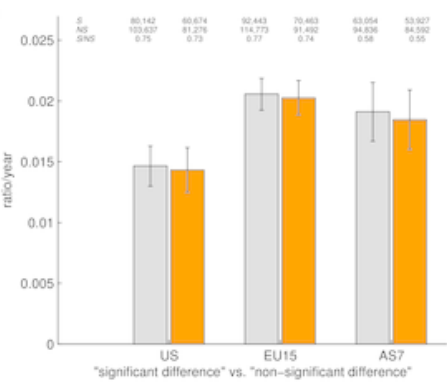

$E$

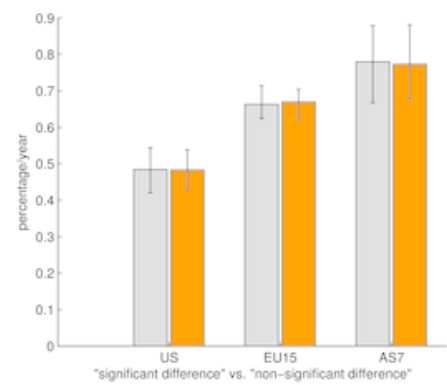

C

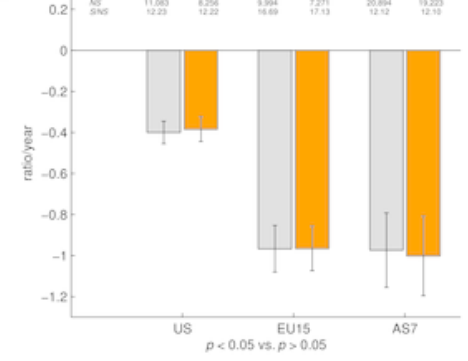

$\mathrm{F}$

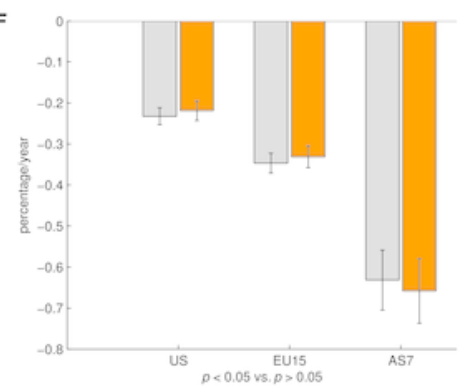


22

Figure 22

Logarithmic plot of the 2013-to-1990 ratio $\left(N_{2013} / T_{2013}\right) /\left(N_{1990} / T_{1990}\right)$, where $N$ is the number of abstracts reporting a certain expression in 2013 or 1990, and $T$ is the total number of papers with an abstract in that year. The number at the right end of each bar is $N_{2013}$. $T_{1990}=561,516$ and $T_{2013}=2,311,772$.

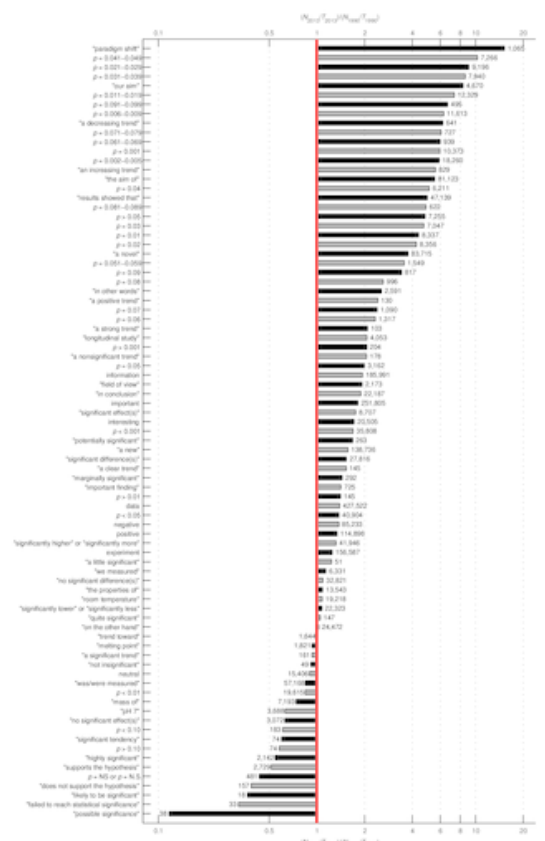


23

Figure 23

Percentage of papers reporting a $p$-value as a function of the size of the $p$-value for three octennia. The numbers at the top of the graph represent the ratio of the percentage of papers in 2006-2013 to the percentage of papers in 1990-1997 averaged across $0.001-0.009,0.011-0.019,0.021-0.029$, etc.

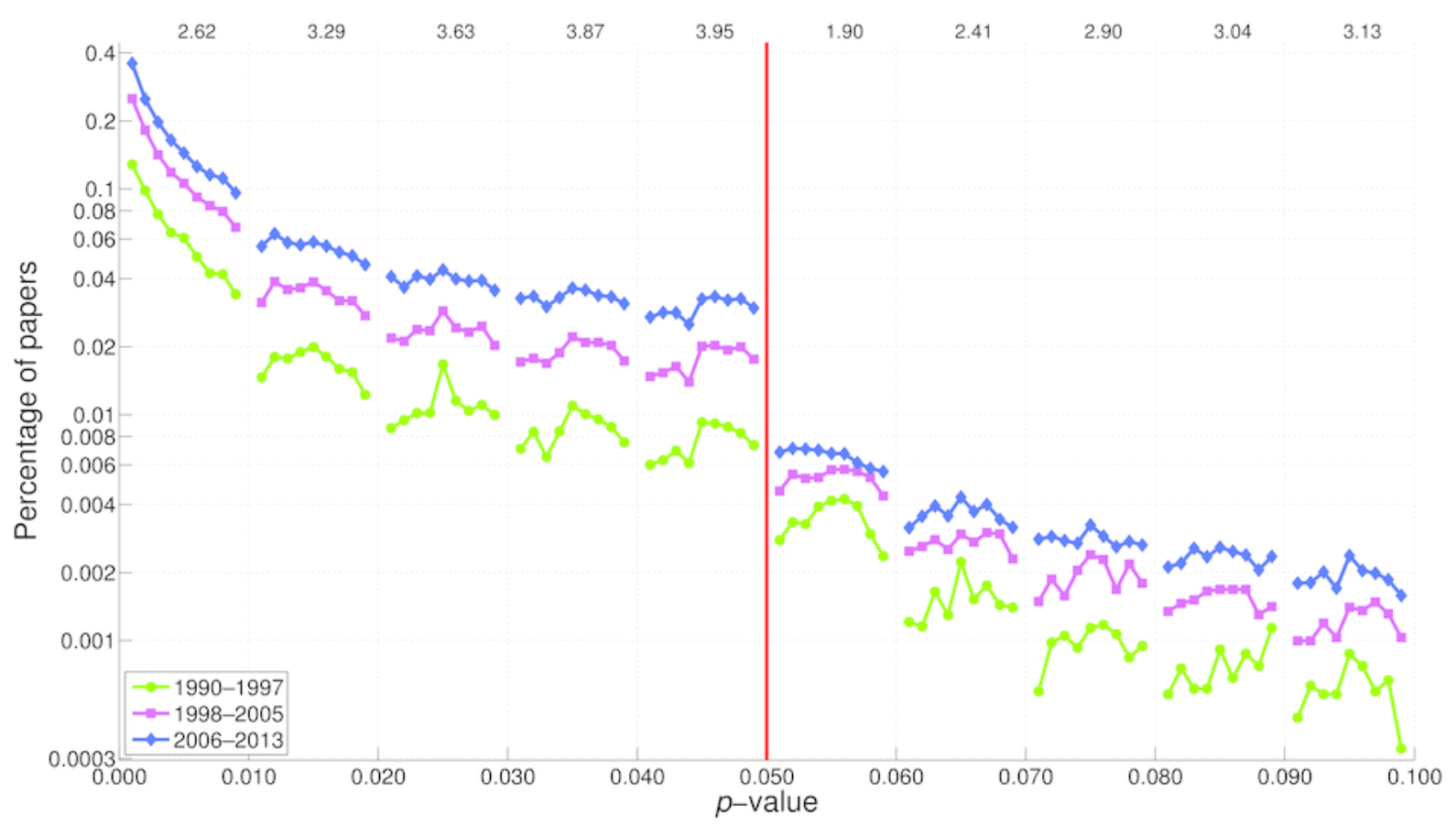


Table $\mathbf{1}$ (on next page)

All search queries and corresponding syntaxes in Scopus 
Table 1. All search queries and corresponding syntaxes in Scopus.

\begin{tabular}{|c|c|c|}
\hline 1. & All abstracts & $\mathrm{ABS}(\{\})$. \\
\hline 2. & $<0.001$ & $\operatorname{ABS}(\{\mathrm{p}<0.001\}$ OR $\{\mathrm{p}<.001\}$ OR $\{\mathrm{p}<=0.001\}$ OR $\{\mathrm{p}<=.001\}$ OR $\{\mathrm{p} \leq 0.001\}$ OR $\{\mathrm{p} \leq .001\})$ \\
\hline 3. & $>0.001$ & $\operatorname{ABS}(\{\mathrm{p}>0.001\}$ OR $\{\mathrm{p}>.001\})$ \\
\hline 4. & $<0.01$ & $\operatorname{ABS}(\{\mathrm{p}<0.01\}$ OR $\{\mathrm{p}<.01\}$ OR $\{\mathrm{p}<=0.01\}$ OR $\{\mathrm{p}<=.01\}$ OR $\{\mathrm{p} \leq 0.01\}$ OR $\{\mathrm{p} \leq .01\})$ \\
\hline 5. & $>0.01$ & $\operatorname{ABS}(\{p>0.01\}$ OR $\{p>.01\})$ \\
\hline 6. & $<0.05$ & $\operatorname{ABS}(\{\mathrm{p}<0.05\}$ OR $\{\mathrm{p}<.05\}$ OR $\{\mathrm{p}<=0.05\}$ OR $\{\mathrm{p}<=.05\}$ OR $\{\mathrm{p} \leq 0.05\}$ OR $\{\mathrm{p} \leq .05\})$ \\
\hline 7. & $>0.05$ & $\operatorname{ABS}(\{p>0.05\}$ OR $\{p>.05\})$ \\
\hline 8. & $<0.10$ & $\operatorname{ABS}(\{\mathrm{p}<0.10\}$ OR $\{\mathrm{p}<.10\}$ OR $\{\mathrm{p}<=0.10\}$ OR $\{\mathrm{p}<=.10\}$ OR $\{\mathrm{p} \leq 0.10\}$ OR $\{\mathrm{p} \leq .10\})$ \\
\hline 9. & $>0.10$ & $\operatorname{ABS}(\{p>0.10\}$ OR $\{p>.10\})$ \\
\hline 10. & $=0.001$ & $\operatorname{ABS}(\{\mathrm{p}=0.001\}$ OR $\{\mathrm{p}=.001\})$ \\
\hline 11. & $0.002-0.005$ & $\operatorname{ABS}(\{p=0.002\}$ OR $\{p=.002\}$ OR $\{p=0.003\}$ OR $\{p=.003\}$ OR $\{p=0.004\}$ OR $\{p=.004\}$ OR $\{p=0.005\}$ OR $\{p=.005\})$ \\
\hline 12. & $0.006-0.009$ & $\operatorname{ABS}(\{\mathrm{p}=0.006\} \mathrm{OR}\{\mathrm{p}=.006\}$ OR $\{\mathrm{p}=0.007\} \mathrm{OR}\{\mathrm{p}=.007\}$ OR $\{\mathrm{p}=0.008\}$ OR $\{\mathrm{p}=.008\}$ OR $\{\mathrm{p}=0.009\}$ OR $\{\mathrm{p}=.009\})$ \\
\hline 13. & $0.011-0.019$ & $\begin{array}{l}\text { ABS }(\{p=0.011\} \text { OR }\{p=.011\} \text { OR }\{p=0.012\} \text { OR }\{p=.012\} \text { OR }\{p=0.013\} \text { OR }\{p=.013\} \text { OR }\{p=0.014\} \text { OR }\{p=.014\} \text { OR }\{p=0.015\} \text { OR }\{p \\
=.015\} \text { OR }\{p=0.016\} \text { OR }\{p=.016\} \text { OR }\{p=0.017\} \text { OR }\{p=.017\} \text { OR }\{p=0.018\} \text { OR }\{p=.018\} \text { OR }\{p=0.019\} \text { OR }\{p=.019\})\end{array}$ \\
\hline 14. & 0.021-0.029 & $\begin{array}{l}\text { ABS }(\{p=0.021\} \text { OR }\{p=.021\} \text { OR }\{p=0.022\} \text { OR }\{p=.022\} \text { OR }\{p=0.023\} \text { OR }\{p=.023\} \text { OR }\{p=0.024\} \text { OR }\{p=.024\} \text { OR }\{p=0.025\} \text { OR }\{p \\
=.025\} \text { OR }\{p=0.026\} \text { OR }\{p=.026\} \text { OR }\{p=0.027\} \text { OR }\{p=.027\} \text { OR }\{p=0.028\} \text { OR }\{p=.028\} \text { OR }\{p=0.029\} \text { OR }\{p=.029\})\end{array}$ \\
\hline 15. & $0.031-0.039$ & $\begin{array}{l}\text { ABS }(\{p=0.031\} \text { OR }\{p=.031\} \text { OR }\{p=0.032\} \text { OR }\{p=.032\} \text { OR }\{p=0.033\} \text { OR }\{p=.033\} \text { OR }\{p=0.034\} \text { OR }\{p=.034\} \text { OR }\{p=0.035\} \text { OR }\{p \\
=.035\} \text { OR }\{p=0.036\} \text { OR }\{p=.036\} \text { OR }\{p=0.037\} \text { OR }\{p=.037\} \text { OR }\{p=0.038\} \text { OR }\{p=.038\} \text { OR }\{p=0.039\} \text { OR }\{p=.039\})\end{array}$ \\
\hline 16. & $0.041-0.049$ & $\begin{array}{l}\text { ABS }(\{p=0.041\} \text { OR }\{p=.041\} \text { OR }\{\mathrm{p}=0.042\} \text { OR }\{\mathrm{p}=.042\} \text { OR }\{\mathrm{p}=0.043\} \text { OR }\{\mathrm{p}=.043\} \text { OR }\{\mathrm{p}=0.044\} \text { OR }\{\mathrm{p}=.044\} \text { OR }\{\mathrm{p}=0.045\} \text { OR }\{\mathrm{p} \\
=.045\} \text { OR }\{\mathrm{p}=0.046\} \text { OR }\{\mathrm{p}=.046\} \text { OR }\{\mathrm{p}=0.047\} \text { OR }\{\mathrm{p}=.047\} \text { OR }\{\mathrm{p}=0.048\} \text { OR }\{\mathrm{p}=.048\} \text { OR }\{\mathrm{p}=0.049\} \text { OR }\{\mathrm{p}=.049\})\end{array}$ \\
\hline 17. & $0.051-0.059$ & $\begin{array}{l}\text { ABS }(\{p=0.051\} \text { OR }\{p=.051\} \text { OR }\{p=0.052\} \text { OR }\{p=.052\} \text { OR }\{p=0.053\} \text { OR }\{p=.053\} \text { OR }\{p=0.054\} \text { OR }\{p=.054\} \text { OR }\{p=0.055\} \text { OR }\{p \\
=.055\} \text { OR }\{p=0.056\} \text { OR }\{p=.056\} \text { OR }\{p=0.057\} \text { OR }\{p=.057\} \text { OR }\{p=0.058\} \text { OR }\{p=.058\} \text { OR }\{p=0.059\} \text { OR }\{p=.059\})\end{array}$ \\
\hline 18. & $0.061-0.069$ & $\begin{array}{l}\text { ABS }(\{p=0.061\} \text { OR }\{p=.061\} \text { OR }\{p=0.062\} \text { OR }\{p=.062\} \text { OR }\{p=0.063\} \text { OR }\{p=.063\} \text { OR }\{p=0.064\} \text { OR }\{p=.064\} \text { OR }\{p=0.065\} \text { OR }\{p \\
=.065\} \text { OR }\{p=0.066\} \text { OR }\{p=.066\} \text { OR }\{p=0.067\} \text { OR }\{p=.067\} \text { OR }\{p=0.068\} \text { OR }\{p=.068\} \text { OR }\{p=0.069\} \text { OR }\{p=.069\})\end{array}$ \\
\hline 19. & $0.071-0.079$ & $\begin{array}{l}\text { ABS }(\{p=0.071\} \text { OR }\{p=.071\} \text { OR }\{\mathrm{p}=0.072\} \text { OR }\{\mathrm{p}=.072\} \text { OR }\{\mathrm{p}=0.073\} \text { OR }\{\mathrm{p}=.073\} \text { OR }\{\mathrm{p}=0.074\} \text { OR }\{\mathrm{p}=.074\} \text { OR }\{\mathrm{p}=0.075\} \text { OR }\{\mathrm{p} \\
=.075\} \text { OR }\{\mathrm{p}=0.076\} \text { OR }\{\mathrm{p}=.076\} \text { OR }\{\mathrm{p}=0.077\} \mathrm{OR}\{\mathrm{p}=.077\} \text { OR }\{\mathrm{p}=0.078\} \text { OR }\{\mathrm{p}=.078\} \text { OR }\{\mathrm{p}=0.079\} \text { OR }\{\mathrm{p}=.079\})\end{array}$ \\
\hline 20. & 0.081-0.089 & $\begin{array}{l}\text { ABS }(\{p=0.081\} \text { OR }\{p=.081\} \text { OR }\{p=0.082\} \text { OR }\{p=.082\} \text { OR }\{p=0.083\} \text { OR }\{p=.083\} \text { OR }\{p=0.084\} \text { OR }\{p=.084\} \text { OR }\{p=0.085\} \text { OR }\{p \\
=.085\} \text { OR }\{p=0.086\} \text { OR }\{p=.086\} \text { OR }\{p=0.087\} \text { OR }\{p=.087\} \text { OR }\{p=0.088\} \text { OR }\{p=.088\} \text { OR }\{p=0.089\} \text { OR }\{p=.089\})\end{array}$ \\
\hline 21. & $0.091-0.099$ & $\begin{array}{l}\operatorname{ABS}(\{\mathrm{p}=0.091\} \text { OR }\{\mathrm{p}=.091\} \text { OR }\{\mathrm{p}=0.092\} \text { OR }\{\mathrm{p}=.092\} \text { OR }\{\mathrm{p}=0.093\} \text { OR }\{\mathrm{p}=.093\} \text { OR }\{\mathrm{p}=0.094\} \text { OR }\{\mathrm{p}=.094\} \text { OR }\{\mathrm{p}=0.095\} \text { OR }\{\mathrm{p} \\
=.095\} \text { OR }\{\mathrm{p}=0.096\} \text { OR }\{\mathrm{p}=.096\} \text { OR }\{\mathrm{p}=0.097\} \text { OR }\{\mathrm{p}=.097\} \text { OR }\{\mathrm{p}=0.098\} \text { OR }\{\mathrm{p}=.098\} \text { OR }\{\mathrm{p}=0.099\} \text { OR }\{\mathrm{p}=.099\})\end{array}$ \\
\hline 22. & 0.01 & $\operatorname{ABS}(\{\mathrm{p}=0.010\}$ OR $\{\mathrm{p}=.010\}$ OR $\{\mathrm{p}=0.01\}$ OR $\{\mathrm{p}=.01\})$ \\
\hline 23. & 0.02 & $\operatorname{ABS}(\{\mathrm{p}=0.020\}$ OR $\{\mathrm{p}=.020\}$ OR $\{\mathrm{p}=0.02\}$ OR $\{\mathrm{p}=.02\})$ \\
\hline 24. & 0.03 & $\operatorname{ABS}(\{\mathrm{p}=0.030\}$ OR $\{\mathrm{p}=.030\}$ OR $\{\mathrm{p}=0.03\}$ OR $\{\mathrm{p}=.03\})$ \\
\hline 25. & 0.04 & $\operatorname{ABS}(\{\mathrm{p}=0.040\}$ OR $\{\mathrm{p}=.040\}$ OR $\{\mathrm{p}=0.04\}$ OR $\{\mathrm{p}=.04\})$ \\
\hline 26. & 0.05 & $\operatorname{ABS}(\{\mathrm{p}=0.050\}$ OR $\{\mathrm{p}=.050\}$ OR $\{\mathrm{p}=0.05\} \mathrm{OR}\{\mathrm{p}=.05\})$ \\
\hline 27. & 0.06 & $\operatorname{ABS}(\{\mathrm{p}=0.060\}$ OR $\{\mathrm{p}=.060\}$ OR $\{\mathrm{p}=0.06\} \mathrm{OR}\{\mathrm{p}=.06\})$ \\
\hline 28. & 0.07 & $\operatorname{ABS}(\{\mathrm{p}=0.070\}$ OR $\{\mathrm{p}=.070\}$ OR $\{\mathrm{p}=0.07\}$ OR $\{\mathrm{p}=.07\})$ \\
\hline 29. & 0.08 & $\operatorname{ABS}(\{\mathrm{p}=0.080\}$ OR $\{\mathrm{p}=.080\}$ OR $\{\mathrm{p}=0.08\}$ OR $\{\mathrm{p}=.08\})$ \\
\hline 30. & 0.09 & $\operatorname{ABS}(\{\mathrm{p}=0.090\}$ OR $\{\mathrm{p}=.090\}$ OR $\{\mathrm{p}=0.09\}$ OR $\{\mathrm{p}=.09\})$ \\
\hline 31. & $\mathrm{p}=\mathrm{NS}$ or $\mathrm{p}=\mathrm{N} . \mathrm{S}$. & $\mathrm{ABS}(\{\mathrm{p}=\mathrm{NS}\}$ OR $\{\mathrm{p}=\mathrm{N} . \mathrm{S}\})$. \\
\hline 32. & "significant difference(s)" & $\begin{array}{l}\text { ABS((\{significant difference }\} \text { OR \{significant differences\} OR \{significantly different\} OR \{differed significantly\}) AND NOT (\{no significant } \\
\text { difference\} OR \{no significant differences\} OR \{no statistically significant difference\} OR \{no statistically significant differences\} OR \{not significantly } \\
\text { different\} OR \{did not differ significantly\})) }\end{array}$ \\
\hline
\end{tabular}




\begin{tabular}{|c|c|c|}
\hline 33. & "no significant difference(s)" & $\begin{array}{l}\text { ABS(\{no significant difference\} OR \{no significant differences\} OR \{no statistically significant difference }\} \text { OR \{no statistically significant differences\} } \\
\text { OR \{not significantly different\} OR \{did not differ significantly\}) }\end{array}$ \\
\hline 34. & "significant effect(s)" & $\begin{array}{l}\text { ABS }((\{\text { significant effect\} OR \{significant effects\}) AND NOT (\{no significant effect\} OR \{no significant effects\} OR \{no statistically significant effect\} } \\
\text { OR \{no statistically significant effects\} OR \{not a significant effect\} OR \{not a statistically significant effect }\}))\end{array}$ \\
\hline 35. & "no significant effect(s)" & $\begin{array}{l}\text { ABS( \{no significant effect\} OR \{no significant effects\} OR \{no statistically significant effect\} OR \{no statistically significant effects\} OR \{not a } \\
\text { significant effect\} OR \{not a statistically significant effect }\} \text { ) }\end{array}$ \\
\hline 36. & "supports the hypothesis" & $\begin{array}{l}\text { ABS((\{supports the hypothesis\} OR \{support the hypothesis\} OR \{supports our hypothesis\} OR \{support our hypothesis\}) AND NOT (\{does not } \\
\text { support the hypothesis\} OR \{do not support the hypothesis\} OR \{does not support our hypothesis\} OR \{do not support our hypothesis\})) }\end{array}$ \\
\hline 37. & "does not support the hypothesis" & ABS(\{does not support the hypothesis\} OR \{do not support the hypothesis\} OR \{does not support our hypothesis\} OR \{do not support our hypothesis\}) \\
\hline 38. & "significantly higher/more" & ABS(\{significantly higher\} OR \{significantly more\}) \\
\hline 39. & "significantly lower/less" & $\operatorname{ABS}(\{$ significantly lower $\}$ OR \{significantly less $\})$ \\
\hline 40. & "marginally significant" & ABS("marginally significant") \\
\hline 41. & "important finding" & ABS("important finding" OR "important findings") \\
\hline 42. & "pH 7" & ABS("ph 7") \\
\hline 43. & "mass of" & ABS("mass of") \\
\hline 44. & "room temperature" & ABS("room temperature") \\
\hline 45. & "melting point" & ABS("melting point") \\
\hline 46. & "field of view" & ABS("field of view") \\
\hline 47. & "the properties of" & ABS("the properties of") \\
\hline 48. & "the aim of" & ABS("the aim of") \\
\hline 49. & "our aim" & ABS("our aim") \\
\hline 50. & "results showed that" & ABS("results showed that") \\
\hline 51. & "in conclusion" & ABS("in conclusion") \\
\hline 52. & "longitudinal study" & ABS("longitudinal study") \\
\hline 53. & "in other words" & ABS("in other words") \\
\hline 54. & "on the other hand" & ABS("on the other hand") \\
\hline 55. & "a novel" & ABS("a novel") \\
\hline 56. & "a new" & ABS("a new") \\
\hline 57. & "was/were measured" & ABS("was measured" OR "were measured") \\
\hline 58. & "we measured" & ABS("we measured") \\
\hline 59. & "paradigm shift" & ABS("paradigm shift") \\
\hline 60. & data & $\mathrm{ABS}($ data $)$ \\
\hline 61. & information & ABS(information) \\
\hline 62. & experiment & ABS(experiment) \\
\hline 63. & important & ABS(important) \\
\hline 64. & interesting & ABS(interesting) \\
\hline 65. & neutral & ABS(neutral) \\
\hline 66. & positive & ABS(positive) \\
\hline 67. & negative & ABS(negative) \\
\hline 68. & "highly significant" & ABS("highly significant" AND NOT "not highly significant") \\
\hline 69. & "trend toward" & ABS("trend toward") \\
\hline 70. & "an increasing trend" & $\mathrm{ABS}($ "an increasing trend") \\
\hline
\end{tabular}




\begin{tabular}{lll}
\hline 71. & "a decreasing trend" & ABS("a decreasing trend") \\
\hline 72. & "potentially significant" & ABS("potentially significant") \\
\hline 73. & "a nonsignificant trend" & ABS("a nonsignificant trend" OR "a non significant trend") \\
\hline 74. & "a significant trend" & ABS("a significant trend") \\
\hline 75. & "quite significant" & ABS("quite significant") \\
\hline 76. & "a clear trend" & ABS("a clear trend") \\
\hline 77. & "a positive trend" & ABS("a positive trend") \\
\hline 78. & "a strong trend" & ABS("a strong trend") \\
\hline 79. & "significant tendency" & ABS("significant tendency") \\
\hline 80. & "a little significant" & ABS("a little significant") \\
\hline 81. & "not insignificant" & ABS("not insignificant") \\
\hline 82. & "possible significance" & ABS("possible significance") \\
\hline 83. & "failed to reach statistical & significance" \\
\hline 84. & "likely to be significant" & ABS("failed to reach statistical significance") \\
\hline
\end{tabular}


PeerJ Reviewing Manuscript 